Linköping University Medical Dissertations No. 1772

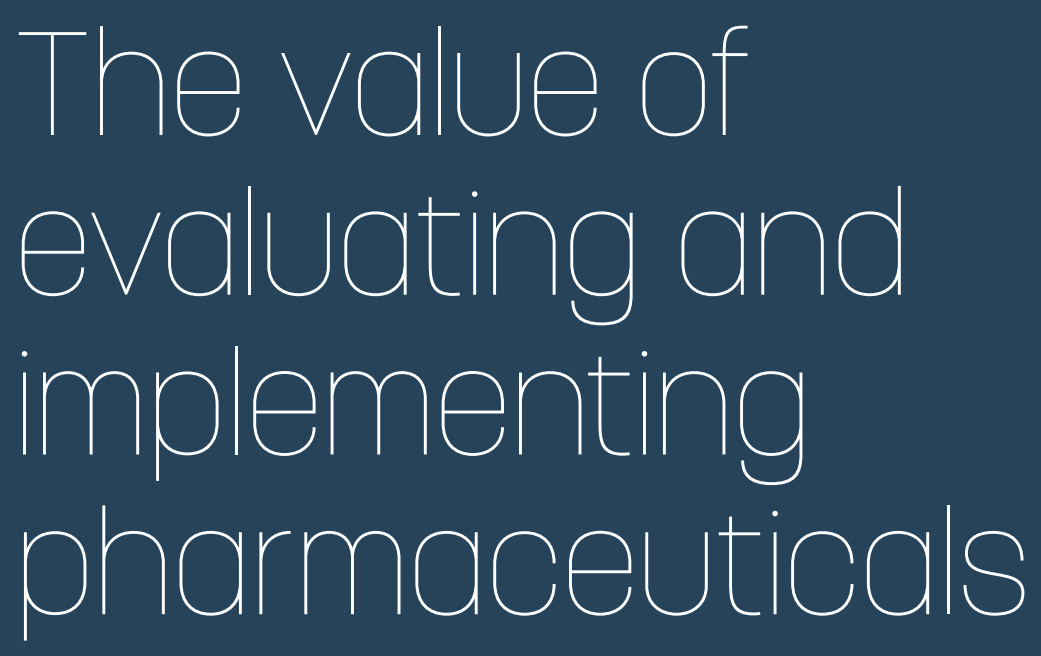

Kasper Johannesen 



\title{
The value of evaluating and implementing pharmaceuticals
}

\author{
Kasper Johannesen
}

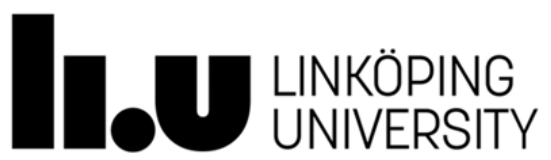

Department of Medical and Health Sciences

Linköping University, Sweden

Linköping 2021 
$((\mathrm{cc})$ EY-NC NonCommercial 4.0 International License.

https://creativecommons.org/licenses/by-nc/4.0/

@ Kasper Johannesen, 2021

Cover: Tomas Hägg

Published article has been reprinted with the permission of the copyright holder.

Printed in Sweden by LiU-Tryck, Linköping, Sweden, 2021

ISBN 978-91-7929-685-8

ISSN $0345-0082$ 
To Hanna, Kai and Arthur

The ultimate test of man's conscience may be his willingness to sacrifice something today for future generations whose words of thanks will not be heard.

Gaylord Nelson 



\section{CONTENTS}

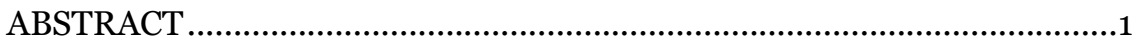

SVENSK SAMMANFATTNING .......................................................... 3

LIST OF PAPERS ........................................................................ 5

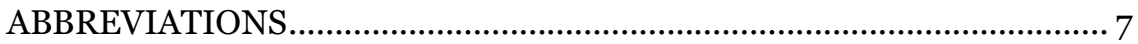

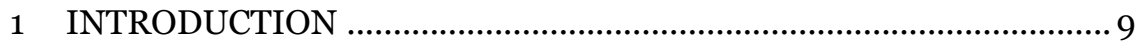

1.1 Aim \& research questions ..............................................................11

$1.2 \quad$ Outline of the thesis ...................................................................11

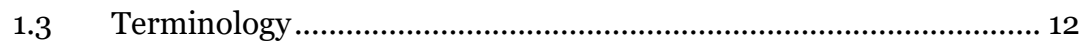

$1.4 \quad$ Funding and conflicts of interest.................................................... 14

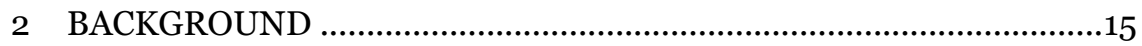

2.1 Characteristics of pharmaceuticals ................................................... 15

2.2 Pharmaceutical development ....................................................... 15

2.3 The assessment and implementation of pharmaceuticals .................17

$2.4 \quad$ The value of pharmaceuticals .............................................................24

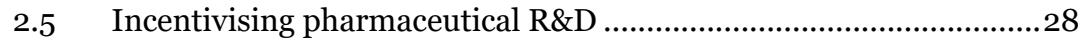

2.6 Setting the studies and research questions into perspective .............30

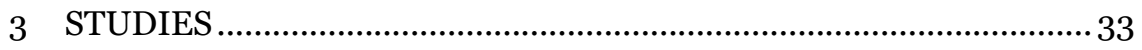

3.1 Getting value today and incentivising for the future (Paper 1).........3 34

3.2 How to design the cost-effectiveness appraisal process (Paper 2) ...40

3.3 Subcategorizing the Expected Value of Perfect Implementation

(Paper 3)....................................................................................... 46

3.4 The effectiveness of ticagrelor in routine clinical care (Paper 4) ..... 54

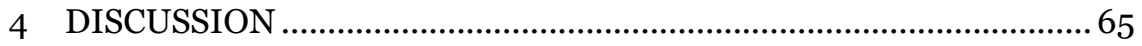

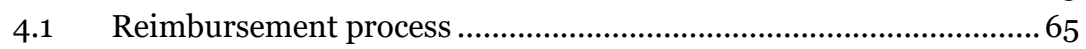

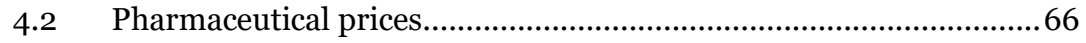

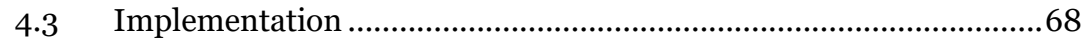

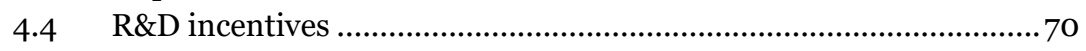

4.5 Value of pharmaceuticals in clinical practice....................................71

5 AREAS OF FUTURE RESEARCH.............................................. 75

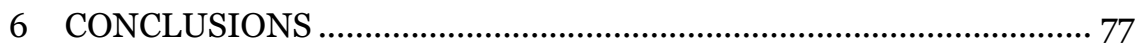

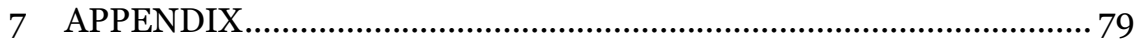

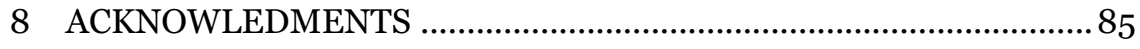

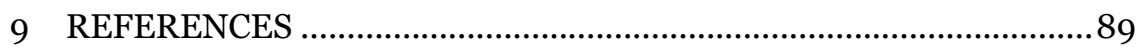




\section{ABSTRACT}

Pharmaceuticals are a central part of high-quality health care and a resource for improving population health. However, high prices set by private companies who develop and own the rights to new pharmaceuticals question the value that they contribute to the health care system. Publicly funded health care systems need to get the most from limited health care resources, which has become even more apparent in recent years with ageing populations, rapid technological development, and more recently the impact of COVID-19. Reducing pharmaceutical prices increase the current value that they offer to health care systems, but price reduction also decreases incentives to develop future treatments. Hence, the health care systems must balance the objective of improving the value from the treatments available today and incentivising the development of future treatments.

Governments and health care decision makers use a variety of policies to control prices and use of pharmaceuticals. However, these policies are rarely the focus of formal analysis and their effect on short- and long-term population health is often unclear. The aim of this thesis was to investigate how policies that control pharmaceutical prices and implementation impact population health and incentives for pharmaceutical research and development $(\mathrm{R} \& \mathrm{D})$.

The first study in this thesis outlines a framework for assessing the effect of pharmaceutical policies on population health and pharmaceutical earnings and shows that price reducing policies can increase the current value of pharmaceuticals to health care systems while lowering R\&D incentives. The design of specific policies determines the impact as well as the distribution of the gains of lower prices across patients, health care providers, pharmacies, and other affected parties. The second study analyses the trade-off between accuracy and cost of the cost-effectiveness appraisals for pharmaceuticals by viewing it as a diagnostic test that aims to identify costeffective treatments. The study identifies some policy relevant conclusions, including that the process should be flexible over time and depend on characteristics of the treatment undergoing assessment. Study three, investigating the impact of regional implementation variation of the antiplatelet ticagrelor, found that an additional 1,100 Quality Adjusted Life Years (QALYs) could have been gained from achieving equal implementation across health care regions. This represents a value of SEK 285 million from avoiding regional implementation variation of ticagrelor (given a value of SEK 250,000 per QALY). The study also shows that avoiding delays due to sequential decisions on reimbursement, treatment guidelines, and funding 
could have significant value. Finally, the fourth study investigates the comparative effectiveness of ticagrelor using observational data collected as part of routine clinical care in the SWEDEHEART registry. The study finds similar reduction in mortality as observed in the pivotal randomised clinical trial of ticagrelor, the PLATO trial. Furthermore, the importance of appropriate methods for observational research on comparative effectiveness are demonstrated, highlighting the importance of using appropriate methods when investigating the effectiveness of treatments used in clinical practice.

In conclusion, this thesis shows the importance of analysing and understanding the effect of policies that control price and implementation of pharmaceuticals, whether the goal is to maximise the value from currently available pharmaceuticals or to also incentivise the development of new pharmaceuticals. Although the value of improving implementation may not be as obvious or tangible as savings from lowering pharmaceutical prices, improving implementation may contribute more to population health than reinvesting potential savings from price reductions. 


\section{SVENSK SAMMANFATTNING}

Läkemedel är en viktig komponent i dagens hälso- och sjukvård och en resurs som bidrar till att förbättra hälsan i befolkningen. Om läkemedelspriserna som sätts av de privata företag som utvecklar och äger rättigheterna till nya läkemedel är höga kan dock värdet som läkemedlen bidrar med till hälso- och sjukvården ifrågasättas. Offentligt finansierade hälso- och sjukvårdssystem behöver få ut mesta möjliga av begränsade resurser, vilket har blivit ännu tydligare de senaste åren med en åldrande befolkning, snabb teknisk utveckling och en global pandemi. Att sänka läkemedelspriserna kan öka värdet som läkemedlen bidrar med till hälsooch sjukvårdssystemen idag. Samtidigt kan lägre priser minska incitamenten att utveckla framtida behandlingar. Därför måste hälso- och sjukvårdssystemen hitta en balans mellan att maximera värdet från de behandlingar som finns tillgängliga idag och att samtidigt stimulera utvecklingen av framtida behandlingar.

Myndigheter och beslutsfattare inom hälso- och sjukvården använder olika policyer för att kontrollera priser på och användning av läkemedel. Dessa policyer är dock sällan föremål för formell analys och hur de påverkar hälsan på kort och lång sikt är ofta oklart. Syftet med den här avhandlingen var att undersöka hur policyer som styr läkemedelspriser samt implementering av nya läkemedel kan påverka både hälsan i befolkningen och incitament för forskning och utveckling (FoU) av läkemedel.

Den första studien beskriver ett ramverk för att bedöma effekten av läkemedelspolicyer på både hälsa och läkemedelsintäkter. Studien visar att policyer som inkluderar prissänkningar kan öka värdet som läkemedel bidrar med för hälso- och sjukvårdssystemen idag samtidigt som FoUincitamenten minskar. Utformningen av specifika policyer avgör storleken på effekterna och fördelningen av de vinster som lägre priser kan ge för patienter, vårdgivare, apotek och andra berörda parter. Den andra studien analyserar avvägningen mellan hur noggranna och hur kostsamma kostnadseffektivitetsbedömningar av läkemedel skall vara. Detta görs genom att betrakta bedömningen som ett diagnostiskt test med syftet att identifiera kostnadseffektiva behandlingar. Studien identifierar några policyrelevanta slutsatser, till exempel att processen bör vara flexibel över tid och baseras på egenskaperna hos behandlingen som är föremål för bedömning. Studie tre undersöker effekterna av regionala variationer vid implementeringen av trombocythämmaren ticagrelor. Studien visar att ytterligare 1100 kvalitetsjusterade levnadsår (QALYs) kunde ha vunnits 
om alla regioner hade implementerat ticagrelor i samma utsträckning som regionerna med högst implementering. Värdet av att undvika regionala variationer vid implementering av ticagrelor skulle därmed kunna skattas till åtminstone 275 miljoner kronor (om en QALY antas vara värd 250000 kronor). Studien visar också att det kan uppstå betydande kostnader i termer av förlorad hälsa om implementeringen styrs av sekventiella beslut där behandlingsriktlinjer och tillgänglig finansiering inte är synkade med beslutet att subventionera läkemedlet. I den fjärde studien undersöks effekten av ticagrelor i klinisk praxis genom att använda data från kvalitetsregistret SWEDEHEART. Studien finner att mortalitetsrisken när ticagrelor ges i rutinsjukvård reduceras i samma utsträckning som i den randomiserade PLATO-studien. Studien visar också på vikten av att använda lämpliga metoder för observationsforskning som undersöker kausala behandlingseffekter av läkemedel i klinisk praxis.

Sammanfattningsvis visar avhandlingen på vikten av att analysera och förstå effekten av policyer som styr pris på och implementering av läkemedel, oavsett om målet är att maximera värdet av tillgängliga läkemedel eller om hänsyn ochså skall tas till att stimulera utvecklingen av nya läkemedel i framtiden. Värdet av att förbättra användningen av effektiva och kostnadseffektiva läkemedel är inte lika uppenbart eller konkret som besparingar från sänkta läkemedelspriser men förefaller kunna bidra till förbättrad hälsa i befolkningen både på kort och lång sikt. 


\section{LIST OF PAPERS}

I. Johannesen K, Henriksson M. Getting value today and incentivising for the future: Pharmaceutical development and healthcare policies. Nordic Journal of Health Economics 2017; 5:77-96.

II. Johannesen K, Claxton K, Sculpher M, Wailoo A. How to design the cost-effectiveness appraisal process of new healthcare technologies to maximise population health: A conceptual framework. Health Economics 2018; 27:e41-54.

III. Johannesen K, Janzon M, Jernberg T, Henriksson M. Subcategorizing the Expected Value of Perfect Implementation to Identify When and Where to Invest in Implementation Initiatives. Medical Decision Making 2020; 40:327-38.

IV. Johannesen K, Siverskog J, Henriksson M, Janzon M, Lindahl B, Grönqvist E. The effectiveness of ticagrelor in routine clinical care A natural experiment utilising the variation in implementation across treatment centres and over time as an instrumental variable. Manuscript 


\section{ABBREVIATIONS}

2SLS

ACS

ADHD

ASA

CS

DKK

ERG

ERP

EU

EMA

EVPIM

FN

FP

ICER

INB

INHB

INMB

IRP

FDA

HTA

LIF

LiU

MAA

$\mathrm{MAH}$

MI

MTA

NICE

NSTEMI

NT-council

OLS

PD-L1
Two-stage least squares

Acute coronary syndrome

Attention-Deficit/Hyperactivity Disorder

Acetylsalicylic acid

Consumer surplus

Danish krone

Evidence Review Group

External Reference Pricing

European Union

European Medicine Agency

Expected Value of Perfect Implementation

False negative

False positive

Incremental Cost-Effectiveness Ratio

Incremental Net Benefit

Incremental Net Health Benefit

Incremental Net Monetary Benefit

International Reference Pricing

Food and Drug Administration

Health Technology Assessment

The trade association for the research-based pharmaceutical industry in Sweden

Linköping University

Marketing Authorisation Approval

Marketing Authorisation Holder

Myocardial infarction

Multiple Technology Appraisal

National Institute for Health and Care Excellence

Non-ST-segment elevation myocardial

New Therapies-council

Ordinary least squares

Programmed death-ligand 1 


$\begin{array}{ll}p \text { EVPIM } & \text { Population EVPIM } \\ \text { PLATO } & \text { the Platelet Inhibition and Patient Outcomes } \\ \text { PS } & \text { Producer surplus } \\ \text { PSA } & \text { Probabilistic sensitivity analysis } \\ \text { PT } & \text { Parallel trade } \\ \text { R\&D } & \text { Research and Development } \\ \text { RCT } & \text { Randomised Controlled Trial } \\ \text { SEK } & \text { Swedish krona } \\ \text { SMC } & \text { the Scottish Medicine Council } \\ \text { STA } & \text { Single Technology Appraisal } \\ \text { STEMI } & \text { ST-segment elevation myocardial } \\ \text { SWEDEHEART } & \text { The Swedish Web System for Enhancement and Develop- } \\ & \text { ment of Evidence-Based Care in Heart Disease Evaluated } \\ & \text { According to Recommended Therapies } \\ \text { TLV } & \text { The Dental and Pharmaceutical Benefits Agency } \\ \text { TN } & \text { True negative } \\ \text { TNF } & \text { Tumor Necrosis Factor } \\ \text { TP } & \text { True positive } \\ \text { UK } & \text { The United Kingdom } \\ \text { US } & \text { United States of America } \\ \text { VBP } & \text { Value Based Pricing } \\ \text { VOI } & \text { Value of information }\end{array}$




\section{INTRODUCTION}

Medical technologies are a key part of health care and contribute to improving patient and population health. One category of technologies is pharmaceuticals, an integrated part of health care. Studies have shown that pharmaceuticals have improved longevity over the past decades and generated substantial value to patients and society. ${ }^{1-4}$ However, these gains have not been achieved without controversy as the price of pharmaceuticals is a topic of intense and continued debate.

Pharmaceuticals are primarily developed and sold by private companies. Developing and getting a new pharmaceutical to the market is associated with significant risk and substantial cost. Studies estimate an average cost of about one to three billion USD.,6 To cover the cost associated with developing and bringing new pharmaceuticals to the market, pharmaceutical companies are allowed market exclusivity for a period via the patent system. This provides companies with an opportunity to cover the development cost by setting a price higher than would be achieved in a competitive market. However, with limited resources, health care providers need to assess if the price is acceptable given the health benefits provided by pharmaceuticals.

Before pharmaceutical products can be implemented in clinical practice, they undergo a series of assessment procedures. The first step is the regulatory process, which evaluates the benefit-risk ratio, i.e. whether the pharmaceutical provides more good than harm. Within the EU, this is evaluated by the European Medicine Agency (EMA), and the formal approval is made by the European Commission. ${ }^{7}$ Subsequently, a reimbursement process is often employed at a national level to determine whether a treatment should be included in the publicly funded or insurance-based health care system. The reimbursement process varies across countries, but the process generally includes some form of Health Technology Assessment (HTA) used to evaluate the consequences of implementing the treatment in clinical practice. ${ }^{8}$ As part of this process, many countries use cost-effectiveness analyses to assess whether the value generated by a new treatment is larger than the opportunity cost, i.e. whether a new treatment generates more value than can be obtained by investing equivalent resources elsewhere. ${ }^{9}$ Some reimbursement processes also include comparisons, negotiations, and agreements (confidential or public) on price. After, or as part of, the reimbursement process, treatment recommendations and guidelines are updated to reflect the recommended use of the new treatment. 
Often, it is only after all the above steps that a new pharmaceutical is recommended for use in clinical practice. ${ }^{8}$

Pharmaceuticals and other health care technologies only provide value to patients, the health care system, and pharmaceutical companies when used in clinical practice. Hence, low and varying implementation of costeffective treatments, as observed across treatment areas, regions, and countries, ${ }^{10-14}$ is a loss for both patients and producers. ${ }^{15,16}$ Despite the aligned interests of stakeholders to address low or varying implementation, this is a persistent issue that also raises concerns about equal access to treatment.

In relation to pharmaceutical prices, the incentives of health care providers and producers are clearly in conflict. During the period of market exclusivity, producers aim to set prices so that they maximise profits. High prices result in lower value for health care providers compared with the competitive prices they can expect to pay after patents expire. This situation results in a general dilemma: producers would prefer high prices as well as fast approval and implementation, whereas health care providers would prefer low prices and implement products only when they are expected to provide value. In addition, low prices may spill over to weaker incentives to develop new pharmaceuticals. Hence, there appears to be a trade-off between getting more value today (i.e. lower prices) and fewer new technologies being developed, resulting in lower long-term population health. 


\subsection{Aim \& research questions}

The overall aim of this thesis is to study the effect of policies that control pharmaceutical price and implementation.

The following research questions are investigated:

- How are pharmaceutical policies (including international reference pricing (IRP), the reimbursement process, and implementation) expected to impact population health and R\&D incentives? (Paper 1)

- How to design the cost-effectiveness appraisal process of new health care technologies to maximise population health? (Paper 2)

- What is the impact of regional implementation variation of pharmaceuticals in terms of population health and producer earnings?

(Paper 3)

- What is the comparative effectiveness of the antiplatelet ticagrelor when used in clinical practice? (Paper 4)

These research questions are investigated in two theoretical (Papers 1 and 2) and two empirical (Papers 3 and 4) studies.

\subsection{Outline of the thesis}

Chapter 2 provides a background for the research questions and studies included in this thesis. Chapter $\mathbf{3}$ describes the four studies that provide the basis for this thesis. The chapter presents the introduction, method, results, and interpretation of each paper sequentially, i.e. there is no overall method and result section in this thesis. This structure was used due to the different nature of the studies, theoretical and empirical, and because the later studies sprang from and built on findings in the earlier studies. The introduction sections put the findings of the studies into context of the research gaps and policy environment at the time of the study. The method and result sections are mainly a summary of the corresponding sections in the papers, although some additional results are included to complement Papers 3 and 4 . The interpretation section puts the results of the study into perspective given the current system of assessing and implementing pharmaceuticals and complements, rather than summarises, the discussion section in the individual papers. Description of the antiplatelet ticagrelor, which is the subject of the case studies in Papers 3 and 4, is included in Section 3.3.2. Chapter 4 discusses and synthesises the key findings across the studies, Chapter 5 outlines key areas of future research, and Chapter 6 provides some concluding remarks. 


\subsection{Terminology}

This thesis and the included papers draw on different research disciplines, including health economics, microeconomics, and medicine. This diverse approach poses some challenges around terminology since some terms have different meanings and some concepts are defined differently across disciplines. This section briefly describes and defines some of the key concepts used in this thesis as well as references to where in the thesis the concept is introduced and described in greater detail. Although this is not an exhaustive list of concepts used or analysed in this thesis, my hope is that this will reduce confusion and frustration for readers.

Consumer is the standard economic term for the consumer of an economic good (i.e. product). The concept of consumers can be challenging when it comes to pharmaceuticals, but I hope Section 2.3 provides a satisfactory description.

Consumer surplus is the value of a product to consumers. In economics this is defined as the difference between how much someone is willing to pay for a product (the reservation price) and the price that is paid for the product. Section 2.3 described consumer surplus in the case of pharmaceuticals.

Cost-effectiveness, as used within health economics, refers to the relationship between cost and effect of treatments, often assessed and presented as the Incremental Cost-Effectiveness Ratio (ICER) (section 2.3.2).

Dynamic efficiency relates to maximising long-term value, e.g. maximising long-term health given an optimal level of R\&D investment.

Earnings (gross earnings), refers to the gross earnings that companies generate on pharmaceutical products, which is the revenue (price * quantity) minus the cost of production (cost of goods) and distribution. This is also how producer surplus is defined, and does not include the cost of R\&D.

Expected rent on pharmaceuticals is defined in this thesis as the earnings (i.e. producer surplus) during the patent protected period (Section 2.4).

Health care technology is a broad term for treatments and interventions used in the health care system, including but not limited to pharmaceuticals.

Implementation is used as a broad term and includes both the adoption of treatments in clinical practice (when use of the treatment starts) as well as implementation level describing the proportion of patients treated. This terminology is used to be consistent with the value of implementation framework used in Paper 3 (Section 3.3). 
International Reference Pricing (IRP) is a price setting mechanism where prices are based on or prices in other countries (section 2.3.2). Worth to note, that IRP, as used in this thesis, is the same as external price referencing (ERP) used by other authors. ${ }^{17-19}$

Marketing Authorization Approval (MAA) is granted by regulatory agencies and is a prerequisite before a pharmaceutical product can be used as part of standard clinical practice.

Marketing Authorization Holder (MAH) is the pharmaceutical company who owns the patent and the MAA, and therefore the rights to sell a pharmaceutical product during the time of patent protection.

New Chemical Entity is used to describe a chemical or biological entity that has not yet or previously been approved for medicinal use by regulatory agencies.

Pharmaceuticals, drugs, medicines, and treatments are used interchangeably throughout the thesis and pharmaceuticals are defined in section 2.1. A distinction between pharmaceutical product (e.g. pill or injection) and pharmaceutical technology (which is used to produce a pharmaceutical product) is described in Section 2.2.

Private good is an item of value, e.g. a car, a computer or medicinal product, where the owner of the item can exclude others from using it.

Producer refers to a pharmaceutical company producing a pharmaceutical product, generally the MAH when discussing the value of pharmaceuticals during the patent protected period.

Producer surplus is the value (i.e. earnings, as defined above) of a product to producers, equal to the revenue minus cost of production and distribution (Section 2.4).

Public good, are goods such as official statistics, streetlights and knowledge, where people cannot be excluded from using or benefiting from the items (non-excludable) and where peoples use does not impact the use or benefit that others get from the items (non-rival).

Research and development (R\&D) is a term encompassing the research and work needed to discover and develop a new pharmaceutical product, including identification of new chemical entities and all clinical trials needed to demonstrate safety and efficacy.

Societal perspective, as used within health economics, which describe a broad perspective on cost and effect where non-health care costs and effects are taken into account.

Static efficiency refers to maximising the value from a given resource of products (e.g. maximising the value from currently available pharmaceutical products). 


\subsection{Funding and conflicts of interest}

Financial support for study 3 and 4 was provided in part by a grant from Östergötland Region, Sweden.

I have been a part-time PhD student while conducting the work on this thesis. I was employed as a health economist at AstraZeneca AB from the start of my PhD studies in 2013 until 2015. Since 2015, I have been employed in a similar function by Bristol-Myers Squibb AB. Neither of these companies have provided any funding for the studies included in this thesis or had any influence on the studies or work conducted as part of this thesis. The studies on ticagrelor, where AstraZeneca is the marketing authorisation holder, was initiated after I ended my employment at the company. All views are my own and do not reflect those of the companies where I do or have worked. 


\section{BACKGROUND}

This chapter provides the background for this thesis and starts by defining pharmaceuticals and providing a brief overview of the development and the different assessment processes that pharmaceuticals undergo before they are used in clinical practice. This is followed by a section on the value of pharmaceuticals, which is central to the studies included in this thesis. After a section that discuss the incentives for pharmaceutical R\&D, the background ends by placing the studies included in this thesis into perspective.

\subsection{Characteristics of pharmaceuticals}

The definition of pharmaceutical produces varies across regions and has changed over time. Within the EU, pharmaceuticals, i.e. medicinal products, are defined in the following way:

Medicinal product:

(a) Any substance or combination of substances presented as having properties for treating or preventing disease in human beings; or

(b) Any substance or combination of substances which may be used in or administered to human beings either with a view to restoring, correcting or modifying physiological functions by exerting a pharmacological, immunological or metabolic action, or to making a medical diagnosis.

(European Commission, 2004) ${ }^{20}$

A pharmaceutical product (e.g. pill, injection, and infusion) is a private good: after being used by one individual, it cannot be used by another. In contrast, a pharmaceutical technology that provided the basis for making a pharmaceutical product can be classified as a global public good, since it is globally accessible, non-rival, and non-excludable. As with other global public goods, this creates free-rider and collective action problems around the development of pharmaceutical technologies, where everybody would like to use them once they are developed and available, but nobody wants to pay the price to develop them on their own. ${ }^{21-24}$

\subsection{Pharmaceutical development}

Developing and bringing a new pharmaceutical to the market is associated with high risk and high cost. Only a small percentage of new chemical entities make it from basic research to being used in clinical practice. ${ }^{25-27}$ This 
is exemplified in Figure 2.1 presenting the probability of making it through the different phases of clinical trials.

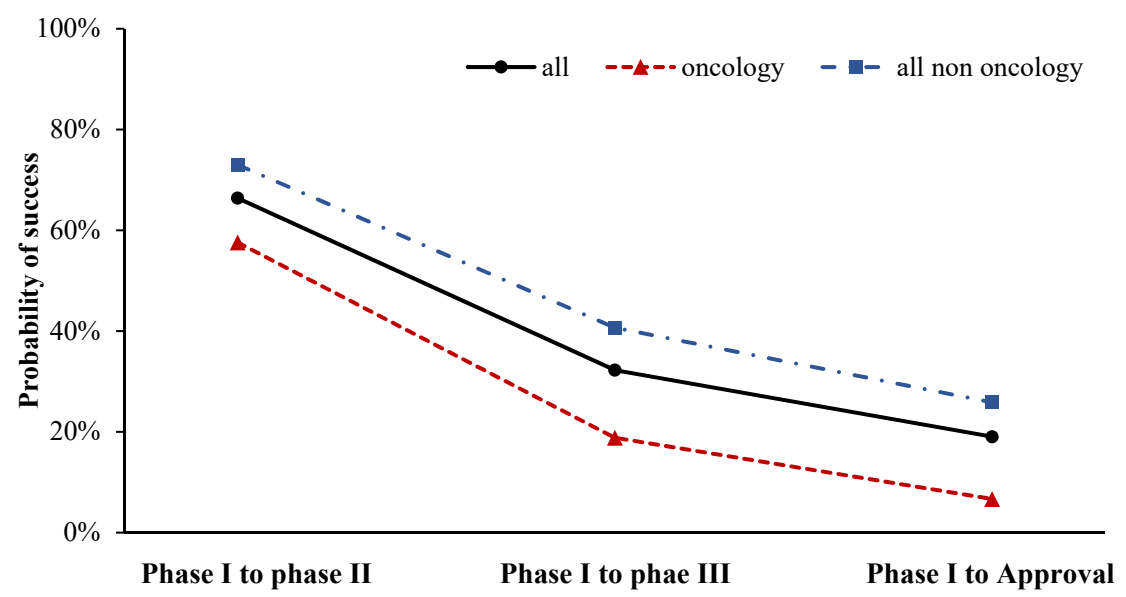

Figure 2.1 Probability of success through the clinical trials for pharmaceuticals. Source: Developed based Wong et al. (2019) ${ }^{26}$

The average cost of developing a new pharmaceutical is substantial and has increased over time, although estimates of this cost vary considerably between studies. Some studies suggest that this cost is over two billion USD, ${ }^{28,29}$ although these studies have been criticised for overestimating the R\&D cost. ${ }^{6,30,31}$ More recent studies have produced lower cost estimates of 600 to 1,000 million USD,, 632 but these studies have been criticised for not including all relevant costs. For example, the 600 million cost estimate by Prasad and Mailankody (2017) appears to have significant survivorship bias, since they only include the development cost for those pharmaceutical companies that were successful in getting new products approved.5,33,34 Including only the cost of products that make it through the R\&D process (i.e. survivors) underestimates the total expected cost of developing a new product. Regardless of the exact cost, pharmaceutical research has a high cost but low probability of success.

Once developed and approved, many pharmaceutical products can be produced at a low cost. Therefore, producers would be unable to cover their development costs in a fully competitive market for pharmaceutical sales that would bring the cost of pharmaceuticals down toward the cost of production. The inability to cover development costs would lead to a market failure in the development of new pharmaceuticals, where no or very few new pharmaceutical would be developed. To incentivise development of new products, producers are granted market exclusivity through the patent system. This provides producers an opportunity to cover their investments by setting higher prices until the end of the patent protected period. After 
patent expiration, competitors can enter the market, which often brings down the price significantly, as exemplified by the effect of the generic drug substitution in Sweden. ${ }^{35,36}$

The higher prices on pharmaceuticals during patent protection leads to lower value of these products to health care systems as well as inefficiencies from lower than optimal use.17,37-39 Further discussion around the value of pharmaceuticals to producers and the rest of society in the period during and after patent protection is included in Section 2.4, and further discussion around the use of patents to incentivise pharmaceutical is presented in Section 2.5.

\subsection{The assessment and implementation of pharma- ceuticals}

Society wants to know if new pharmaceuticals and medical technologies are safe, effective, and worthwhile, in essence:

Can it work? Does it work? Is it worth it? (Haynes, 1999). $4^{40}$

The first of these questions relates to whether a treatment can work under ideal circumstances, as in randomised controlled trials (RCTs) of a select patient population. This question is the focus of the regulatory process, which evaluates findings from clinical trials regarding efficacy and safety. The second question concerns effectiveness and whether the treatment does work when implemented in clinical practice where patient population, patient follow-up, and other treatment practices may be different from those in clinical trials. The third question is linked to the value of the treatment and whether it is worth paying for the treatment. The last two questions are the focus of the health technology assessment, which are central to the reimbursement process.

\subsubsection{Regulatory process}

The regulatory process assess the efficacy and safety of pharmaceuticals to determine whether pharmaceuticals have an acceptable benefit-risk ratio. Within Europe, this assessment is predominantly done by the centralised EMA procedure, which assesses the clinical evidence of the pharmaceutical. The assessment and recommendation of the EMA provide the basis for the decision that is taken by the European Parliament. When approved, pharmaceuticals are granted Marketing Authorisations Approval (MAA) and are then allowed to be used by physicians and patients within the EU as part of standard clinical practice.7 Similar regulatory processes are in place for countries outside the EU including, for example, the Food and Drug Administration (FDA) in the US. 
There are clear requirements for the type of evidence and studies needed to demonstrate the efficacy and safety for the regulatory assessment, which most often require evidence from one or more RCTs. This reflect that RCTs are considered the gold standard for determining causal relationships and to ensure that the efficacy and safety observed in trials are indeed caused by the pharmaceutical. This approach ensures high interval validity in the trails that form the basis of the benefit-risk assessment. However, RCTs seldom reflect clinical practice, leading to low external validity (e.g. patients and treatments in the trial does not reflect current treatment practice). ${ }^{41-44}$ This lack of external validity can be a significant hurdle when assessing the expected effectiveness and value of implementing a treatment in clinical practice.

\subsubsection{Reimbursement process}

Most of the spending on patented pharmaceuticals is funded by either public health care system, as in Sweden, or health care insurance, as in the Netherlands. 45 Both these systems have limited resources to spend on pharmaceuticals and other health care interventions. The reimbursement process investigates whether products approved by regulatory agencies constitute good use of health care resources. This process determines whether a treatment should be reimbursed and funded.

Reimbursement processes vary between countries. ${ }^{8}$ Often, the processes include an assessment of the value of a pharmaceutical, which depends on the cost and effect of using the pharmaceutical in clinical practice (Section 2.4). The sophistication and complexity in the estimation of longterm cost and effect and how this information is used to inform reimbursement decisions varies considerably across countries. ${ }^{46-48}$ Another area of divergence is how prices are set or regulated. Some countries use policies such as International Reference Pricing (IRP) that reference prices in other countries, and some countries use confidential discounts or other price agreements. $8,19,49$

\section{Cost-effectiveness appraisal}

In many countries, the formal cost-effectiveness appraisal of pharmaceuticals is a central part of the reimbursement process. 47 The cost-effectiveness appraisal estimates the long-term cost and effect of implementing a treatment in clinical practice to ascertain whether the treatment represent good use of health care resources.

The main result of a cost-effectiveness analysis within health care is generally the incremental cost-effectiveness ratio (ICER). The ICER is the ratio of the incremental cost $(\Delta \mathrm{C})$ and effect $(\Delta \mathrm{E})$ of using a (new) treat- 
ment in comparison to the most relevant alternative treatment (comparator) (Equation 1). The ICER represents the resources needed to obtain one additional unit of health. Therefore, treatments with a low ICER are more cost-effective and vice versa. Effects are often estimated in terms of Quality Adjusted Life Years (QALYs), which incorporates both morbidity and mortality. A cost-effectiveness analysis using QALYs as the outcome is sometimes referred to as a cost-utility analysis, where the ICER represents how much it cost to gain on additional QALY (i.e. one additional year of life in perfect health) 50,51 :

$$
\text { [1] ICER }=\frac{\Delta C}{\Delta E}=\frac{C_{\text {new }}-C_{\text {comparator }}}{E_{\text {new }}-E_{\text {comparator }}}
$$

When determining whether a treatment is considered cost-effective, i.e. provides good value for money, the ICER is often compared to a costeffectiveness threshold $(\lambda)$. When the ICER is below this threshold, it is considered cost-effective and vice versa. An alternative, but related, way to assess cost-effeteness is to estimate the incremental net benefit (INB) of the treatment, which is positive when the ICER is below the threshold. INB can be calculated in terms of incremental net monetary (INMB) or health (INHB) benefits. ${ }^{i}, 50-53 \mathrm{~A}$ key factor in assessing cost-effectiveness with these approaches, is what the threshold should represent and what its value should be. This is described and discussed further in Section 2.4 on the value of pharmaceuticals.

A general challenge for cost-effectiveness appraisals is the limited and uncertain information on long-term effect and cost available at the time of the reimbursement process. ${ }^{54-56}$ These appraisals rely heavily on the data from the clinical trials that inform the regulatory assessment. Limited duration of trial follow-up, selected patient populations, and the relevance of comparator(s) included in the trials can lead to significant uncertainty around the effectiveness and cost of implementing treatments into clinical practice. The uncertainty around long-term effect and cost could be reduced by conducting further research, increased scrutiny, or waiting until more evidence becomes available. That is, additional accuracy in the estimation of cost-effectiveness comes at a cost, which consists of a monetary (the cost of more detailed assessment or further research) and time component (the health loss from delayed implementation of cost-effective treatments).

Therefore, agencies need to balance the accuracy and cost of the appraisal process. In addition, because decision makers may not be able to defer decisions or commission further research, a main question is how to account for uncertainty in the decision making. ${ }^{57,58}$ Analysis of the accuracy

${ }^{\mathrm{i}} I N M B=\Delta E * \lambda-\Delta C$, and $I N H B=\Delta E-\frac{\Delta C}{\lambda}$ 
vs. cost trade-off and how to incorporate uncertainty into the cost-effectiveness assessment was the focus of study 2.

\section{Price setting}

Although producers have the right to set prices of their products, there are certain restrictions on what prices they can set within different countries due to policies employed by reimbursement agencies or other governmental authorities. ${ }^{8,19,59}$ One such example is IRP where prices is other countries are used as a benchmark. IRP systems can be designed in different ways, but the general principle is that it determines the price, or the maximum price that will be allowed, based on the prices in other countries. ${ }^{8,19}$ For example, in Norway producers are not allowed to set higher prices than the average price of the three lowest prices in Austria, Belgium, Denmark, Finland, Germany, Great Britain, Ireland, The Netherlands, and Sweden. ${ }^{60}$

Value based pricing (VBP), an alternative approach to setting prices, where prices reflects the value that products represent. Under this system, reimbursement agencies recommend treatments that are priced so that they provide value, which is generally linked to cost-effectiveness and having an ICER below the threshold. Producers are free to set whatever prices they want, but the reimbursement agencies only recommends treatments that have prices at which the treatment is perceived to provide value. ${ }^{61,62}$

The value of pharmaceuticals varies across countries based on current treatment practice, patient population, as well as a country's ability and willingness to pay for health care improvements. For this reason, VBP would lead to differential pricing across countries. It has been argued that differential pricing based on ability to pay is equitable and leads to improved dynamic efficiency compared to harmonised prices. ${ }^{63-66}$ Nevertheless, many European counties use IRP, ,8,19 which may appear attractive and fair as it ensures a country is not paying more than other countries.

Lower prices and the political attraction of not paying more than neighbouring countries appear to be an important rationale for IRP. This was also the motivation behind the IRP system proposed in Sweden in 2012. ${ }^{18}$ However, there is no such thing as a free lunch. Reduction in prices from IRP has resulted in pharmaceutical companies being unwilling to set lower prices in lower income countries as well as delaying the access and sometimes not making the products available at all in some countries to avoid price reduction in other countries. ${ }^{67-69}$ This shows that the gains from IRP in high income countries comes at the expense of lower income countries where, in a worse-case scenario, access is denied altogether. In addition, the harmonisation of prices across countries due to IRP reduces dynamic efficiency in the development of pharmaceuticals, which is expected to lead to fewer new treatments being developed. ${ }^{63-66}$ 
Despite the inequality of IRP, there is often limited analysis of the expected effect of changing or introducing IRP systems. This was also the case with the proposal to introduce an IRP system in Sweden in 2012. This system was estimated to reduce pharmaceutical spending by around SEK 1.9 billion. ${ }^{18}$ However, no formal assessment of how this would impact incentives for pharmaceutical R\&D and therefore future population health was carried out. This proposed IRP system, with no accompanying consequence analysis, was the main motivator for the work presented in Paper 1.

\section{The reimbursement process in Sweden}

Established in 2002, the Dental and Pharmaceutical Benefits Agency (TLV), specifically its pharmaceutical benefits board, makes decision on whether prescription pharmaceuticals should be reimbursed as part of the pharmaceutical benefits scheme in Sweden (högkostnadsskyddet). The reimbursement process is initiated by the marketing authorisation holder, who submits an application for reimbursement. A working group at TLV assess the clinical evidence and the cost-effectiveness estimations submitted by the company. This assessment forms the basis of the reimbursement recommendation made by the TLV board.35,70

The New Therapies council (NT-council) is an organisation set up by the Swedish regions to make recommendations about the use of pharmaceuticals. The NT-council was established to support equitable and evidence-based health care across Swedish health care regions, particularly related to pharmaceuticals used in hospital care, which are not part of the standard TLV appraisal process for prescription pharmaceuticals. The NTcouncil can request TLV to perform a cost-effectiveness assessment, which the NT-council then considers in their decision making and treatment recommendations. 71,72

Reimbursement decisions and treatment recommendations by the TLV and NT-council are grounded in the ethical principles for health care prioritisation in Sweden outlined in the 1996/97:60 proposition. ${ }^{\text {ii }}$ This proposition specifies that health care prioritisation in Sweden must consider three foundational principles: human dignity; need and solidarity; and cost-effectiveness. 35,73

Both TLV and the NT-council operate a value-based pricing system where producers are free to set prices, but only treatments assessed to be cost-effective are reimbursed and recommended. Therefore, cost-effectiveness assessment is central in the reimbursement process, with TLV assessing the ICER put forward by the company as well as producing their

\footnotetext{
ii There is further legislation detailing the remint for TLV, ${ }^{216}$ but the 1996/97:60 proposition remains the overarching guide for health care prioritisation in Sweden.
} 
own ICER estimate as part of their cost-effectiveness appraisal. The need and solidarity principle is incorporated into the decision making by operating a higher threshold for pharmaceuticals treating more severe conditions. ${ }^{71,74}$ The human dignity principle sets limits for what can be included in the cost-effectiveness assessment (e.g. socioeconomic status, ethnicity, or age) and was a motivation for updating the TLV guidelines in 2015 to no longer include cost of extending the life of people who are no longer in the workforce. 75,76

\subsubsection{Implementation}

Regulatory approval implies that treatments can be used in clinical practice and reimbursement decisions determine whether they will be funded. Approval in these processes is still no guarantee that a treatment is actually

implemented and used in clinical practice. Ultimately, as treatment decisions are made by physicians, variation in treatment practice is expected. This variation is a significant challenge for health care systems as it lead to suboptimal treatment and outcome for patients as well as raise questions about equal access to health care.13,15,16,77,78 In Sweden, this issue has been

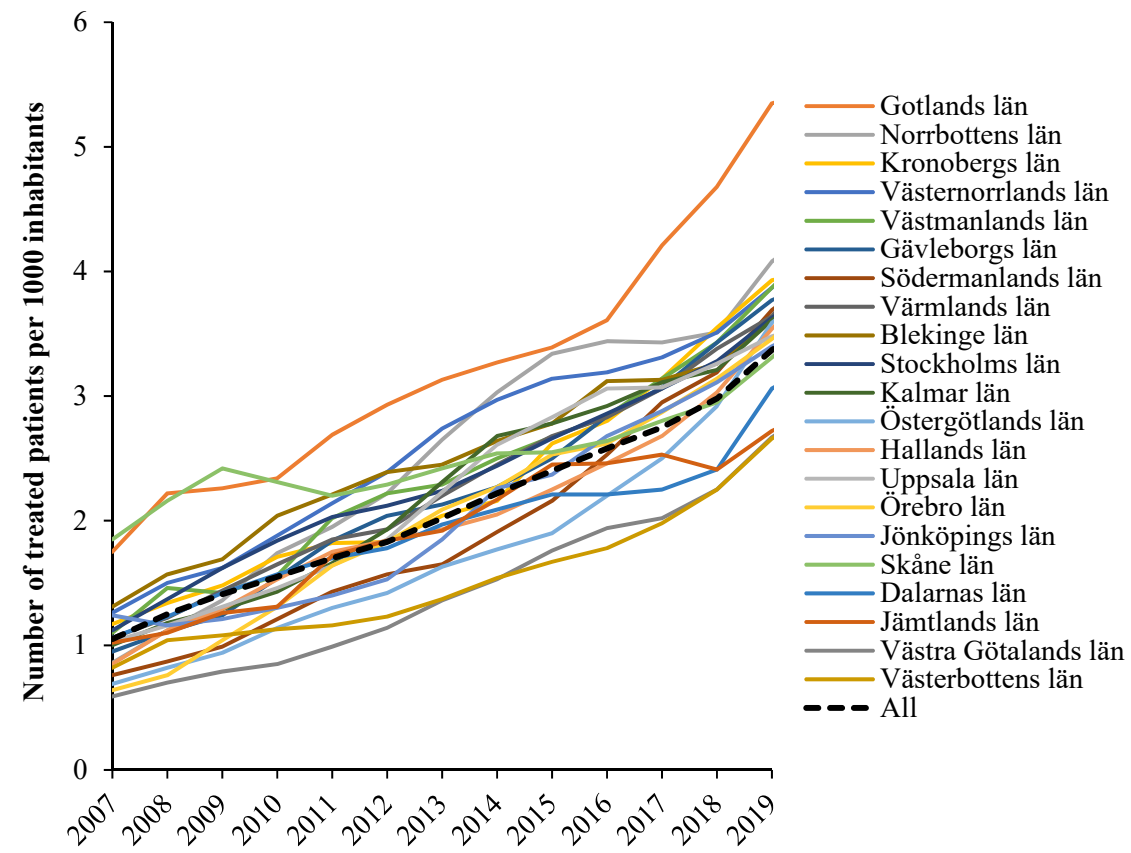

Figure 2.2 Number of patients per 1,000 inhabitants treated with TNF inhibitors. Source: The National board of health and welfare (Socialstyrelsen) statistical database, pharmaceuticals, ATC-code L04AB..$^{218}$ 
exemplified and documented in several studies and quality registries, showing significant variation in treatment practice across health care regions. 14,79-85 Figures 2.2 and 2.3 provide two examples based on the use of Tumor Necrosis Factor (TNF) inhibitors and treatment for Attention-Deficit/Hyperactivity Disorder (ADHD).

National treatment guidelines, drug formulary committees, and local resource allocation are some of the processes that supplement reimbursement decisions in guiding and determining the implementation into clinical practice at a regional level in Sweden.17,35 This thesis does not study these individual processes (but instead estimate the consequence of de-

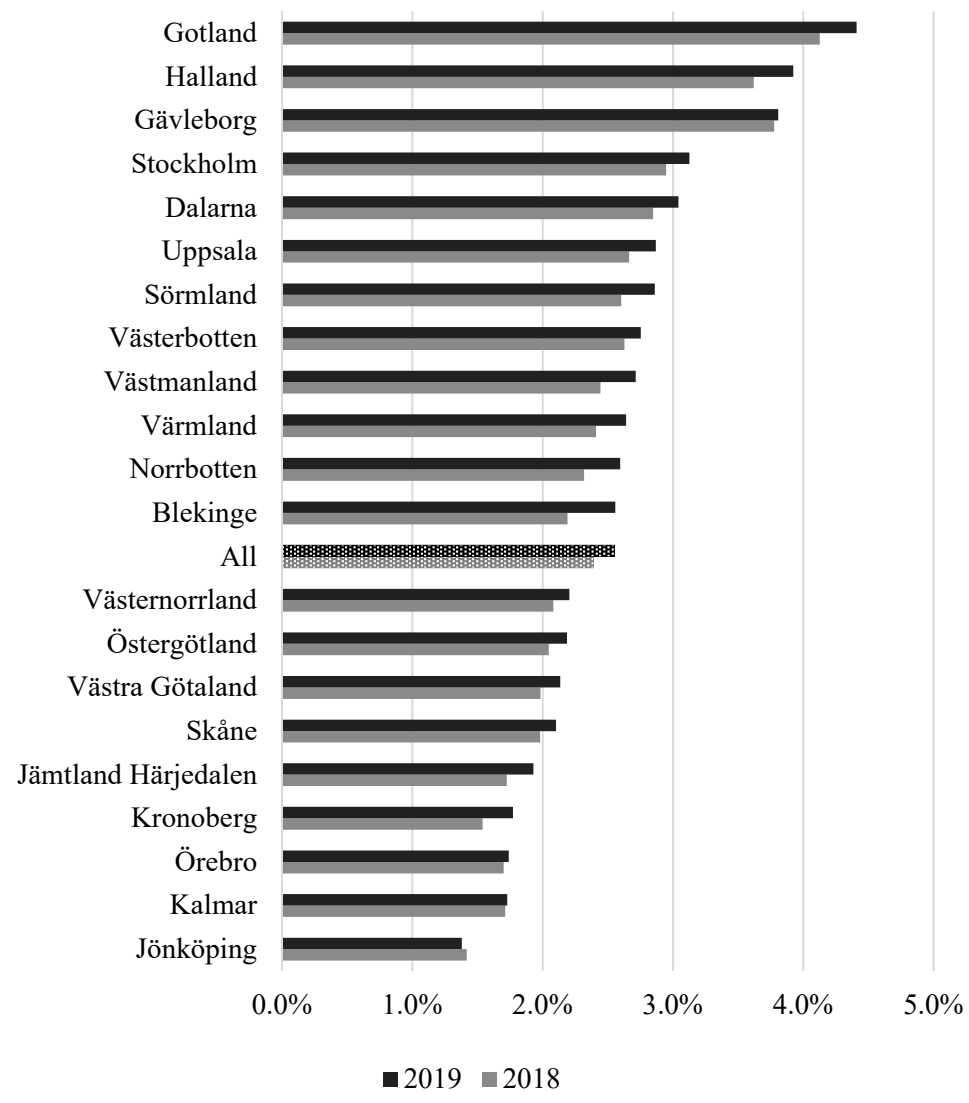

Figure 2.3 Proportion of children and adolescents (0 to 17 years) treated with ADHD medication. Source: vardenisiffror.se, ATC-codes: N06BA, excluding N06BA07 + C02AC02. ${ }^{219}$ 
layed and varying implementation in study 3 and 4). Therefore, the individual processes and factors determining implementation after the reimbursement process are not described in further detail here. This is not because these are unimportant for implementing and getting value from treatments in clinical practice; rather, these issues are outside the scope of this thesis.

\subsection{The value of pharmaceuticals}

As with beauty, the value is in the eye of the beholder. The reimbursement process aims to determine the value of using treatments in clinical practice. But value to whom?

Within economics the value of a product can be estimated in terms of consumer and producer surplus, which represent the value generated to consumers and producers from buying and selling a product. ${ }^{86}$ In a publicly funded or insurance-based health care system, it can be unclear who the consumers of pharmaceuticals are. Patients are those benefitting and consuming the pharmaceutical product, but the health care systems can also be described as the consumers given their use (consumption) of pharmaceuticals as part of health care provision. ${ }^{87}$ This issue is made even more complex as these different groups of consumers face different costs related to a given pharmaceutical. The following section elaborates on this issue and presents different definitions of the value (consumer surplus) of pharmaceuticals through a patient, health care, and societal perspective.

\subsubsection{Consumer surplus}

The effect of a pharmaceutical is the treatment effect it provides in comparison to the most relevant alternative treatment. iii For example, if a treatment reduces mortality, the effect of the treatment is the additional life years gained. Assessing the value of a pharmaceutical must incorporate the cost of acquiring the treatment effect. In a publicly funded health care system, the cost paid by a patient is often different than that paid by the health care system. Patients often only pay a small (or zero) co-payment with the majority of the cost falling on the health care system. A treatment that reduces mortality is clearly valuable to patients when it comes at a low or zero cost. In contrast, the value to the health care system may be significantly lower if the treatment is associated with high cost for the health care provider. In fact, the value to the health care system might even be negative if greater gains in life expectancy could be obtained by investing the resources in other treatments.

\footnotetext{
iii The alternative treatment could be no treatment.
} 
The value of treatments given different perspectives is formalised in Table 2.1, which is adapted from Claxton et al. (2010). ${ }^{11}$ The table outlines that the value varies and includes different costs based on the perspective. For patients, a treatment has value when it generates more benefit then it cost in reduced private consumption. With a health care perspective, a treatment generates value when the health gains of the treatment $\left(\Delta \mathrm{E}_{\mathrm{H}}\right)$ is larger than what is displaced elsewhere in the health care system, i.e. opportunity cost $\left(\Delta \mathrm{C}_{\mathrm{HC}} / \lambda_{\mathrm{HC}}\right)$. When taking a broader societal perspective, the assessment of value includes the impact across all public sectors as well as private value of the treatment. These different perspectives can explain the at times heated public debate where patients demand access to specific treatments that reimbursement agencies denies or limits access to. It is rational for patients to want access to treatments they perceive as valuable, but equally rational for reimbursement agencies to restrict access when treatments do not constitute good use of public resources.

Table 2.1 Value given different perspectives, adapted from Claxton et al. (2010). ${ }^{51}$

\begin{tabular}{ll}
\hline Perspective & Value (INB) \\
\hline Patient & $\Delta \mathrm{E}_{\mathrm{H}}-\Delta \mathrm{C}_{\mathrm{PC}} / \lambda_{\mathrm{PC}}$ \\
\hline Health care & $\Delta \mathrm{E}_{\mathrm{H}}-\Delta \mathrm{C}_{\mathrm{HC}} / \lambda_{\mathrm{HC}}$ \\
\hline Societal & $\left(\Delta \mathrm{E}_{\mathrm{H}}+\Delta \mathrm{E}_{\mathrm{oPS}}\right)-\left(\Delta \mathrm{C}_{\mathrm{PC}} / \lambda_{\mathrm{PC}}+\Delta \mathrm{C}_{\mathrm{HC}} / \lambda_{\mathrm{HC}}+\Delta \mathrm{C}_{\mathrm{oPS}} / \lambda_{\mathrm{oPS}}\right)$ \\
\hline
\end{tabular}

INB: Incremental net benefit; $\Delta \mathrm{E}_{\mathrm{H}}$ : incremental health effect; $\Delta \mathrm{E}_{\mathrm{oPS}}$ : incremental other public sector effects; $\Delta \mathrm{C}_{\mathrm{PC}}$ : impact on private consumption; $\lambda_{\mathrm{PC}}$ : consumption value of health, $\Delta \mathrm{C}_{\mathrm{HC}}$ : incremental health care cost; $\lambda_{\mathrm{HC}}$ : marginal productivity of the health care system; $\Delta \mathrm{C}_{\mathrm{oPs}}$ : cost falling on other public sectors; $\lambda_{\mathrm{oPs}}$ : marginal productivity of other public sectors

If the purpose is to maximise population health, then the cost-effectiveness threshold should reflect the marginal productivity of the health care system. A decision rule of having an ICER below this threshold translates into having a positive impact on population health. If one wishes to take a broader societal perspective, then costs falling on other public sectors and on private consumption should be valued based on the opportunity cost in these sectors. ${ }^{\text {iv }}$ In that case, we would assess the complete societal value of a treatment. However, knowing the opportunity cost across all sectors makes this a challenging approach to implement in practice. In addition, even with a broad societal perspective, it is important to consider the purpose of the health care system and assess the health effects from resources allocated to health care..$^{1}$

\footnotetext{
iv Under the assumption that budgets are fully flexible and optimally set, the opportunity cost will be equivalent across sectors and the threshold should reflect the consumption value of health. However, since we do not live a world with optimal resource allocation and the assumption of fully flexible and optimal budgets are clearly not met, I will not direct further attention or discussion towards this hypothetical state of nature.
} 
The National Institute for Health and Care Excellence (NICE), which is responsible for making reimbursement decisions for England and Wales, has been clear about their objective in terms of maximising population health and that the threshold should represent the opportunity cost within the health care system. ${ }^{88-91}$ In Sweden, this has been less clear, and the initial methods guidelines from TLV stated that cost-effectiveness analyses submitted to the agency should have a societal perspective, taking into account both health care and non-health care costs and effects. ${ }^{22}$ However, it has not been fully clear what the threshold in Sweden is or ought to reflect, with different authors providing different perspectives. ${ }^{62,93-97}$ Furthermore, TLV updated their guidelines in 2015 after concerns had been raised about the alignment between including the (non-health care) cost from extending the life of patients no longer in the workforce, and the human dignity principle. After updating the methods guide, TLV now appears to operate closer to a health care perspective.75,96,98 TLV can, and does, still consider non-health care cost and benefits in their decision making "when relevant", although it is unclear how exactly this is included into decision making.

This thesis generally takes a health care perspective when evaluating and discussing the consumer value of pharmaceuticals. This approach reflects the current practice of TLV in Sweden, as outlined above, and my background and "upbringing" during my health economic education in the UK. However, the frameworks and assessments outlined in this thesis would also be valid given a broader perspective on the value of pharmaceuticals.

Taking a health care perspective does not entail that the threshold must represent the marginal productivity of the health care system. In fact, the 1996/97:60 proposition indicates that having an ICER below or above the marginal productivity of the health care system should not be the main, or at least the only, decision criteria for health care prioritisation in Sweden. ${ }^{35,71}$ Cost-effectiveness is one of the principles underpinning health care prioritisation in Sweden, but the need and solidarity principle states that more health care resources should go to those with the greatest need. Therefore, health care decision making needs to balance the objective of maximising population health and ensuring an equitable distribution of health, an efficiency vs. equity trade-off. In Sweden, this is operationalised by allowing a higher cost-effectiveness threshold for more severe diseases and conditions. ${ }^{62,71,74,96}$ Some argue that it would be better to assess costeffectiveness given the marginal productivity of the health care system to 


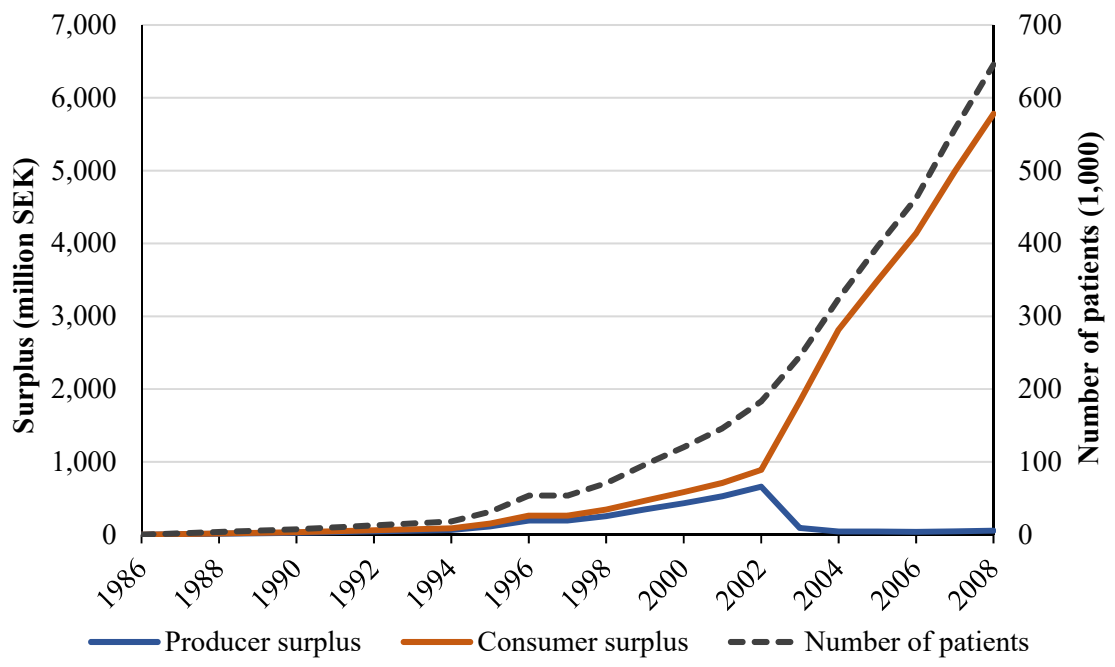

Figure 2.4 Consumer and producer surplus, per year, from the use of simvastatin in Sweden. ${ }^{i}$ Source: Adapted from Lindgren and Jönsson (2012). ${ }^{173}$

reflect the negative INB implied by allowing an ICER above the marginal productivity. ${ }^{96}$ Decision makers can still incorporate need and solidarity by accepting negative INB, which implies that they put higher value on the QALYs gained than those lost. Mathematically, it is equivalent whether such equity weights are applied to QALY gains or on the threshold to account for need and solidarity.

The value generated by pharmaceuticals change over time since price and use change over time, as exemplified in Figure 2.4. The price of pharmaceuticals generally fall significantly when the patent expires due to increased competition, which increase the value to consumers, as seen in Figure 2.4 in the years after 2002. This demonstrates the importance of taking a long-term perspective when assessing the overall value of pharmaceuticals. The graph also shows the importance of implementation and how significant value could have been gained from increased use, which is the focus of study 3.

\subsubsection{Producer surplus}

Producer surplus represents the value acquired by the producer of a pharmaceutical and is the revenue (price * quantity) minus the cost of producing and delivering the product. The total value to producers is the producer surplus accumulated over time, so total value depends on the price per patient and the number of patients over time. Hence, the level of implementation is a significant determinant of producer surplus as illustrated in Figure 2.4. 
Pharmaceuticals are protected by patents to incentivise R\&D by providing an opportunity for producers to cover the investments needed to develop a new treatment. During this period, producers can set higher prices and earn higher revenues as they are effectively acting as a monopoly until the patent expires. This excess earning from monopoly pricing has been described as rent or rent extraction. ${ }^{88,86,99}$ After the patent expires, other producers may enter the market, leading to increased competition. The impact of patent expiry is clearly demonstrated by the significant price reductions due to generic drug entry observed in Sweden.35,36 The competitive market after patent expiry reduces the earnings, as exemplified in Figure 2.4, which are shared between the competing firms. The main value of successfully developing a new pharmaceutical, to the marketing authorisation holding company, is therefore the total expected earnings, i.e. expected rent, generated during the period of patent protection.

\subsection{Incentivising pharmaceutical R\&D}

Expected rent during patent protection is the key financial incentive for the development of new technologies under the system of patent protection. ${ }^{100-105}$ Policies that determine price and implementation of pharmaceuticals impact rent by controlling the revenue of currently used products and by impacting expected rent on future products.

\subsubsection{How large should expected rent be?}

Pharmaceutical prices and pharmaceutical company profits are topics of heated public debate. Critics argue that pharmaceutical companies set too high prices, earn too high profits, and take the health care system hostage when setting high prices for life saving treatments. ${ }^{31-33}$ Others argue that pressuring pharmaceutical prices will lead to lower spending on pharmaceutical R\&D and lower long-term population health. ${ }^{64,106-109}$

Theoretical studies and analyses show that a system of differential pricing where countries pay prices based on their ability to pay is associated with improved dynamic efficiency (i.e. higher long-term value from pharmaceuticals) compared to more uniform prices. ${ }^{64,66,110-112}$ Monopoly pricing during patent protection is, nevertheless, inefficient in terms of getting the most value from pharmaceuticals in the short-term. Price reductions could increase consumer surplus even more than it reduces producer surplus if use is increased, improving static efficiency. ${ }^{17,37-39}$ However, unless producers are compensated, this is expected to result in lower R\&D investments and fewer new technologies being developed.

Under a VBP system, producers will be able to set prices so that the ICER is equal to the threshold. This is consistent with countries paying 
based on willingness and ability to pay and would lead to differential pricing if used across countries. ${ }^{62,64,110}$ However, some argue that producers should not be allowed to extract all surplus during patent protection and that consumers should get a part of the value. ${ }^{113}$ Others argue that allowing producers to set even higher prices during patent protection would lead to even greater dynamic efficiency and therefore even higher long-term population health. ${ }^{114-116}$

In practice, producers are unlikely to gain all surplus during patent protection in a VBP system. Pharmaceuticals often face competition from other similar but not identical patented pharmaceuticals, which can create price competition even during the period of patent protection. ${ }^{17}$ Similarly, when a pharmaceutical is approved for multiple indications, it is likely that some of these indications will provide consumer surplus, unless producers are allowed to set indication-specific prices or set one average price that is cost-effective on average, but not cost-effective for all indications. ${ }^{61,117}$

\subsubsection{Alternative ways to incentivise $R \& D$}

Patents are not optimal and lead to inefficiencies, although one must not forget that a market failure motivates their use in the first place. The high prices that maximise producer surplus result in underuse, which causes both static and dynamic inefficiency (lower combined producer and consumer surplus).17,37-39 The inefficiencies of patents are well known, $3^{8,102,105,118-120}$ and several alternative proposals on how to address these inefficiencies related to pharmaceuticals have been proposed.

One set of policy proposals focuses on how to reduce the inefficiencies of patent protection and monopoly pricing. Some suggest pricing mechanisms to reduce the static inefficiencies by paying producers lump sum payments that represent the producer surplus under monopoly pricing while paying a lower price per patients that cover the marginal cost of production. $39,78,121$ This would improve static efficiency without reducing dynamic efficiency. Others have proposed reducing high prices and the "super normal profits" by linking prices to the cost of developing a given pharmaceutical. ${ }^{122,123}$ However, it is challenging to determine the cost of pharmaceutical development and the magnitude of profits required to incentivise R\&D given the high failure rate, as outlined in Section 2.2. ${ }^{\mathrm{v}}$

\footnotetext{
${ }^{v}$ It might also be noted that a system of paying based on pharmaceutical R\&D cost may even increase the overall price of pharmaceuticals. Firstly, companies would have little incentives to keep cost down if they are passed on to consumers. But even more so, not all pharmaceuticals that make it to the market generate sufficient earnings to cover the development cost. A study by Grabowsky and Vernon (2000) found that only three in ten pharmaceuticals earned profits that covered the investment needed to bring the product to the market. ${ }^{21}$ When deciding whether to continue the development of a new chemical entity, past investments in this entity are irrelevant and should be regarded as sunk cost. Hence, the decision should be based on whether the remaining development cost can be covered by the expected rent This shows why we would expect a significant number of products not to cover the development costs.
} 
Other policies seek alternatives ways to incentivise R\&D. Proposals include innovation prizes, increased public funding of pharmaceutical research, and lowering the cost of pharmaceutical development through different evidence requirements for regulatory approval and reimbursement recommendations. $38,118,124-127$

Most of these proposals are not new and build on ideas that have been around for years. $38,78,128$ This indicates that even though there might be substantial value from reducing inefficiency or using alternative approaches to incentivise pharmaceutical $\mathrm{R} \& \mathrm{D}$, the system of patent protection is likely to remain the main driver for incentivising R\&D. Therefore, it is important to assess how currently used reimbursement policies impact the incentives for pharmaceutical R\&D under the system of patent protection.

\subsection{Setting the studies and research questions into perspective}

This thesis studies the effect of policies that determine the price and implementation of pharmaceuticals. This aim is investigated by assessing how different policies and suboptimal implementation influence consumer surplus and expected rent given a health care perspective and a VBP system like the one operated in Sweden. The stylised representation of consumer and producer surplus over time presented in Figure 2.5 put the studies into perspective in relation to which parts are being investigated.

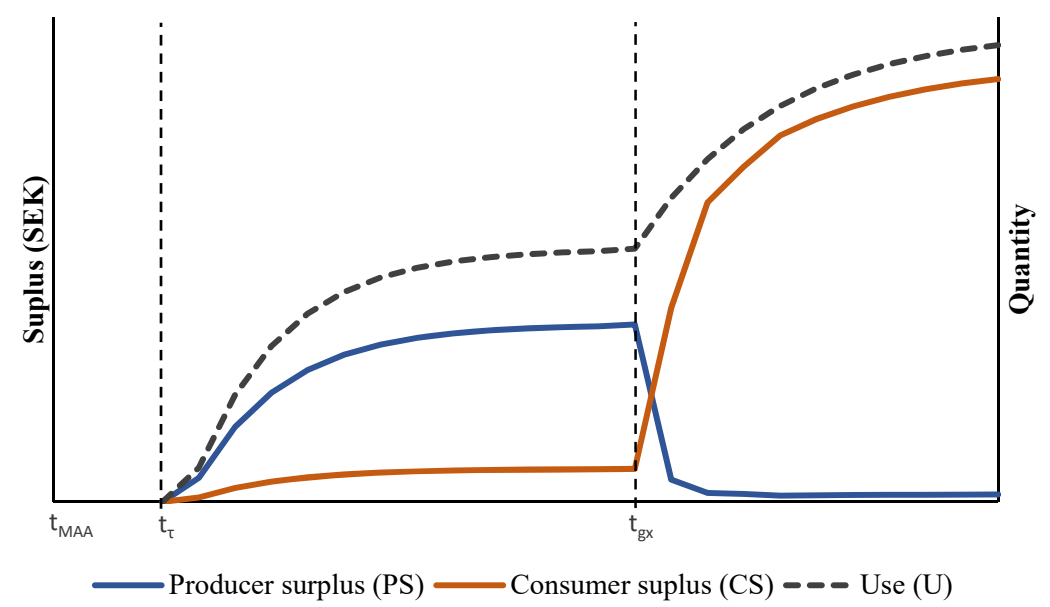

Figure 2.5 Stylised example of consumer surplus (CS), producer surplus (PS), and use $(U)$ over time. $t_{\mathrm{MAA}}$ : time of marketing authorisation approval; $t_{\tau}$ : time of reimbursement recommendation; $\mathrm{tgx}_{\mathrm{gx}}$ : time patent expiry 
Study 1 examines the expected impact of pharmaceutical policies, including international reference pricing (IRP) (impacting CS and PS), the reimbursement process (determining $t_{\tau}$ ), and implementation (impacting U, which determines CS and PS). Study 2 investigates the accuracy vs. cost trade-off for the cost-effectiveness appraisal, which determines $t_{\tau}$, impacts pricing, and determines what technologies get reimbursed (all impacting CS and PS). Study 3 estimates the impact of regional implementation variation and assess the value (PS and CS) of eliminating implementation variation (i.e. increasing U). This study uses the case study of ticagrelor treatment for patients with myocardial infarction in Sweden. Study 4 investigates the comparative effectiveness of ticagrelor in clinical practice, with the effectiveness being a key determinant for cost-effectiveness and value of using ticagrelor in Swedish clinical practice (CS).

\subsubsection{What is not in this thesis}

To avoid disappointing readers, it is worth understanding what this thesis leaves out. This thesis does not aim to investigate nor to make positive statements or normative judgements about static vs. dynamic efficiency of pharmaceutical R\&D. That is, the aim is not to be prescriptive about the trade-off between getting health today and incentivising future R\&D to improve long-term health. Similarly, the thesis does not venture into further discussion on alternative ways to incentivise pharmaceutical R\&D. Although this thesis investigates the impact of regional implementation variation and estimates its impact on population health and producer surplus, this thesis does not focus on the causes for regional variations and how these are best addressed. 


\section{STUDIES}

This chapter presents the four studies that formed the basis for the four papers and this thesis. This chapter complements rather than simply summarise the papers, which are presented in full at the end of this thesis. The introduction describes the context and background for why the study was conducted in relation to the policy environment at the time of the study. The methods and results sections mainly summarise what is reported in the papers, although some additional material is included for studies 3 and 4. This is followed by an interpretation section that puts the study results into perspective and expands on the discussion sections in the papers.

The antiplatelet ticagrelor, in the treatment of myocardial infarction, was used as a case study in study 3 and was the focus of the comparative effectiveness estimation in study 4 . A description of ticagrelor and relevant data on effectiveness and cost-effectiveness is described in the methods section of study 3 (Section 3.3.2). 


\subsection{Getting value today and incentivising for the fu- ture (Paper 1)}

\subsubsection{Introduction}

An investigation initiated by the Swedish government proposed the introduction of IRP in Sweden as a complement to the VBP system in 2012. This "Wallström investigation" outlined an IRP system referencing the prices in six other European countries at different times after marketing authorisation approval, and it was estimated that this system would reduce pharmaceutical spending by around SEK 1.9 billion. ${ }^{18}$ Despite the detailed IRP proposal and estimation of expected savings, there was limited analysis of how this system would impact incentives to develop new pharmaceuticals. The lack of analysis and discussion around this proposed change to pharmaceutical price setting in Sweden was the motivation for the work that developed into Paper 1.

The purpose of this work was to outline and use a framework to analyse how IRP and other policies commonly used to regulate price and use of pharmaceuticals are expected to influence consumer surplus and expected rent. In doing so, the work analyses and discusses how these policies are likely to impact R\&D incentives through the impact on expected rent.

\subsubsection{Method}

A theoretical framework was developed for expected rent and consumer surplus during patent protection. The framework was then used to analyse how different policies impact expected rent and consumer surplus.

The framework defines expected rent and consumer surplus as the accumulated surplus during the period of patient protection from the time of marketing authorisation approval ( $\left.\mathrm{t}_{\mathrm{MAA}}\right)$ to the time of paten expiry $\left(\mathrm{t}_{\mathrm{gx}}\right)$. The period of patent protection was the focus because generic substitution, as operated in Sweden, drives down pharmaceutical prices toward marginal cost of production after patent expiry. In this way, the company with marketing authorisation approval is unlikely to gain much, if any, of the earnings generated after patent expiry. By assessing the impact that these policies are expected to have on expected rent for pharmaceuticals, the paper assesses the potential impact on R\&D incentives.

The policies investigated in this study include: duration of market exclusivity, price setting (VBP vs IRP), implementation into clinical practice, and generic substitution. 


\subsubsection{Results}

The main results of the study is presented in Table 3.1 and Figure 3.1.

This study found that delayed implementation reduced both expected rent and producer surplus. A similar result was seen regarding lower implementation in clinical practice. This shows that producers and consumers have aligned incentives in ensuring that cost-effective treatments are implemented appropriately and without delay. The paper discusses how heterogeneous treatment effect can lead to variation in the value of implementation to consumers depending on who gets the treatment. That is, there can be higher value from providing the treatment to patients who benefit the most and lower value from providing the treatment to patients who benefit the least. Hence, consumers may have decreasing marginal returns from improving implementation, whereas producers get the same value from implementation improvements regardless of the patient level benefit.

Table 3.1 Illustration of the expected policy impact. The arrows demonstrate the impact on expected rent and consumer surplus; where $\uparrow, \downarrow$ and $\rightarrow$ indicate an increase, decrease and no impact, respectively. ${ }^{129}$

\begin{tabular}{|c|c|c|}
\hline & Expected rent & Consumer surplus \\
\hline $\begin{array}{l}\text { Reduced time of "market exclusivity" } \\
\text { (implementation at time } t_{\tau} \text { instead of } t_{\text {MAA }} \text { ) }\end{array}$ & $\downarrow$ & $\downarrow$ \\
\hline $\begin{array}{l}\text { Price reduction due to due to IRP or PT } \\
\left(\mathrm{P}^{\mathrm{Actual}}<\mathrm{P}^{\mathrm{M}}\right)\end{array}$ & $\downarrow$ & $\uparrow / \rightarrow^{\Phi}$ \\
\hline $\begin{array}{l}\text { Lower than } Q^{\mathrm{M}} \text { adaptation into clinical practice } \\
\left(\mathrm{Q}^{\text {Actual }}<\mathrm{Q}^{\mathrm{M}}\right)\end{array}$ & $\downarrow$ & $\downarrow$ \\
\hline
\end{tabular}

This work showed that price reductions will transfer surplus from producers to consumers. If the price reductions do not lead to change in utilisation then the gain in consumer surplus is equal to the loss in producer surplus. If price reductions increase utilisation then the price reduction will decrease the deadweight loss of monopoly pricing and increase static efficiency. However, unless producers are compensated from the loss in producer surplus this increase in static efficiency comes at the expense of lower dynamic efficiency. Another key finding is that policy design of price reductions determines who gain the surplus, e.g. patients, the health care system or pharmacies. 

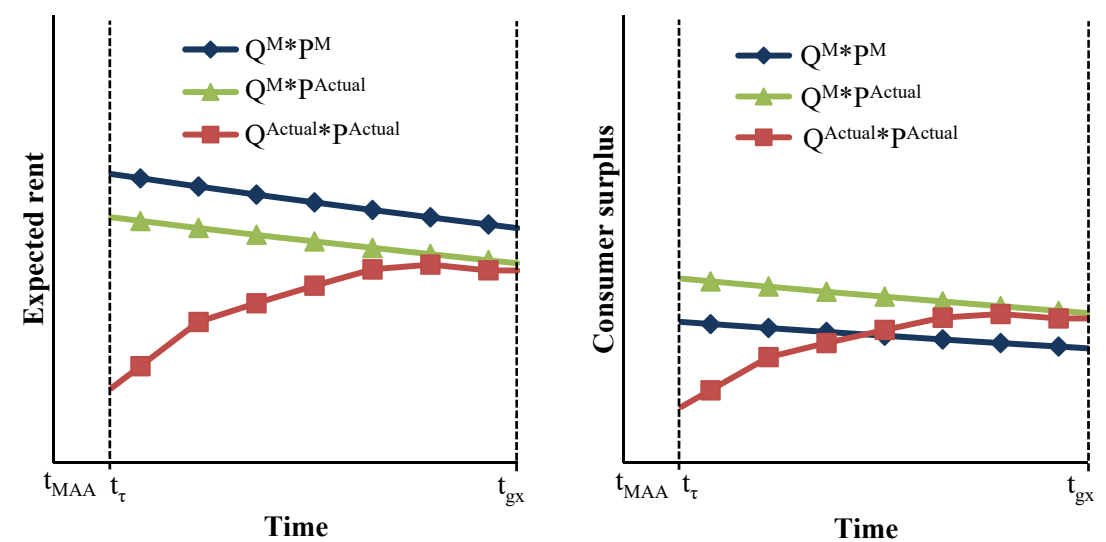

Figure 3.1 Numerical example illustrating the impact of the duration of market exclusivity (implementation at time $\mathrm{t}_{\tau}$ instead of $\mathrm{t}_{\mathrm{MAA}}$ ), price setting $\left(\mathrm{P}^{\text {Actual }}<\mathrm{P}^{\mathrm{M}}\right)$, and lower implementation $\left(\mathrm{Q}^{\mathrm{Actual}}<\mathrm{Q}^{\mathrm{M}}\right)$ in clinical practice on expected rent and consumer surplus. $t_{\mathrm{MAA}}$ : time of marketing authorisation approval; $\mathrm{t}_{\tau}$ : time of reimbursement recommendation; tgx: time patent expiry; $\mathrm{Q}^{\text {Actual }}$ : Quantity given ac-

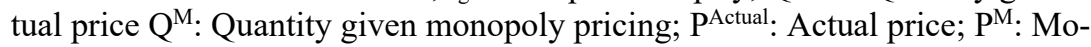
nopoly pricing. ${ }^{129}$

Expected rent is defined as the accumulated producer surplus during patent protection. Therefore, generic substitution or other price reductions post patent expiry do not impact expected rent in this analysis. However, it should be noted that such policies are important for maximising the longterm consumer surplus.

The main analysis in this paper focuses on how pharmaceutical policies impact the expected rent and consumer surplus in a particular country. The paper extends the analysis to outline how price reduction in relatively small countries like the Scandinavian countries may have significant impact on global expected rent due to the widespread use of IRP; that is, price reductions in smaller countries can cause price reductions in other and larger countries. This leads to some policy relevant conclusions on the need for confidential discounts to increase producers' willingness to offer lower prices.

\subsubsection{Interpretation}

The framework was developed to provide formal as well as intuitive assessment of policies that impact pharmaceutical price or use. The framework outlines the expected effect of policy initiatives and improves understanding of the trade-off between maximising the value of currently available technologies and incentivising the development of future technologies. 
This framework outlines how price reductions lead to a surplus transfer from producers to consumers. Policies that restrict the implementation and use of cost-effective treatment will lead to a loss for both consumers and producers.

The IRP system that was proposed in 2012 was never implemented. Instead, the pharmaceutical industry and the Swedish government made an agreement where pharmaceutical companies would lower the prices of products older than 15 years $^{\mathrm{vi}}$ to produce savings of SEK 800 million. ${ }^{130}$ This reduction in pharmaceutical spending is lower than the savings from IRP estimated in the "Wallström Proposal"; however, the SEK 1.9 billion estimate was criticised for overestimating the savings from the proposed IRP system by, for example, including savings that would be generated by patent expiry without the introduction of IRP. ${ }^{131}$ The fact that the Swedish government made this agreement with the industry, wording around "continued analysis of the IRP proposal" in the 15 year rule legislation, and the saving from IRP estimated in a later governmental inquiry of SEK 700 million, ${ }^{17}$ indicate that the SEK 1.9 billion was an overestimation of the saving that could be expected from the proposed IRP system.

Using the framework presented in the paper we can analyse the impact of the 15-year rule on consumer surplus and expected rent to understand why this agreement was preferred over the proposed IRP system:

\section{Expected rent}

- Lowering price after 15 years reduces the value of market exclusivity only when extending past 15 years. Since 15 years is longer than the market exclusivity expected for most pharmaceuticals, it is unlikely to have any significant impact on average expected rent across future pharmaceuticals.

- The 15-year rule provides predictability around future price decreases compared to IRP, where it is challenging, if not impossible, to predict both short- and long-term prices. Therefore, the 15 -year rule provides more predictability and certainty around expected rent.

\section{Consumer surplus}

- More certainty around the savings with the 15 -year rule given the commitment from the industry. It is difficult to estimate the expected savings from IRP since it depends on many factors, including how exchange rates develop over time.

\footnotetext{
${ }^{\text {vi }}$ Defined as 15 years since the time of marketing authorisation approval (MAA).
} 
This analysis illustrates why the industry favoured the 15-year rule as well as why the government agreed to a defined savings of SEK 800 million rather than uncertain savings from IRP. Although the exact savings that would have been gained from implementing the proposed IRP system is unknown, this analysis shows how equivalent reductions in pharmaceutical spending can have significantly different impacts on expected rent and pharmaceutical R\&D incentives. This is an important conclusion that should be considered when designing policy interventions in this area.

Although IRP was not introduced in Sweden, some of the conclusions related to IRP are still relevant since Sweden is a reference country for a number of other countries using IRP. As a result of Swedish prices being referenced, pharmaceutical companies are unlikely to offer prices below the price in other countries in order for treatments to be cost-effective and recommended in Sweden, unless the prices or discounts can be kept confidential.

The framework and conclusions are based on the assumption that incentives for the development of pharmaceuticals are driven by expected rent. Some studies have investigated and confirmed this link, ${ }^{100-102}$ although further empirical research on the association between expected rent and R\&D investments is needed to confirm the effect of pharmaceutical policies on R\&D incentives and future population health.

Implementing and directing resources to a given pharmaceutical instead of spending similar resources on other pharmaceuticals can be perceived as a zero sum game. However, the redistribution of resources between treatments and companies matters for incentives as well as for consumer surplus. Implementing and using treatments that are cost-effective increase consumer surplus and incentivises development of such treatments. Even when consumer surplus is zero in the short term (i.e. ICER is equal to the threshold), directing resources for such treatments incentivises investment in pharmaceutical $\mathrm{R} \& \mathrm{D}$, while still getting the same value from health care resources today.

This work assumes that generic substitution or other price reductions after patent expiry does not impact expected rent. Significant revenues are still generated from pharmaceuticals after patent expiry in some countries. ${ }^{132,133}$ The significant savings from generic substitution and financial pressure on health care systems across the world are likely to result in the post patent earnings to go down in the years to come. Hence, the introduction of generic substitution reform in large markets such as in the US could impact revenues from pharmaceuticals. However, long-term investments in pharmaceutical R\&D should not be impacted significantly by such policies, because companies should already be assuming that these policies have been implemented by the time that new chemical entities make it from the early phases of development to patent expiry. 


\subsection{How to design the cost-effectiveness appraisal process (Paper 2)}

\subsubsection{Introduction}

Estimating the cost-effectiveness of pharmaceuticals is a central part of the reimbursement process in many countries. The time and resources available for cost-effectiveness appraisal varies across countries.46,47 TLV is obliged to conduct the cost-effectiveness appraisal and make a reimbursement decision within 180 days of a submitted application, whereas NICE has 32 weeks under the single technology appraisal (STA) process, ${ }^{\text {vii the }}$ Scottish medicine council (SMC) has 18 weeks (22-26 weeks under specific circumstances), and the Danish Medicines council has 12 weeks.35,134-136 In addition, the external evidence review group (ERG) assessments that are part of the NICE process require additional resources compared to the assessments conducted by the TLV and SMC staff within the agencies. ${ }^{17,137}$

Less time and fewer resources available for the assessment process will likely reduce the accuracy of cost-effectiveness estimates. Therefore, the differences in appraisal processes across countries indicate different cost vs. accuracy trade-offs. There has been limited research on this trade-off to support agencies in striking the balance between cost and accuracy of the process.

The introduction of the STA process in the UK led to a debate about the accuracy vs. cost trade-off of the cost-effectiveness appraisal. A number of academics in the UK were critical of the move from the more extensive multiple technology appraisal (MTA) process to the STA process, arguing that this would lead to increased uncertainty. ${ }^{138-140}$ It was argued that a move to the STA process should only be considered if the burden of proof was moved from NICE to the producers (i.e. the responsibility of demonstrating cost-effectiveness should be placed on the manufacturer under the STA process) and NICE should be free to reject technologies when the burden of proof was not met. ${ }^{139}$ These discussions provided a starting point and background for the work presented here.

The Purpose of this work was to set up an analytic framework and analyse how to design the cost-effectiveness appraisals in order to maximise population health as well as determine what factors influence optimal apprisal design. The goal was to gain insight into policy-relevant questions about the appraisal process, especially how rigorous the process should be, who should bear the burden of proof, and how price agreements, re-submissions, and revaluations influence optimal design.

\footnotetext{
vii The STA process is 40 weeks with producers submitting material at week 8 .
} 


\subsubsection{Method}

The framework designed and used in this work views the appraisal process as a diagnostic test aimed at identifying cost-effective treatments. In this context, the aim of the appraisal process is to determine whether the trueICER of a technology is above or below the cost-effectiveness threshold, with the true-ICER representing the true and unbiased cost-effectiveness of a treatment. The true-ICER is unknown at the time of the reimbursement assessment and may never be known with complete certainty due to uncertainty around the long-term cost and effect of implementing a treatment in clinical practice.

Pharmaceutical companies have incentives to present ICERs (claimedICER) that are below the threshold to increase the likelihood of getting approval. Agencies, therefore, do their own assessment of cost-effectiveness, which often relies on adapting the cost-effectiveness appraisals submitted by companies. These appraisal-ICERs represent agencies' estimates of cost-effectiveness.

Due to uncertainty around long-term cost and effect of implementing a treatment into clinical practice, the appraisal-ICER can be both above and below the true-ICER. This leads to some truly cost-effective treatments being deemed not cost-effective (appraisal-ICER $>\lambda \&$ true-ICER $<\lambda$ ), and some non-cost-effective treatments being deemed cost-effective (appraisal-ICER $<\lambda \&$ true-ICER $>\lambda$ ). Viewing the appraisal process as a diagnostic test classifies these as false negative (FN) and false positive (FP), respectively. True positives (TP) and true negatives (FN) are those treatments that are correctly identified as being cost-effective and not cost-effective, respectively (true positive: appraisal-ICER $<\lambda \&$ true-ICER $<\lambda$; and true negative: appraisal-ICER $>\lambda \&$ true-ICER $>\lambda$ ).

The ability of the appraisal process to correctly identify whether a treatment is cost-effective depends on the true-ICER of the treatment. When the true-ICER is low, there is a higher probability that the treatment will be assessed as cost-effective; whereas, when the true-ICER is high, the treatment is less likely to be deemed cost-effective. ${ }^{90,141-143}$ The relationship between the true-ICER and the probability of a positive appraisal outcome $(\mathrm{P}[$ test +$])$ is outlined in Figure 3.2. 


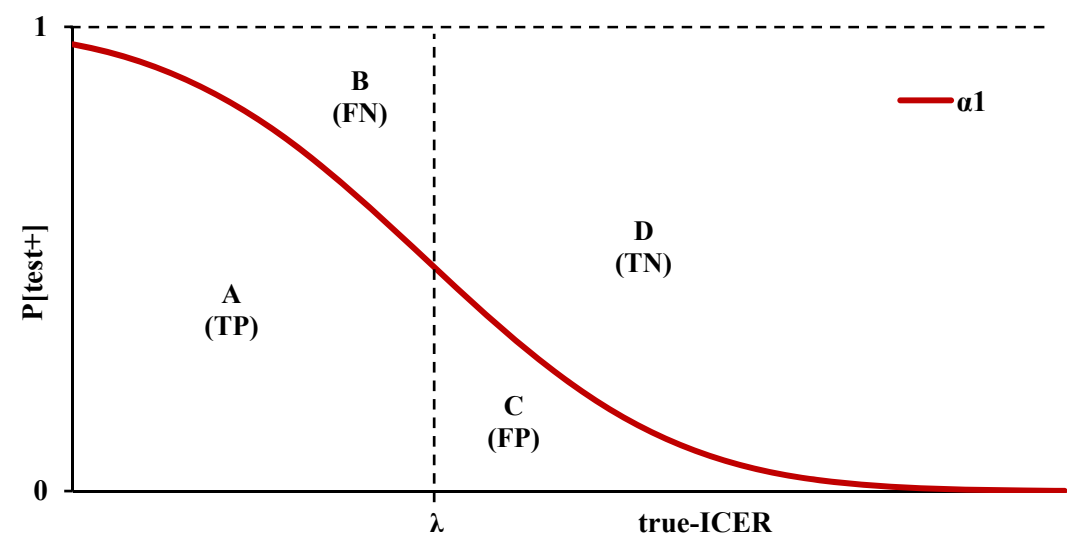

Figure 3.2 Probability of positive cost-effectiveness appraisals, $\mathrm{P}[$ test + ] , as a function of the true-ICER for appraisal process $\alpha 1$. FN: false negative; TN: true negative; TP: true positive; FP: false positive. ${ }^{144}$

The areas below the curves in Figures 3.2 are linked to the sensitivity and specificity of the cost-effectiveness process:

Sensitivity is the true positive rate, i.e. the probability of classifying a cost-effective technology as cost-effective: $\frac{A}{A+B}$

Specificity is the true negative rate, i.e. probability of classifying a non-cost-effective technology as non-cost-effective: $\frac{D}{C+D}$

Reimbursement agencies can improve both sensitivity and specificity by operating a more accurate appraisal process, represented by $\beta$ in Figure 3.3.a. Improved accuracy could be obtained by allowing for more time and resources for the appraisal process, which comes at an increased monetary and/or time cost due to delayed implementation. Agencies can also chose to increase sensitivity at the expense of lower specificity and vice versa, as represented by a1, a2, and $\alpha_{3}$ in Figures 3.3.b and 3.3.c. This change in sensitivity and specificity level can be made by changing the definition of when a technology is considered cost-effective, which could be done by changing the threshold or in relation to how uncertainty is taking in to account. $^{\text {viii }}$

\footnotetext{
viii An example of this could be agencies using a lower threshold when uncertainty around the ICER is high and vice versa. This would result in more technologies being deemed not cost-effective (increase specificity but lower sensitivity), compared to a scenario where the same threshold is used regardless of uncertainty.
} 

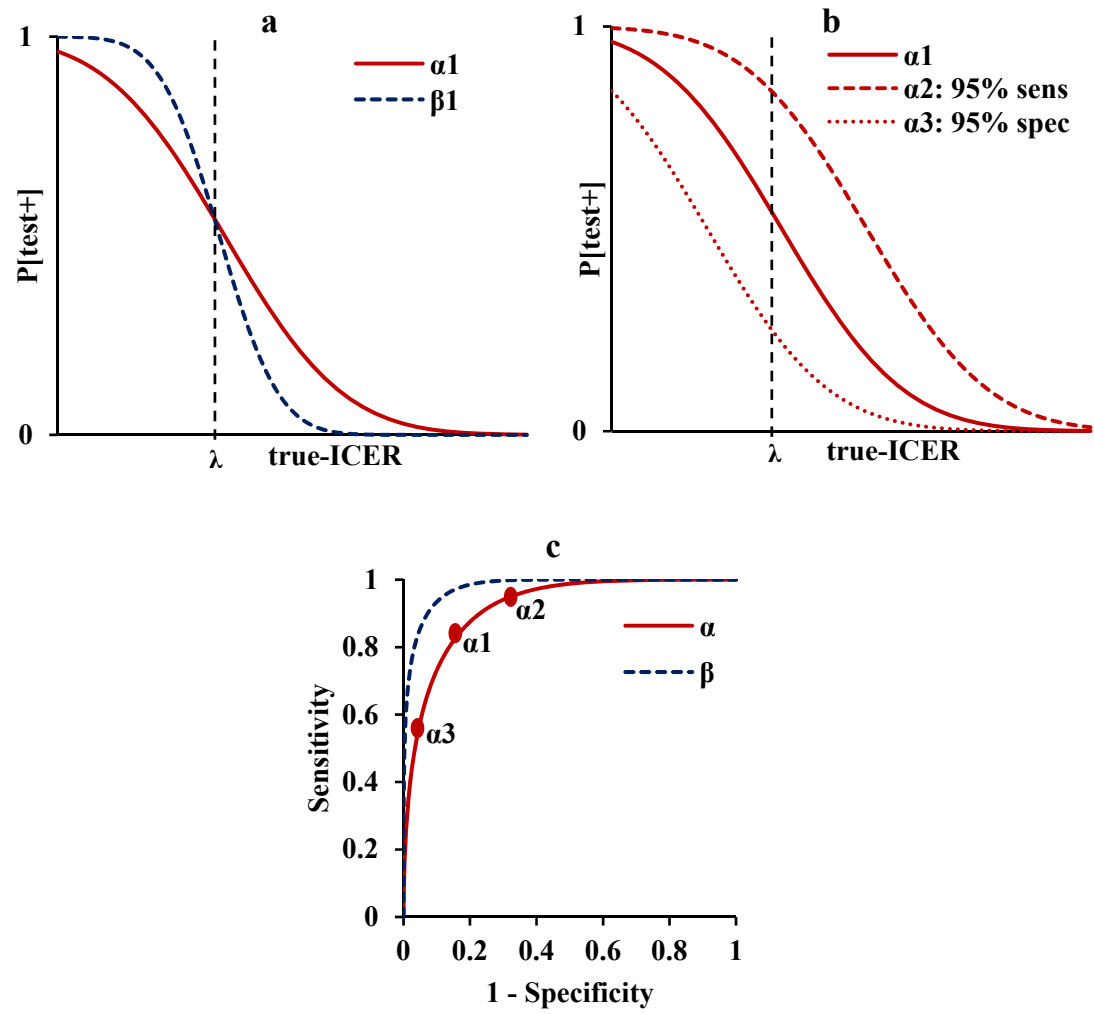

Figure 3.3 (a) Probability of positive cost-effectiveness appraisal, P[test + ], as a function of the true-ICER for process $\alpha 1$ and $\beta 1$. (b) Probability of positive costeffectiveness appraisal as function of true-ICER for process $\alpha$ at different sensitivity and specificity combinations $(\alpha 1, \alpha 2$, and $\alpha 3)$. (c) Receiver operating characteristic curve for process $\alpha$ and $\beta .^{144}$

Paper 2 outlines the consumer and producer surplus of true positive, true negative, false positive, and false negative decisions. The framework is then used to assess how to design the process to maximise population health under some different scenarios and levels of complexity: 1) One-off test with exogenous pricing; 2) endogenous pricing; and 3) allowing for appeals, resubmission, and revaluations.

\subsubsection{Results}

A main finding of this paper is that no one optimal cost-effectiveness appraisal process can be identified. The optimal level of accuracy vs. cost and sensitivity vs. specificity depends on several treatment-specific and country-specific factors, including the true-ICER, comparative effectiveness, and number of patients. Since the true-ICER and number of patients are 
country specific, this could explain the variation in appraisal process across countries.

The study shows that it is worth using a more accurate process to assess technologies with a larger patient population and longer time of relevance. Similarly, it is worth increasing sensitivity (at the cost of lower specificity) if a higher proportion of technologies is expected to be cost-effective or the cost-effective technologies have larger patient populations or time of relevance.

This work discusses the distinction between reducing uncertainty (i.e. accuracy vs. cost) and how uncertainty is taken into account (sensitivity vs. specificity). Placing the burden of proof on the appraisal agency will restrict how the process can be operated in terms of sensitivity and specificity and could hinder optimal operation of the process.

The study also shows that optimal operation of the appraisal process changes if prices are endogenous to the process, i.e. if prices are dependent on how the process is designed or operated. When prices are endogenous to the process, it is valuable to operate a more rigorous process or to operate a given process with higher specificity to discourage companies from setting high prices at which treatments are not cost-effective. However, it is relevant to note that operating the process with higher specificity to incentivise cost-effective pricing comes the cost of lower probability of identifying these cost-effective technologies, due to lower sensitivity. The analysis also shows that when allowing for (during or after appraisal) price agreements, re-evaluations, and appeals, it is most likely optimal to operate the process with higher specificity since the cost of false negatives is expected to reduce more than the cost of false positive.

\subsubsection{Interpretation}

While there is no one optimal design of the cost-effectiveness appraisal process, this work provides relevant conclusions regarding how to design and operate the cost-effectiveness process. Reimbursement agencies seldom have the possibility or mandate to commission further research or delay the decision until further evidence becomes available. ${ }^{\mathrm{ix}}$ Instead, many agencies can provide conditional approval where certain conditions must be met at a later point in time to maintain the reimbursement, 58,145 which is a way to reduce the cost of false positives. Probabilistic sensitivity analysis (PSA) and value of information analysis (VOI) could be used to quantify and take uncertainty into account during decision making.54,55 Although these methods have been around for as long as cost-effectiveness has been

\footnotetext{
${ }^{\text {ix }}$ Agencies can give a negative recommendation and ask companies to reapply at a later time, but then they are in effect providing a rejection, not just delaying the decision problem.
} 
a key decision criteria, they do not appear to be incorporated in the decision-making process in a structured or systematic way. Regardless of the specific method used to quantify uncertainty, a more structured approach to incorporating uncertainty and assessment of how it impacts sensitivity and specificity of the process is warranted.

Optimal design of the appraisal process should consider how the process influences pricing incentives. In a VBP system, price setting is likely to be more endogenous compared to countries such as Norway where IRP is used to define the maximum price companies can set. However, the widespread use of IRP reduces endogenous price setting also in countries like Sweden. Because, unless companies can offer confidential discounts, it is unlikely that the operation of the appraisal process will incentivise companies to set lower prices when these prices are referenced through IRP.

Paper 1 outlines why it would be important to allow for confidential discounts to get lower prices when public list prices are referenced by other countries. However, a recent study found that allowing for confidential discounts appear to increase "gaming" and lead to higher initial price offers, ${ }^{146}$ a risk also discussed in this paper. Therefore, it is important to consider how and when to allow for confidential discounts, and it is probably also worth increasing rigor or specificity of the appraisal process when allowing for such discounts.

This paper did not discuss how expected competition may impact optimal appraisal design. When similar products are approved for the same indication, it may lead to competition and price reductions, as in the case treatment for hepatitis C and PD-L1 inhibitors. ${ }^{17,147,148}$ If approval of similar products is expected in the near term and expected to result in price reductions, it would lower the cost of false positives while increasing the cost of false negatives. In such situations, it would be optimal to operate the process with higher sensitivity and lower specificity.

It would be interesting to complement the conceptual model and theoretical analysis in this paper with empirical studies on the sensitivity and specificity of real-world appraisal processes. Reviewing the effectiveness and cost-effectiveness of treatment approved or rejected by reimbursement agencies in the past would enable sensitivity and specificity estimates of the processes. Such evaluations would provide increased understanding around the cost and benefit of different appraisal approaches, which would be valuable in improving these processes going forward. Evaluating the reimbursement process requires the ability to determine the effect and value of implementing treatment in clinical practice, which is the focus of Papers 3 and 4 . 


\subsection{Subcategorizing the Expected Value of Perfect Implementation (Paper 3)}

\subsubsection{Introduction}

The benefit and value of treatments are only realised when they are implemented in clinical practice. Low and varying implementation of cost-effective treatments lead to health loss for patients. Sub-optimal implementation is an issue observed both across and within countries..$^{10-14}$ In Sweden, several studies have found significant variation in treatment practice and in the use of pharmaceuticals across health care regions. ${ }^{14,79-85}$ However, few studies have estimated the health consequences of varying implementation and the value of addressing this variation.

Fenwick et al. (2008) outlined a framework to estimate the expected value of perfect implementation (EVPIM), i.e. the value of achieving perfect implementation compared to the current or expected level of implementation. ${ }^{149}$ The framework has also been used to estimate the expected value of specific implementation strategies (EVSIM) and extended to estimate the value of improving implementation in specific sub-groups and taking into account future implantation patterns. ${ }^{150-154}$

The purpose of this work was to estimate the value of eliminating regional implementation variation using the EVPIM framework on the case study of ticagrelor for secondary prevention of myocardial infarction in Sweden. Paper 3 outlines how we extended the EVPIM framework to estimate the value of addressing regional implementation variation as well as slow and low implementation. This extension and how it may be used to identify when and where to invest in implementation improvements is the main focus of the paper. The results below complement the estimated health sector gains presented in the paper with estimates of producer surplus gains from improved implementation.

\subsubsection{Method}

The EVPIM framework presented by Fenwick et al. (2008) estimates the expected value of improving implementation from the current (or expected) level of implementation ( $\rho$ ) to a perfect level of implementation. The value (per patient) of such implementation improvement is the value from the increased probability of being treated: EVPIM $=\operatorname{INB}(1-\rho) .{ }^{149}$ EVPIM is the patient level value of perfect implementation, with $p$ EVPIM representing the population level EVPIM, i.e. the value of treating those eligible patients that would not have received treatment given current or expected implementation. The $p$ EVPIM depends on the INB per patient, 
the number of patients $\left(I_{t}\right)$ in each period from when the technology becomes available $\left(t_{o}\right)$ until the technology loses relevance $(T)$, and the discount rate $r$, as illustrated in equation 2 and Figure 3.4.a.

[2] $\quad p$ EVPIM $=\sum_{t=0}^{T} \frac{I_{t}}{(1+r)^{t}}\left(1-\rho_{t}\right) \operatorname{INB}_{t}$.

The work in the study extends the EVPIM framework by estimating the value of eliminating slow (A), low (B), and delayed (C) implementation (Figure 3.4.b). In addition, and more central to this thesis, the framework is extended to estimate the value of regional implementation variation (D) by estimating the value of increasing implementation from the actual or expected level of implementation $(\rho)$ to the level of the highest implementing health care entity $\left(\rho_{t}^{\text {high }}\right)$ (Figure 3.4.c).

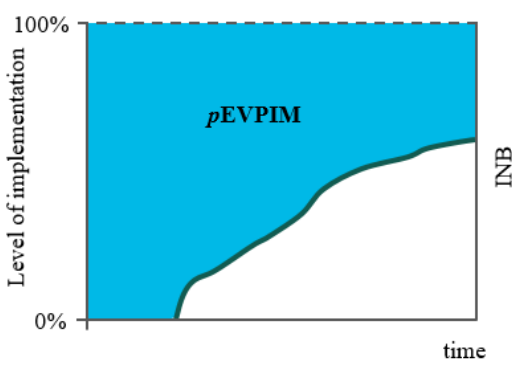

b

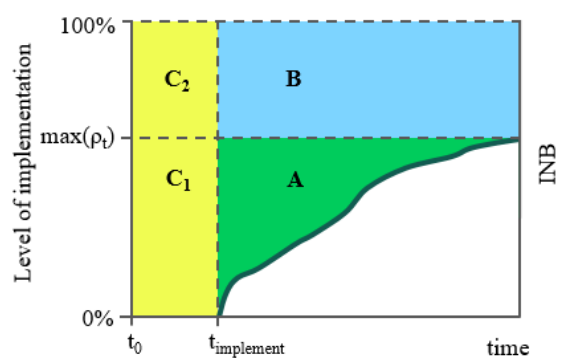

c

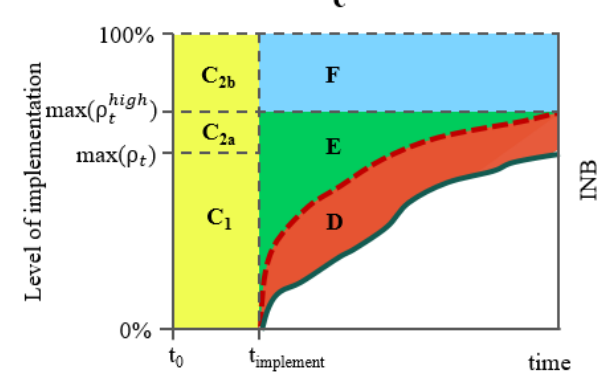

- $\rho$ is the average level of implementation

-- $\rho^{\text {high }}$ is the implementation in the highest implementing region

Figure 3.4 Graphical representation of (a) $p$ EVPIM. (b) the expected value of eliminating slow (A), low (B) and delayed $\left(\mathrm{C}=\mathrm{C}_{1}+\mathrm{C}_{2}\right)$ implementation. (c) the expected value of eliminating regional implementation variation $(D) \cdot \max \left(\rho_{t}\right)$ : highest average level of implementation; $\max \left(\rho_{t}^{\text {high }}\right)$ : maximal level of implementation achieved in the highest implementing region; $\mathrm{t}_{0}$ : time when the technology becomes available for use; $t_{\text {implement }}$ : time when implementation starts. ${ }^{155}$ 


\section{Ticagrelor case study}

Antiplatelet treatment is part of the standard care for patients experiencing myocardial infarction. One of the treatments that is recommended in both national and international guidelines, is the P2y12-inhibitor ticagrelor, which is used for secondary prevention in patients with coronary artery disease $\mathrm{e}^{156-158}$

Ticagrelor was approved by the EMA in December 2010 for secondary prevention after experiencing acute coronary syndrome. 159 The efficacy and safety of ticagrelor was demonstrated in the Platelet Inhibition and Patient Outcomes (PLATO) phase-III clinical trial comparing ticagrelor to clopidogrel in 18,624 patients with acute coronary syndrome. ${ }^{\mathrm{x}, 160}$ TLV provided a positive reimbursement decision for ticagrelor in June 2011 and it was included in the national treatment guidelines by the National Board of Health and Welfare (Socialstyrelsen) in December 2011. ${ }^{161,162}$ Ticagrelor has since been approved by the EMA for another treatment indication, but it is the initial treatment indication of 12-month treatment in patients with acute coronary syndrome that is studied in Papers 3 and 4 .

The effectiveness and cost-effectiveness estimates of ticagrelor used in this work were based on efficacy observed in the PLATO trial and a trial based cost-effectiveness analysis published by Henriksson et al. (2014) (Table 3.2). ${ }^{160,163}$

Table 3.2 Data on effect, and cost-effectiveness of ticagrelor.

\begin{tabular}{lccc}
\hline & Ticagrelor & Clopidogrel & Difference \\
\hline Death from any cause $^{160}$ & $4.5 \%$ & $5.9 \%$ & $1.4 \%$ \\
\hline QALY $^{163}$ & 9.66 & 9.53 & 0.13 \\
\hline Drug cost in SEK & 7,523 & 6,453 & 1,070 \\
\hline Total health care costs in SEK & 163 & 343,560 & 3,243 \\
\hline ICER in SEK/QALY & 346,803 & & 25,022 \\
\hline INHB per patient in QALY* & & & 0.117 \\
\hline INMB per patient in SEK* & & & 29,257 \\
\hline
\end{tabular}

ICER, incremental cost-effectiveness ratio; INHB, incremental net health benefit; INMB, incremental net monetary benefit; QALY, quality adjusted life year.

*Based on a threshold of SEK 250,000 per QALY

Information on the use of ticagrelor and other P2Y12-inhibitors across Swedish health care regions between 2011 and 2015 was obtained from the Swedish Web System for Enhancement and Development of EvidenceBased Care in Heart Disease Evaluated According to Recommended Therapies (SWEDEHEART) registry. SWEDEHEART is a national quality registry of the treatment and outcome of patients admitted to cardiac care

\footnotetext{
${ }^{\mathrm{x}}$ Both ticagrelor and clopidogrel is given in combination with acetylsalicylic acid (ASA).
} 
units across Sweden and has been shown to have close to complete information for this patient population. ${ }^{164}$ Further description and detail of the SWEDEHEART registry is available elsewhere. ${ }^{164-166}$

This study focused on the treatment in patients with an age below 80 years as treatment guidelines did not provide clear recommendation for patients 80 years or older..$^{162,167}$ To estimate EVPIM, this study defined eligible patients $\left(I_{t}\right)$ as those treated with dual antiplatelet treatment, i.e. excluding patients only treated with clopidogrel or acetylsalicylic acid (ASA) monotherapy. Data from the registry showed that the use of ticagrelor increased over time and varied significantly across health care regions (Figures 3.5 and 3.6). The highest average implementation level of ticagrelor across all health care regions $\left(\max \left(\rho_{t}\right)\right)$ was $79 \%$, which was observed in the last year (2015) of the study. The highest implementation level observed in any specific health care region $\left(\max \left(\rho_{t}^{h i g h}\right)\right)$ was $94 \%$. Estimation of producer surplus was based on the price of ticagrelor (Table 3.2) and assumed marginal cost of $10 \%$.

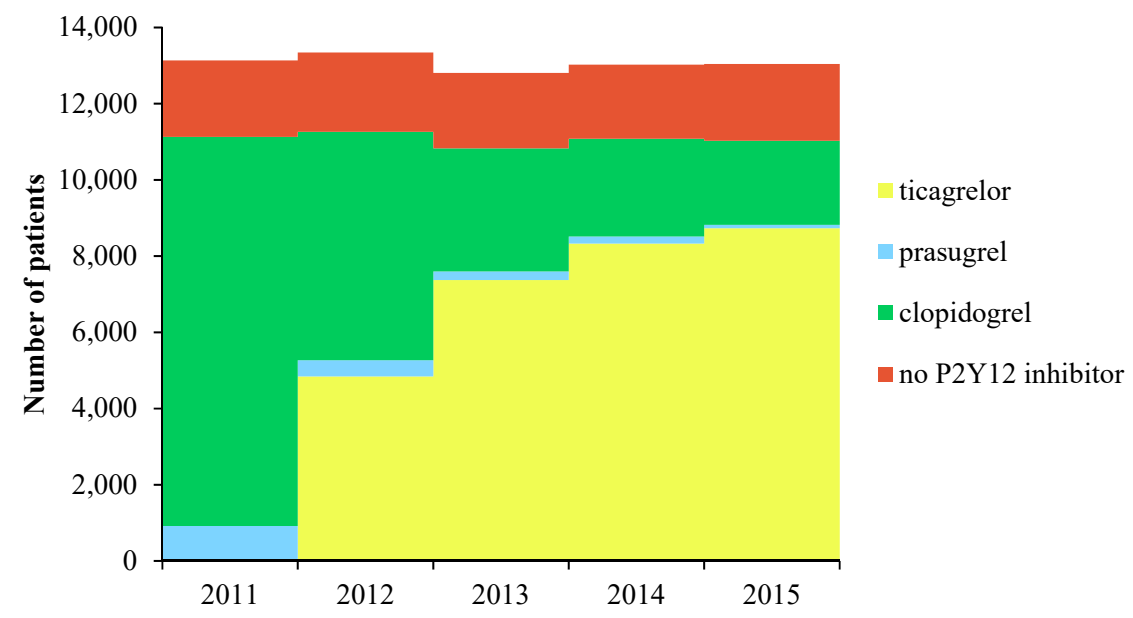

Figure 3.5 Number of MI patients (age $<80)$ with and without P2Y12-inhibitor in Sweden. ${ }^{155}$ 


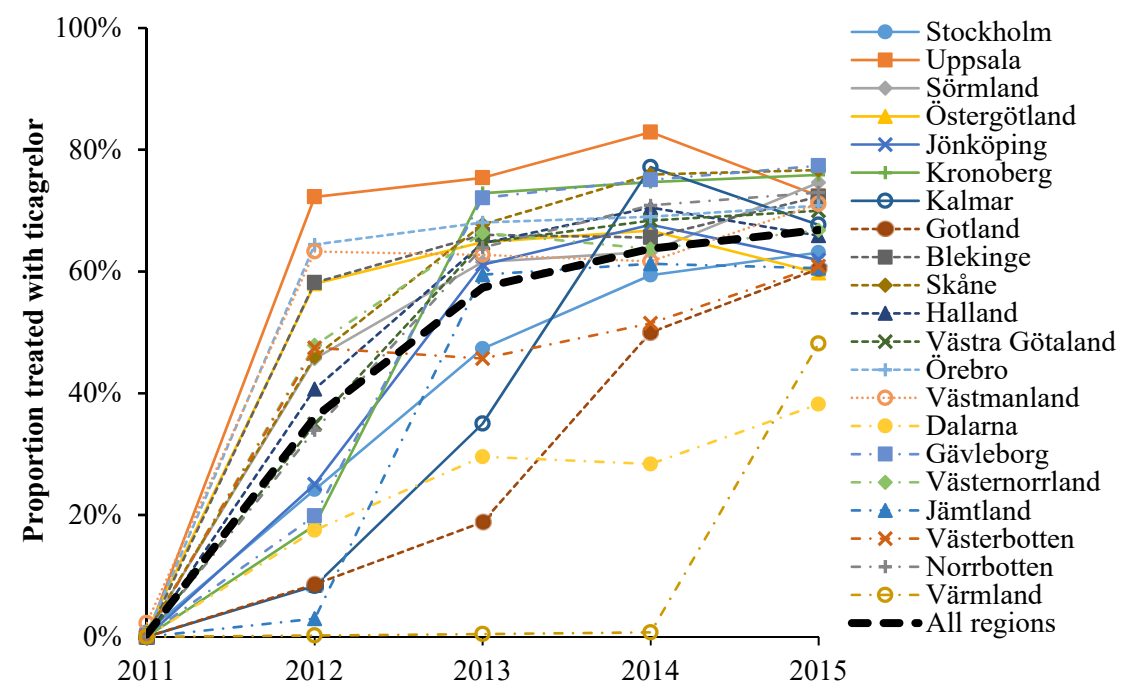

Figure 3.6 Proportion of dual antiplatelet treated MI patients (age $<80$ ) receiving ticagrelor per health care region in Sweden. ${ }^{155}$

\subsubsection{Results}

It is estimated that an additional 26,006 patients would have been treated with ticagrelor if perfect implementation could have been reached, which would have increased population health by 2,941 QALYs and increased producer surplus by SEK 170 million (Table 3.3).

Eliminating regional implementation variation by ensuring that all regions had the same implementation level as the highest implementing regions would have resulted in 10,318 additional patients treated with ticagrelor. This represents 1,138 QALYs and SEK 66 million in producers surplus, which is $39 \%$ of the total $p$ EVPIM. In terms of mortality, it would have resulted in 144 fewer deaths. Improving implementation to the level of the highest three and five implementing regions would have gained 989 and 896 QALYs, representing $34 \%$ and $31 \%$ of total $p$ EVPIM, respectively. 
Table 3.3 The number of additional patients and the value of treating these patients with ticagrelor given different improvements in implementation.

\begin{tabular}{|c|c|c|c|c|}
\hline & $\begin{array}{c}\text { Number of } \\
\text { (additional) } \\
\text { patients } \\
\text { treated } \\
\end{array}$ & $\begin{array}{c}\text { INB } \\
\text { QALY } \\
\text { (discounted) }\end{array}$ & $\begin{array}{l}\text { Producer sur- } \\
\text { plus in SEK } \\
\text { thousands } \\
\text { (discounted) }\end{array}$ & $\begin{array}{c}\text { \% of } \\
p \text { EVPIM }\end{array}$ \\
\hline $\begin{array}{l}\text { Treated with dual antiplatelet } \\
\text { (P2Y12-inhibitor \& ASA) }\end{array}$ & 55,324 & & & \\
\hline Treated with ticagrelor & 29,318 & 3,168 & 183,307 & \\
\hline$p$ EVPIM & 26,006 & 2,941 & 170,155 & \\
\hline \multicolumn{5}{|c|}{ Value of eliminating slow (A), low (B), and delayed implementation $(\mathrm{C}=\mathrm{C} 1+\mathrm{C} 2)$} \\
\hline A & 5,727 & 644 & 37,246 & $21.9 \%$ \\
\hline B & 9,198 & 1,000 & 57,883 & $34.0 \%$ \\
\hline $\mathrm{C}$ & 11,081 & 1,297 & 75,026 & $44.1 \%$ \\
\hline$-\mathrm{C} 1$ & 8,765 & 1,026 & 59,345 & $34.9 \%$ \\
\hline$-\mathrm{C} 2$ & 2,316 & 271 & 15,681 & $9.2 \%$ \\
\hline \multicolumn{5}{|c|}{ Value of eliminating regional implementation variation (D) } \\
\hline $\mathrm{D}$ & 10,318 & 1,138 & 65,838 & $38.7 \%$ \\
\hline $\mathrm{E}$ & 2,089 & 234 & 13,555 & $8.0 \%$ \\
\hline $\mathrm{F}$ & 2,742 & 298 & 17,255 & $10.1 \%$ \\
\hline \multicolumn{5}{|l|}{ Sensitivity analysis } \\
\hline highest implementing region & 10,318 & 1,138 & 65,838 & $38.7 \%$ \\
\hline Top 3 regions & 8,959 & 989 & 57,204 & $33.6 \%$ \\
\hline top 5 regions & 8,105 & 896 & 51,814 & $30.5 \%$ \\
\hline Top 10 regions & 5,865 & 647 & 37,446 & $22.0 \%$ \\
\hline
\end{tabular}

$p$ EVPIM: population expected value of perfect implementation; slow (A), low (B), and delayed $(\mathrm{C}=\mathrm{C} 1+\mathrm{C} 2)$ implementation; the value of eliminating regional implementation variation (D) (Figure 3.4). INB: Incremental net benefit; QALY: quality adjusted life years; ASA: acetylsalicylic acid.

\subsubsection{Interpretation}

This study estimates that eliminating regional implementation variation would have generated 1,138 QALYs and contributed SEK 66 million to producer earnings. Using a threshold of SEK 250,000 per QALY reveals a monetary value of consumer surplus of around SEK 285 million, showing a substantial value from improving implementation. The substantial value to both producers and consumers from improved implementation demonstrates an opportunity for public-private partnership in ensuring appropriate and equal access to treatments across Swedish health care regions.

It is estimated that the six months it took from marketing authorisation to reimbursement (TLV decision) likely resulted in a loss of approximately 
500 QALYs. ${ }^{\text {xi }}$ This provides an estimate of the time cost of the appraisal process. It took further six months from the TLV decision to treatment guidelines were updated and implementation was initiated, also representing a loss of around 500 QALYs. These findings indicate a significant value in ensuring that guidelines are updated as part of or at least at the same time as the reimbursement decisions.

Comparing the INB of the health care system and producer surplus indicates that consumers gained the majority of the value generated by ticagrelor use, with $81 \%$ of the combined consumer and producer surplus going to consumers. ${ }^{\text {xii }}$ Although these findings are in line with other case studies, $3,4,168-173$ the number of rejected reimbursement applications, where agencies do not perceive technologies to provide positive INB, indicates that this is not how value is distributed across all products..$^{70,96,143}$

A strength of this study is that it both estimates the value of the observed use as well as the value that could be gained by improving implementation. In contrast, the retrospective nature of this analysis is a limitation since the gains from improved implementation of ticagrelor cannot be achieved in retrospect. Still, a systematic estimation of the relative value of reducing slow, low, or varying implementation of treatments recommended and used in clinical practice could provide valuable information about past implementation patterns. This could inform the value of addressing slow implementation; regional implementation variation; whether implementation varies based on type of treatment or disease area; and how introduction of quality registries has influenced implementation. Such information would also be valuable for predicting future implementation patterns and assessing the value of improving implementation ex ante.

The cost-effectiveness estimates of ticagrelor were based on efficacy estimates and resources used during the PLATO trial, which may not reflect effectiveness or cost-effectiveness in clinical practice. A Swedish based observational study supported the effectiveness of ticagrelor; ${ }^{174}$ however, more recent studies have questioned the effectiveness of ticagrelor when used in clinical practice. ${ }^{175^{-179}}$ This is clearly relevant for the results of our case study since effectiveness estimates are central to the value that ticagrelor provide. Paper 4 investigates this particular issue.

The cost-effectiveness threshold is another factor that impacts the value of implementing treatments into clinical practice. In this study, we use a conservative estimate compared to the threshold values that appear

\footnotetext{
xi $50 \%$ of $\mathrm{C} 1=513$ QALYs.

xii Consumer surplus/(consumer surplus + producer surplus) $=\mathbf{8 1 . 2 \%}$, where consumer surplus $=$ INMB $=(3,168$ QALY $*$ SEK 250,000 per QALY $)=$ SEK 792,000,000 and producer surplus $=$ SEK $183,307,000$.
} 
to be operated by TLV. ${ }^{96,143,180}$ The threshold used here is also similar to a recent estimate on the marginal productivity of the Swedish health care system.97 Having a relevant and valid estimate of the opportunity cost of implementing treatment into clinical practice is central to estimating the value of treatments and the value of improving implementation. This is discussed further in Chapter 4. 


\subsection{The effectiveness of ticagrelor in routine clinical care (Paper 4)}

\subsubsection{Introduction}

The estimated value of increasing ticagrelor implementation in Sweden presented in Paper 3 was based on effectiveness and cost-effectiveness estimates informed by the RCT of ticagrelor vs. clopidogrel in patients treated for acute coronary syndrome. ${ }^{160,163}$ However, observational studies on ticagrelor use in clinical practice has produced varying and conflicting evidence on ticagrelor effectiveness. ${ }^{175-179,181-184}$ Some studies have found positive effects from ticagrelor when used in clinical practice, including a study by Sahlén et al. (2016) who analysed data collected as part of Swedish routine clinical practice.174 Other studies have found zero and even negative effects of ticagrelor use in clinical practice, including a recent study by Szummer et al. (2020) who found an increased risk of mortality associated with ticagrelor in patients above 80 years of age. ${ }^{175-179}$ The studies by Sahlén et al. (2016) and Szummer et al. (2020) both used data from the SWEDEHEART registry collecting information on patients hospitalised for acute coronary syndrome or receiving vascular or coronary interventions for other reasons.

Differences in data sources, inclusion criteria, and statistical analyses make it challenging to ascertain the cause for varying effectiveness estimates across past observational studies. Therefore, it is also difficult to know whether these observational studies question the external validity of the PLATO trial or whether they are influenced by selection or sampling bias.

The conflicting and inconclusive evidence on ticagrelor effectiveness in clinical practice creates uncertainty around the treatment of myocardial infarction, a leading cause of morbidity and mortality, affecting more than 10,000 patients in Sweden each year. ${ }^{185}$ This conflicting and inconclusive evidence questions the value of improving ticagrelor implementation, as estimated in Paper 3.

The purpose of this study was to estimate ticagrelor effectiveness using an instrumental variable approach with variation in treatment practice as an instrumental variable. As a secondary objective, this study aimed to investigate how different methodological approaches impact ticagrelor effectiveness estimates to understand whether this might explain some of the variation in results across previous observational studies on ticagrelor. 


\subsubsection{Methods}

\section{Data sources and patients}

This study identified patients via the SWEDEHEART registry and included patients hospitalised for myocardial infarction between 1 January 2009 and 31 December 2015. A patient's first myocardial infarction during the inclusion period was defined as the index myocardial infarction. Patients with previous myocardial infarction within seven years of the index MI were excluded.

Information on treatment with ticagrelor (and other P2Y12-inhibitors) together with the patient's age, sex, and information related to the index event were obtained from SWEDEHEART. Additional information on prescription drug use, subsequent hospitalisations, and socioeconomic factors (education, country of birth, marital status, and income) was added from other Swedish nationwide data bases (see supplementary appendix to Paper 4 for further detail).

Ethical approval for this study was obtained from the regional ethics board in Linköping, Sweden (Regionala etikprövningsnämnden in Linköping; Dnr 2017/28-36 and Dnr 2019-04891).

\section{Outcome}

The primary endpoint was mortality at 12 months. The secondary endpoint included a combined outcome of mortality, myocardial infarction, or stroke (as in the PLATO trial), ${ }^{160}$ myocardial infarction alone, and stroke alone, all at 12-month follow-up.

\section{Study design}

An instrumental variable was used to estimate the effectiveness of ticagrelor. The instrument was the proportion of patients treated with ticagrelor at a treatment centre in the 90 days before the index myocardial infarction of a newly admitted patient. Therefore, the instrument represents a patient-level measure of the predilection for ticagrelor treatment at the treatment centre and the time a patient was admitted.

This instrumental variable approach exploited the variation in ticagrelor implementation, where the likelihood of being treated with ticagrelor varied by when and where an individual was hospitalised for their myocardial infarction. Patients admitted to the same centre but at different times faced different probabilities of ticagrelor treatment. Similarly, individuals who suffered a myocardial infarction on the same day had different probabilities of receiving ticagrelor based on what treatment centre they were admitted to. 


\section{Statistical analysis}

The impact of the instrument directly on the outcome (reduced form) was estimated using ordinary least squares (OLS) regression and estimates of the average absolute risk difference of being admitted to a treatment centre with a higher predilection for ticagrelor treatment. The effect of being treated with ticagrelor, for those actually treated with ticagrelor, was estimated by two stage least squares (2SLS).

Fixed effects for treatment centres and time (quarters) were included to account for time-invariant differences between treatment centres and national trends in patient outcomes. Hypothesis tests were performed using robust (heteroscedasticity consistent) standard errors clustered on treatment centre, and with a $5 \%$ significance level. All analyses were performed in R.

The main analysis did not include any patient covariates. Sensitivity analysis examined the robustness of the main results by including patient covariates to examine whether the main results were driven by observed confounders.

\section{Subgroup analysis}

Subgroup analyses were performed on age $(<80$ years and $\geq 80$ years) and myocardial infarction classification (ST-segment elevation myocardial infarction (STEMI) and non-ST-segment elevation myocardial infarction (NSTEMI)). We also performed analyses where the patient population was weighted to resemble the patient composition in the PLATO trial in relation to age, gender, previous myocardial infarction, STEMI, and diabetes. Cox regressions was included as sensitivity analysis, estimating the effect (hazard ratios) of the instrument on death within the first 12 months (reduced form).

\section{Alternative analytical approaches}

The study also investigated the effect of ticagrelor using OLS and propensity score analysis, since these methods were used in previous observational studies on ticagrelor. These methods were estimated without the use of the instrument but while adjusting for the full set of patient covariates (i.e. all variables listed in Appendix Table 7.1) and both with and without fixed effects for treatment centre and time. Propensity scores were estimated with logistic regression, based on the full set of covariates, and were implemented as inverse probability weights.

The impact of patient selection was investigated using inclusion and exclusion criteria from past observational studies ${ }^{174-176,179,182-184: 1)}$ patients 
surviving the index hospitalisation; 2) patients treated with a P2Y12-inhibitor; and 3) patients surviving hospitalisation and treated with a P2Y12inhibotor.

\section{Counterfactual analysis}

The main reduced form effect estimates formed the basis of a contractual analysis, which estimated how the 12-month mortality would have looked if ticagrelor had not been implemented in Sweden. This effect was estimated using the regression estimates with the instrument set to zero for all patients. In addition, the effect of eliminating regional implementation variation was estimated using the highest observed instrument value per quarter for all patients.

\section{Analysis on aggregated data}

We also estimated the effectiveness of ticagrelor using data aggregated per quarter for each treatment centre. This analysis was conducted to investigate whether analysis of aggregated data would provide similar effect estimates as those using patient level data. In this analysis, the instrument was the proportion of patients treated with ticagrelor in the previous quarter at the same treatment centre. 


\subsubsection{Results}

\section{Patient population}

Of the 110,593 patients included in the study, 30,773 (27.8\%) were treated with ticagrelor. The proportion of patients treated with ticagrelor increased to an average of around $60 \%$ by the end of the study period (Figure 3.7 ). There were $36,637(33.1 \%)$ patients with STEMI and 79,380 patients (71.8\%) were below 80 years of age. A full overview of patient demographics is included in the Appendix (Table 7.1).

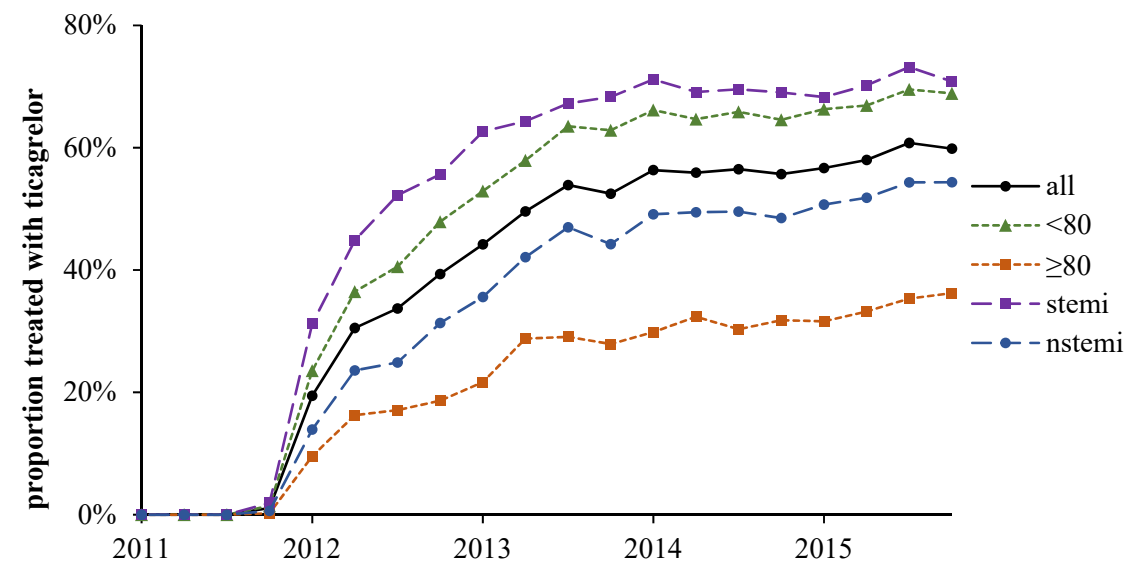

Figure 3.7 Proportion of patients treated with ticagrelor; all patients; age $<80$ years; age $\geq 80$ years; STEMI; and NSTEMI.

\section{Instrument relevance and validity}

A $10 \%$ increase in the predilection for ticagrelor treatment was associated with a $7.6 \%$ (95\% confidence interval 6.9 to 8.3 ) increase in the probability of being treated with ticagrelor. This association was statistically significant, and the F-statistic was 450 (Wald test on the exclusion of the instrument), proving strong support for the instrument. ${ }^{\text {xii }}$

\section{Primary endpoint}

The effect of the instrument directly on 12-month mortality (reduced from) found an absolute risk reduction of 2.89 percentage points (o.56 to 5.21) (Table 3.4). This implies that a 10\% increase in the predilection for ticagrelor treatment at a given treatment centre is associated with a $0.29 \%(0.06 \%$

\footnotetext{
xiii The supplementary appendix (section B3) for Paper 4 provides further discussions about the relevance of the instrument.
} 
to $0.52 \%$ ) reduction in 12 -months mortality for patients treated at that centre. The 2SLS estimated an absolute risk reduction of 3.8 percentage points (0.56 to 7.08) for those patients actually treated with ticagrelor (Table 3.4).

Table 3.4 Absolute risk in (1) non-ticagrelor and (2) ticagrelor treated patients and absolute risk difference on 12-month mortality based on the (3) crude, (4) age adjusted, and (5) fully adjusted reduced form and 2SLS analyses (95\% confidence interval).

\begin{tabular}{|c|c|c|c|c|c|}
\hline \multicolumn{2}{|c|}{$\begin{array}{c}\text { Absolute risk } \\
\%\end{array}$} & \multicolumn{4}{|c|}{$\begin{array}{l}\text { Absolute risk difference } \\
\text { percentage point }\end{array}$} \\
\hline $\begin{array}{c}\text { non-tica } \\
(1)\end{array}$ & $\begin{array}{l}\text { tica } \\
(2)\end{array}$ & & $\begin{array}{l}\text { crude } \\
\text { (3) }\end{array}$ & $\begin{array}{l}\text { age adj } \\
(4)\end{array}$ & $\begin{array}{l}\text { all cov } \\
(5)\end{array}$ \\
\hline $\begin{array}{c}17.10^{* *} \\
(16.84,17.36)\end{array}$ & $\begin{array}{c}4.82 * * \\
(4.58,5.06)\end{array}$ & $\begin{array}{c}\text { Reduced form } \\
\text { 2SLS }\end{array}$ & $\begin{array}{c}-2.89^{*} \\
(-5.21,-0.56) \\
-3.82^{*} \\
(-7.08,-0.56) \\
\end{array}$ & $\begin{array}{c}-2.21^{*} \\
(-4.18,-0.24) \\
-2.95^{*} \\
(-5.71,-0.18)\end{array}$ & $\begin{array}{c}-2.20^{*} \\
(-4.32,-0.09) \\
-2.94 \\
(-5.93,0.04)\end{array}$ \\
\hline$N=79,820$ & $N=30,773$ & & $N=110,593$ & $N=110,593$ & $N=110,593$ \\
\hline
\end{tabular}

Including age (in five-year age groups) as covariate reduced the estimated risk reduction to 2.21 percentage points (o.24 to 4.18) and 2.95 percentage points ( 0.18 to 5.71 ) for the reduced form and 2SLS, respectively (Table 3.4). Controlling for further covariates had a negligible impact on the effect estimates.

\section{Secondary endpoints}

The effect on the combined outcome (12-month mortality, myocardial infarction, or stroke) was similar to the primary endpoint, but no statistically significant effect was observed for myocardial infarction or stroke (when analysed separately).

\section{Subgroup analyses}

Higher absolute risk difference was observed in patients aged $\geq 80$ years $(-5.21$ ( -10.01 to -0.40$)$, reduced form), compared to the $<80$ year group, where the risk difference was not statistically significant on a $5 \%$ level $(-1.64$ ( -3.38 to 0.09$)$, reduced form). The Cox regression found similar risk reduction in the two age groups ( $\mathrm{HR}=0.80$ (o.66 to 0.98$)$ for age $\geq 80$ years and $\mathrm{HR}=0.78$ (0.60 to 1.00) for age $<80$ years).

The analysis using PLATO weights showed an absolute risk difference of -1.32 ( -2.93 to 0.29$)$ and $-1.68(-3.80$ to 0.45$)$ percentage points with the reduced form and 2SLS, respectively. 


\section{Alternative analytical approaches}

The OLS and propensity score analysis found higher effect estimates than the instrumental variable approach, especially when including fixed effects (Table 3.5). Stricter patient selection criteria were associated with lower and non-statistically significant risk differences.

Table 3.5 Absolute risk (1-2) and absolute risk difference of ticagrelor treatment (3) estimated with OLS, propensity score adjusted OLS, and when using more restrictive inclusion and exclusion criteria.

\begin{tabular}{|c|c|c|c|}
\hline \multicolumn{2}{|c|}{$\begin{array}{c}\text { Absolute risk } \\
\%\end{array}$} & \multicolumn{2}{|c|}{$\begin{array}{c}\text { Absolute risk difference } \\
\text { percentage point }\end{array}$} \\
\hline $\begin{array}{c}\text { non-tica } \\
(1)\end{array}$ & $\begin{array}{c}\text { tica } \\
(2) \\
\end{array}$ & & (3) \\
\hline $\begin{array}{c}\text { Full study pop } \\
17.10^{* *} \\
(16.84,17.36)\end{array}$ & $\begin{array}{c}\text { ion }(\mathbf{N}=\mathbf{1 0 0 , 5 9 3}) \\
4.82 * * \\
(4.58,5.06)\end{array}$ & $\begin{array}{l}\text { Main study result } \\
\text { Reduced form }^{\Delta} \\
2 \text { SLS }^{\Delta}\end{array}$ & $\begin{array}{c}-2.89 * \\
(-5.21,-0.56) \\
-3.82 * \\
(-7.08,-0.56)\end{array}$ \\
\hline & & $\begin{array}{l}\text { Alternative analyt } \\
\text { (Excluding fixed e } \\
\text { OLS } \\
\text { Propensity score }\end{array}$ & $\begin{array}{l}\text { approach } \\
\text { s) } \\
-6.15^{* *} \\
(-6.87,-5.42) \\
-6.66^{* *} \\
(-7.42,-5.90)\end{array}$ \\
\hline & & $\begin{array}{l}\text { Alternative analy } \\
\text { (Including fixed ef } \\
\text { OLS }^{\Delta} \\
\text { Propensity score }^{\Delta}\end{array}$ & $\begin{array}{l}\text { approach } \\
\begin{array}{c}-9.88 * * \\
(-11.00,-8.76) \\
-11.09 * * \\
(-12.64,-9.54)\end{array}\end{array}$ \\
\hline $\begin{array}{c}\text { Patients treated } \\
9.89^{* *} \\
(9.62,10.14)\end{array}$ & $\begin{array}{l}\text { P2Y12-inhibitor } \\
\text { 4.82** } \\
(4.58,5.06)\end{array}$ & $\begin{array}{l}N=86.779) \\
\text { Reduced form } \\
\\
2 S_{L S S}\end{array}$ & $\begin{array}{c}-1.40 \\
(-2.91,0.11) \\
-1.77 \\
(-3.66,0.12) \\
\end{array}$ \\
\hline $\begin{array}{c}\text { Patients survive } \\
11.45^{* *} \\
(11.22,11.68)\end{array}$ & $\begin{array}{c}\text { spitalisation }(\mathbf{N}= \\
\quad 3.68 * * \\
(3.47,3.90)\end{array}$ & $\begin{array}{l}\text { 05.099) } \\
\text { Reduced form }^{\Delta} \\
\text { 2SLS }^{\Delta}\end{array}$ & $\begin{array}{c}-0.81 \\
(-2.41,0.79) \\
-1.08 \\
(-3.24,1.08) \\
\end{array}$ \\
\hline $\begin{array}{c}\text { Patients treated } \\
8.28^{* *} \\
(8.05,8.51)\end{array}$ & $\begin{array}{l}\text { P2Y12-inhib \& } \\
\text { 3.68** } \\
(3.47,3.90)\end{array}$ & $\begin{array}{l}\text { Irvived hospitalisat } \\
\text { Reduced form }^{\Delta} \\
\text { 2SLS }^{\Delta}\end{array}$ & $\begin{array}{c}\mathbf{N}=\mathbf{8 5 . 4 0 8}) \\
-0.86 \\
(-2.17,0.45) \\
-1.09 \\
(-2.74,0.57)\end{array}$ \\
\hline
\end{tabular}




\section{Counterfactual analysis}

Figure 3.8 shows the counterfactual estimates of how 12-month mortality would have looked if ticagrelor had not been implemented in Sweden, and if regional implementation variation had been eliminated. This analysis estimates that 464 fewer deaths would have occurred if all regions had implemented to the same extend as the highest implementing region. In patient $<80$ years (i.e. similar patient population as in Paper 3) 187 fewer deaths would have occurred by eliminating regional implementation variation.

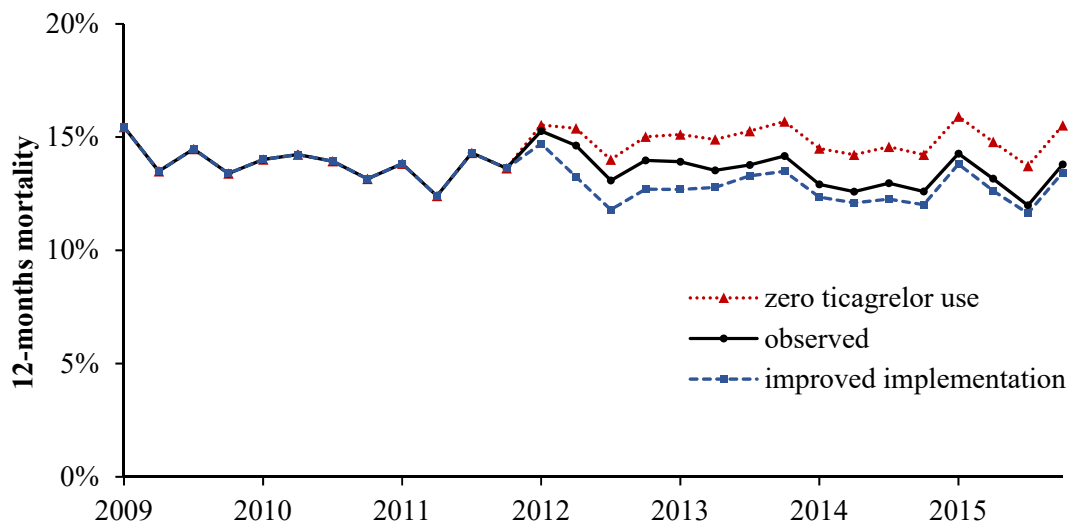

Figure 3.8 Counterfactual graph showing the observed 12-months mortality and how 12-month mortality would have looked if ticagrelor had not been used; and how mortality would have looked if all regions had implemented to the same extend as the highest implementing region (based on the main reduced form effectiveness estimates).

\section{Analysis on aggregated data}

Analysing the effect of ticagrelor using data aggregated per treatment centred produced similar effectiveness estimates as the main (patient level) analysis (Appendix, Table 7.2). The results was close to identical for the reduced form estimates, with the 2SLS producing around 15 to $20 \%$ higher absolute risk differences based on the aggregated data.

\subsubsection{Interpretation}

This study found that the implementation and use of ticagrelor was associated with a statistically significant reduction in 12-month mortality for patients hospitalised with myocardial infarction in Sweden. The results support the external validity of the PLATO trial and the value implementing ticagrelor into Swedish clinical practice, as estimated in Paper 3. 
This study did not find a statistically significant effect in patients below 80 years, which was the patient population included in Paper 3. Analysis of the effect within different age groups indicated that this was driven by an increased risk of death in patients 50 to 55 years of age (Appendix, Figure 7.1). Further investigation is needed to understand the results in these younger patients. In contrast, this study found a statistically significant reduction in mortality for those patients above or equal to 80 years of age. This population was not included in Paper 3 because guidelines did not provide clear treatment recommendation for this population. ${ }^{162,167}$ In this study, the results for the $<80$ and $\geq 80$ year age groups demonstrate the challenges and limitations of estimating the value of implementation based on effectiveness and cost-effectiveness estimates informed by RCTs.

The counterfactual graphs (Figure 3.8) and analysis provides a way to assess the impact of improving implementation. This approach finds a similar number of deaths could have been avoided from improved implementation in patients $<80$ years as estimated in Paper 3 (187 vs. 144, respectively). A limitation of this counterfactual approach, however, is that it requires the ability to conduct a reliable observational study to estimate the effectiveness of treatments in clinical practice. This will not always be possible and can only be done after a significant number of patients have been treated in clinical practice; that is, this approach cannot inform ex ante decisions on implementation initiatives.

Effectiveness estimates varied considerably and statistically when using multivariate OLS and propensity score adjusted OLS regression compared to the instrumental variable approach. This variation in combination with the high effectiveness estimates of OLS and propensity score analysis indicated that they were unable to account for the non-random treatment allocation of ticagrelor, leading to significant selection bias. This is a relevant finding since previous observation studies on ticagrelor have relied on these approaches to account for non-random treatment allocation of ticagrelor in clinical practice. This is also important for future observational studies aiming to confirm the external validity of clinical study results and to estimate the effect of implementing treatments in clinical practice. ${ }^{186-188}$

Stricter patient selection criteria resulted in lower and often insignificant effect estimates. These patient selection criteria appear to introduce bias, since they condition on outcomes defined after treatment initiation, so called bad controls. ${ }^{189,190}$ Because ticagrelor treatment is generally initiated during hospitalisation, conditioning on surviving hospitalisation or having a ticagrelor prescription at or after discharge can introduce bias. Many previous observational studies on ticagrelor restricted study populations to those surviving hospitalisation, those treated with P2Y12-inhibitors, or both, 174-176,179,181-184 which could explain part of the variation in the study results. Using prescription data after hospital discharge to estimate 
the effectiveness of treatments initiated during hospitalisation, bring to mind the analogy of looking for keys under the streetlight rather than where the keys were lost (the so called streetlight effect). Also, when observational studies aim to investigate the external validity of clinical study results, it seems counterproductive to use selection criteria that leads to questions about the external validity of such studies.

The main analysis in our study is based on using a patient level instrument and patient level outcomes. Analysis on data aggregated per treatment centre and quarter showed similar results, especially the reduced form estimates. It would be worth investigating if this interesting finding is generalisable to other treatments and settings. The possibility to use instrumental variable analysis to ascertain casual inference from aggregated data could significantly reduce the time and cost of estimating comparative effectiveness and the value from implementing treatments in Swedish clinical practice.

A limitation of this study is that we only estimated the effectiveness and not the cost-effectiveness of ticagrelor in clinical practice. The results of our study generally align with those of the PLATO trial, supporting the relevance of the trial-based cost-effectiveness analysis. However, patients treated in clinical practice were on average older and had higher absolute risk than those in the PLATO trial, demonstrating a need to update costeffectiveness estimates. Using the effectiveness estimates in our study as well as extending our study to include long-term outcomes and cost could provide a natural starting point for such work. At the same time, ticagrelor is going off patent during 2021, which is expected to lower its price. With lower pricing, the decision around ticagrelor treatment will become focused mainly on effectiveness, highlighting the relevance of the results of this study. 


\section{DISCUSSION}

This chapter provides a discussion of the four studies and their contribution to the overall aim of the thesis. The results and conclusions of the individual papers are synthesised and put into context of some central themes of this thesis: the reimbursement process; pharmaceutical pricing; implementation; R\&D incentives; and the value of pharmaceuticals.

\subsection{Reimbursement process}

This thesis outlines and discusses the benefit and cost of operating the reimbursement process for new health care technologies. This process is important to ensure that we implement and spend our limited health care resources on treatments with positive value. Paper 2 provides some conclusions on how to design the cost-effectiveness appraisal, including that optimal design depends on characteristics of the technologies assessed and that the process therefore should be flexible to change over time and depend on the technology undergoing assessment. While this work and conclusions focus on the cost-effectiveness appraisal, which is one part of the reimbursement process, the conclusions are also relevant for how to design the overall reimbursement process of new health care technologies.

Since its set up in 2002, the overall TLV reimbursement process has not changed significantly, and all treatments are subject to the same process with a maximum of 180 days. It would appear valuable to assess if the current appraisal system is (still) fit for purpose given the technologies that undergo assessments today compared to when the system was first set up. Paper 2 found that it is valuable to spend more time and resources on technologies with large budget impacts and technologies that will be used for many years. Though TLV probably spends more resources on certain appraisals today, this could be formalised so that it is clear when technologies should be subject a more (or less) rigorous assessment process.

It is interesting to observe that the NT-council has implemented an approach where treatments undergo different levels of scrutiny. The "fasttrack" process for PD-L1 inhibitors does not include a formal cost-effectiveness assessment and instead focuses on a simplified medical assessment and cost-comparison. This process is used when another PD-L1 inhibitor has already undergone a full NT-council assessment for the same indication. ${ }^{147}$ In Norway, "NYE METODER" (new methods) has also implemented a system where they decide what type of assessment and level of scrutiny that new treatments need to undergo, with four different pathways 
that include different types of assessments and have different requirements for what materials companies need to submit. ${ }^{191}$

Our work shows how agencies can change the sensitivity and specificity of the process based on how they incorporate uncertainty into decision making. Methods for quantifying uncertainty (e.g. PSA and VOI) have been around for years but are still not (at least not formally) incorporated into decision making in Sweden. TLV generally express their view on uncertainty around cost-effectiveness in their appraisal reports (e.g. medium, higher or very high); however, it is seldom clear how exactly this is determined or even whether this refers to uncertainty of the ICER estimate or decision uncertainty, i.e. uncertainty around whether the ICER is above or below the threshold. Clear guidance on how to quantify uncertainty, how it is considered in decision making, and how acceptance of uncertainty may vary based on budget impact, treatment effect, and ICER estimate would provide a way to change sensitivity and specificity of the appraisal process as well as increase decision transparency. Clear rules for how uncertainty is taken into account and thus "penalising" high levels of uncertainty would have the added benefit of incentivising companies to produce evidence to lower uncertainty or set lower prices. 57

It is important to consider both the monetary cost of operating the reimbursement process as well as the cost of later implementation of health care technologies. Delayed implementation results in lost opportunities of health gains from effective and cost-effective treatments as well as lost revenue for producers. The health impact can be substantial, as shown by estimates in Paper 3, where avoiding delayed implementation could have gained over 1,000 QALYs in this case of ticagrelor. Compared to an estimated cost for each TLV appraisal of around SEK 1 million, ${ }^{17}$ our study indicate that the time cost may be significantly higher than the monetary cost. As noted previously, it is worth paying (with both money and health) to avoid the implementation of "false positive" technologies ${ }^{\mathrm{xiv}}$ and to incentivise producers to set prices so that treatments are cost-effective. At the same time, this thesis demonstrates the need for investigating and understanding the balance between accuracy and cost of the appraisal process.

\subsection{Pharmaceutical prices}

Pharmaceutical cost is a significant and clearly definable part of health care spending. In Sweden, spending on pharmaceuticals was around SEK 50

\footnotetext{
${ }^{\text {xiv }}$ Refers to the definition used in Paper 2, i.e. technologies that are perceived as cost-effective but are in fact not cost-effective.
} 
billion in 2019,148 which makes up around $10 \%$ of total health care spending. ${ }^{192}$ In the context of reimbursement decisions, the focus on prices is understandable since lower prices increase the value and can lower the uncertainty about decisions based on cost-effectiveness. ${ }^{\mathrm{xv}}$ Lowering the prices of pharmaceuticals does not cost jobs within health care and the impact for pharmaceutical companies is perceived as insignificant or at least unclear. Price reductions lead to a transfer of value from producers to consumers in the short term and can reduce the inefficiency of monopoly pricing during the patent protection period. Nevertheless, if this transfer reduces R\&D incentives, it will also result in fewer new treatments being developed in the future, making this a transfer also of health from future to current patients.

This thesis illustrates how the design of price-based policies is important for the value to consumers and producers. As discussed in relation to the 15-year rule, policies with similar reduction in pharmaceutical spending can have different impact on R\&D incentives. The importance of policy design is also outlined in the discussion around parallel trade in $\mathrm{Pa}-$ per 1. A report by TLV estimated that the (privatised) pharmacies in Sweden had earned up to SEK one billion from parallel imports of patented pharmaceuticals in 2012. ${ }^{193}$ In other countries, these savings can be obtained by the health care system, as exemplified by a report estimating that parallel imports reduced pharmaceutical spending in Denmark by DKK 610 million ( $\approx$ SEK 832 million) $)^{\mathrm{xvi}}$ during 2018.194

The widespread use of IRP and reference of Swedish list prices in other countries indicate that pharmaceutical companies are less likely to set low prices in Sweden, making it less likely that they will set prices so that treatments are cost-effective. The recent proposals about implementing IRP in the US could accentuate this issue even further. ${ }^{195}$ The US market is still the single largest source of revenue for pharmaceutical companies. If European prices will be referenced directly or indirectly by the US, ${ }^{\text {xvii }}$ the significant higher list prices in the US will likely start to migrate across the Atlantic. Third party negotiations and price agreements with the NT-council offer opportunities for confidential price agreements in Sweden. However, the current processes are time consuming and not available for all products.17,70 Therefore, although Sweden is not using IRP, it is still important to understand its implications to ensure that pharmaceutical companies are willing to set prices so that treatments are cost-effective in Sweden.

\footnotetext{
${ }^{\mathrm{xv}}$ Lower prices do not lower the uncertainty in the cost-effectiveness estimates (i.e. the ICER distribution), but it does lower the mean ICER and moves the ICER distribution, resulting in more ICER estimates being below the threshold.

xvi Given and exchange rate of 1.36 (2021.04.20).

xvii Indirect price reference refers to when prices are referenced in one set of countries where prices are then referenced by the US.
} 
It is easy to focus on the price and cost of pharmaceuticals, especially since prices are often paid today for benefits that are generated in the years to come; benefits that can be both uncertain and difficult to quantify. This is exemplified and actualised by recent advancements in gene therapies and curative treatment for hepatitis $\mathrm{C}$, which have (or had in the case of hepatitis) significant upfront costs. ${ }^{196-198}$ Treatments for hepatitis C assessed by TLV during 2014 and 2015 (Exviera, Harvoni, Daklinza, Olysio, Sovaldi, Viekirax) provide an interesting example. The first of these treatments (Sovaldi) assessed by TLV had an initial cost of SEK 626,000 per patient, ${ }^{\text {xviii }}$ but was assessed as very cost-effective and even cost-saving in most scenarios (dominant ${ }^{\mathrm{xix}}$ to ICER of SEK 44,028 per QALY). 199 The price of Sovaldi and similar products subsequently reimbursed by TLV was reduced significantly via competition and third party price agreements. ${ }^{148,198}$ Given the cost-effectiveness and price reductions, the majority of surplus from these treatments has probably been realised by consumers. This is similar to what we find in the case of ticagrelor, where we estimated that a majority of surplus (81\%) was gained by consumers. This is also akin to findings in other studies that find substantial value generated from the spending on pharmaceuticals and where the majority of this value is acquired by consumers.3,4,168-173 However, the generalisability of these cases is difficult to assess and it would be relevant to know the overall and average value from spending on pharmaceuticals. At the same time, it would be equally, or maybe even more worthwhile, to investigate the value gained from the $90 \%$ of non-pharmaceutical health care spending where treatments and technologies generally undergo less formal assessment and scrutiny than pharmaceuticals.

Examples of value generated by using specific pharmaceuticals do not entail that reimbursement agencies should let themselves be taken hostage by pharmaceutical companies demanding prices that cannot be justified by available effectiveness and cost-effectiveness evidence. Study 2 demonstrates that it is important to place the burden of proof on producers so agencies can reject new treatments with no or questionable value, to avoid costly decisions and to incentivise cost-effective pricing.

\subsection{Implementation}

Significant value (health and pharmaceutical earnings) can be gained by improving implementation of cost-effective treatments.4,15,16,149,153,200 It is interesting to note that the expected monetary value of perfect ticagrelor

\footnotetext{
xviii Based on 12 weeks of treatment, with some patients needing 24 weeks of treatment, doubling the cost.

${ }^{x i x}$ Dominant here refers to having positive incremental benefit and negative incremental cost, i.e. an effective and cost-saving treatment.
} 
implementation (population EVPIM) of around SEK 735 million $(2,941$ QALYs) estimated in Paper 3 is similar to the savings from the 15-year rule (SEK 800 million) and the IRP proposal in the "Heinsoo investigation" (SEK 700 million). ${ }^{17,130}$ This "perfect" level of implementation is probably unattainable and may not even be desirable due to time spent on the reimbursement process. Still, the monetary value of around SEK 285 million $^{\mathrm{xx}}$ (1,138 QALYs) from eliminating regional implementation variation of ticagelor indicates that the value of ensuring appropriate implementation of reimbursement decisions in Sweden probably far exceeds the value that can be obtained by price-focused policies such as IRP. Gaining additional value in the health care system by improving implementation of recommended treatments adds value to both consumers and producers and therefore has the added benefit of incentivising the development of new health care technologies.

There has been significant focus on equal access to treatments across Swedish health care regions with treatment guidelines and quality registries setting treatment targets for different interventions and disease areas. Still, assessments on regional variation and reports by quality registries continue to find significant and unmotivated variations in treatment practices. ${ }^{17,166,201}$ The case studies on ticagrelor found significant value from avoiding regional implementation variation. This is in line with a previous study by Lundqvist et al. (2013), who estimated that around 10,700 additional women would have been treated with tamoxifen for early breast cancer if all Swedish health care regions had treated in the same way as the highest implementing region, with an estimated gain of around 7,600 QALYs. ${ }^{200}$ However, a key challenge regarding regional variation is to identify and address the issue when it occur and not just estimate the consequences afterwards. The framework for evaluating the value of improving implementation outlined in Paper 3 could be used to help identify when and where to invest in implementation improvements. The large value to both consumers and producers from reducing implementation variation demonstrates that this is an area where further investigation and investment is warranted.

Delay between reimbursement decisions by TLV and updates of national treatment guidelines by the National Board of Health and Welfare (Socialstyrelsen) can lead to significant health loss, as exemplified by the case study on ticagrelor. It would be relevant to investigate if treatment guidelines or recommendations could be updated as part of the reimbursement process, as is done by NICE, 137 as well as for those products undergoing assessment by the NT-council.

\footnotetext{
${ }^{\mathrm{xx}}$ Given a value of SEK 250,000 per QALY.
} 


\subsection{R\&D incentives}

This thesis has studied and discussed how different policies and the implementation of pharmaceuticals can influence the incentives for the R\&D of future health care technologies. These assessments are based on the key assumption that pharmaceutical $\mathrm{R} \& \mathrm{D}$ is largely driven by expected rent from current and future pharmaceuticals during the patent protected period. Both theoretical and empirical studies support the link between expected rent and R\&D incentives. ${ }^{100-104}$ Still, it has been argued that reducing prices and pharmaceutical rent in countries like Sweden, which only constitute a small fraction of pharmaceutical sales, would have minimal impact on global R\&D incentives. ${ }^{18}$ However, price reductions in small markets can have non-marginal impact on global rent and R\&D incentives, due to price spill over via IRP. Furthermore, if countries like Sweden is unwilling to reward and incentivise pharmaceutical $R \& D$ by paying value based prices, it is hard to argue why other countries should pay to uphold R\&D incentives. ${ }^{17}$

Many pharmaceutical companies have consolidated, while at the same time reduced their internal $R \& D$ departments. Instead, companies are increasingly depending on partnerships with universities and smaller companies as well as buying products developed by smaller biotech companies.31,34,202 These small companies and academic institutions that develop new products often sell these products, or the entire company, to large pharmaceutical companies who have the resources and experience of conducting later phase clinical trials, applying for regulatory approval and reimbursement. The value and price paid for acquiring such products depends on the earnings they are expected to generate (i.e. expected rent). Reductions in expected rent lowers the value of future products as well as the earnings that pharmaceutical companies generate today and therefore what companies can pay for such products. This lowers the value of investing in biotech ventures aimed at developing new treatments.

Significant inefficiencies from relying on patents to incentivise pharmaceutical R\&D have been discussed and demonstrated elsewhere. $38,102,118,119$ Alternatives to relying on or reducing the inefficiencies of patent protection have been proposed (as outlined in Section 2.5.2) and the benefit of such changes could be substantial. However, the incentives for free riding in the development of global public goods and the fact that patent protection has been the key incentivising factor for pharmaceuticals during the past several decades indicate that patents are likely to remain a key part in incentivising R\&D in the future. As discussed by Nassim Taleb, the Lindy effect suggests that non-perishable ideas and technologies that have been around for many years (like incentivising $\mathrm{R} \& \mathrm{D}$ via patent protection) are likely to survive and stay relevant for many years into the future as well. ${ }^{203}$ 
This supports the relevance of policy analysis that assumes that patent protection will be a key part in incentivising pharmaceutical $R \& D$ in years to come. Even if patents were to become less important for incentivising $R \& D$, most of the assessments and discussions around the value of pharmaceuticals in this thesis would still be relevant.

Even when $R \& D$ incentives are largely driven by expected rent, this does not dictate that reimbursement agencies should accept higher and non-cost-effective prices to incentivise development of treatments for rare diseases with small patient populations, such as orphan drugs. In such cases, where there might be a market failure from incentivising R\&D through the patent system, it could be worthwhile to investigate alternative or supplementary incentives as has been done by prolonging patent protection, different requirements around clinical studies, data needed for regulatory approval, and willingness to accept larger uncertainty around costeffectiveness. ${ }^{127}$ Although it has been argued that the human dignity principle could support paying higher prices for orphan drugs in Sweden,74,204,205 it is not obvious that this potential market failure should be solved by accepting ICERs that are double of what would normally be accepted for similarly severe but less rare conditions.

\subsection{Value of pharmaceuticals in clinical practice}

The value generated by implementing pharmaceuticals into clinical practice depends on their comparative effectiveness and the opportunity cost of paying for the treatment. There is continuous, and probably never ending, discussion around the external validity of clinical trial results.41-44,206,207 This debate underlines the importance of data sources as well as appropriate methods for evaluating the effectiveness of treatments in clinical practice. In study 4, we found that ticagrelor reduced the 12-month mortality of patients hospitalised for myocardial infarction in Sweden. This study appears to confirm the external validity of the PLATO trial as well as the value of increasing ticagrelor implementation, as estimated in study 3. Studies on the comparative effectiveness when used in clinical practice are central to estimating the value that treatments contribute to patients and health care systems.

The impact of statistical approach and patient selection observed in study 4 shows the importance of appropriate study design and methodological consideration within observational research. The number of studies using propensity scores have increased significantly in recent years. ${ }^{208}$ Propensity score adjustment relies on adjusting for observed confounders (i.e. selection on observables) to account for the non-random treatment assignment in clinical practice. The results of our study demonstrate the importance of considering, and testing, whether it is reasonable to assume 
that controlling for observed confounders can account for selection bias, as for example proposed by Oster (2019). ${ }^{209}$ Using alternative methods that do not rely on selection on observables could provide powerful tools for estimating comparative effectiveness, as exemplified with our instrumental variable analysis. This is also something that TLV has been tasked to investigate and is something that will help to better utilise the high-quality nationwide registers that we have in Sweden as well as in the other Nordic countries. ${ }^{186,210}$

Research on the opportunity cost within the health care system has made significant progress in recent years.97,211-214 Knowing the opportunity cost of implementing new treatments is central to determining the value that treatments constitute, as outlined in Section 2.4.1. Nevertheless, it is still unclear whether the decision threshold used to inform reimbursement decisions in Sweden reflect opportunity costs in the health care system, society's willingness to pay for health improvement, or a decision rule derived from past decision (i.e. historical happenstance). ${ }^{62,93-97}$

Estimates of opportunity costs within the health care system have generally been lower than the thresholds used as decision criteria in the respective countries. 97,211-214 Although these estimates are associated with significant uncertainty, it raises the questions about the health implications from current decision rules. The estimate by Siverskog and Henriksson of SEK 180,000 per QALY is lower than the 250,000 threshold used in Paper $3 .{ }^{97}$ Using this threshold would lower the value of ticagrelor implementation but would not change the main conclusions of this paper (since the ICER estimate for ticagrelor is SEK 25,022 per QALY). However, in other cases such as the Orkambi example presented in the recent publication by Siverskog and Henriksson (2021), this threshold would imply a significant health loss from implementing this treatment. Reimbursing Orkambi, with an ICER of SEK 1.5 million, may still be in alignment with the principles for how to prioritise health care within Sweden, if the distribution of population health is seen as more equitable. ${ }^{6}$ However, as long as we do not know who bears the cost of lower health from reallocating health care resources, we are unable to assess if such redistribution leads to a more equitable distribution of health or equally inequitable as well as lower population health.

Different perspectives have been put forward regarding how to use these estimates of marginal productivity in decision making. Some argue that it should be used as the threshold, $96,211,215$ while others argue that the decision threshold should be even lower to ensure that new treatments contribute to population health already during the period of patent protection. ${ }^{113}$ However, it is also argued that it would be optimal to operate a threshold higher than that of the marginal productivity to improve dynamic 
efficiency and in that way increase long-term population health. ${ }^{64,114-116}$ Although not always obvious or clearly stated, these positions include both matters of fact as well as normative value judgements. The decision threshold determines what value we get from currently available technologies and how much producers earn during patent protection, which determines the value and incentives of developing future technologies. The impact of different thresholds on current and future population health is a something that can be investigated through empirical research. In contrast, even if or when we know the current and future health outcomes resulting from different thresholds, it is still a value judgement whether we should chose the threshold that maximises current or long-term population health.

This thesis does not intend to make value judgement on the purpose of health care decision making in terms of maximising current or long-term population health. Instead, this work provides analysis and tools to help assess how commonly used prioritisation policies impact consumer surplus and expected rent, something that is needed to understand and inform the balance between getting value today and incentivising R\&D. 


\section{AREAS OF FUTURE RESEARCH}

This thesis has identified several areas in need of further research. This chapter reiterates some of the areas where further research seems most warranted and appear to have high relevance and value.

To improve the value from operating cost-effectiveness assessment and the reimbursement process, it would be valuable to understand the process's past performance. Evaluating past decisions with the most recent and country specific data could estimate the cost of the process (monetary and implementation delays) as well as the number of correct (true positive and true negative) vs. incorrect (false positive and false negative) decisions. This type of evaluation is already happening as exemplified by project that TLV and the Swedish trade association for the research-based pharmaceutical industry (LIF) are conducting, in relation to how well TLV (and producers) have estimated long-term outcomes within oncology. Our instrumental variable analysis in Paper 4 and TLV's investigation into comparative effectiveness estimation, could provide relevant guidance on how to estimate the value of previously approved technologies. ${ }^{186}$

Producers have limited opportunities to offer confidential discounts on prescription drugs in Sweden, in comparison with other countries. ${ }^{17}$ Investigation is needed to understand whether confidential discounts will increase producers willingness to offer discounts and cost-effective prices in Sweden. Further study is also needed on how best to design such systems to avoid complex and costly systems as well as potential adverse pricing incentives.

The high number of QALYs that could have been gained by improving the implementation of ticagrelor demonstrates that being able to predict low and varying implementation ex ante and identify how to improve implementation could have substantial value for both consumers and producers. As discussed earlier, a starting point could be to investigate implementation patterns of previously implemented pharmaceuticals to identify trends across disease areas, over time, and the effect of treatment targets and quality registries.

Nationwide treatment, quality, and patient registries in Sweden and in other Nordic countries are often described as a "gold mine" for observational research investigating comparative effectiveness of treatments in clinical practice..$^{78}$ However, we can only extract the "gold" (i.e. causal inference) from these data sources with methods able to account for the nonrandom allocation of treatments in clinical practice. Instrumental variables 
appear to be underutilised in research on comparative effectiveness of medical interventions, ${ }^{186}$ and further research is needed to determine the general applicability of this approach and investigate the ability deduce causal inference from aggregate data.

The estimation of the marginal productivity of the UK health care system by Claxton et al. (2015) identified that this estimate varied significantly between disease areas, with some having significantly lower productivity than others. ${ }^{211}$ This could indicate deliberate distribution of health care resources based on medical need and severity across different disease areas, or inefficient resource allocation. This underlines the need for research on the productivity of the large number of health care interventions and health care areas where evidence on effectiveness and cost-effectiveness is scarce. Such investigations could inform disinvestment decisions that could free up resources to invest in implementing or expanding the use of cost-effective treatments.

Society's prioritisation of short-term vs. long-term population health comprise a challenging value judgement on intergenerational equity, which is in need to more public debate and ethical inquiries. To inform such debate and value judgement, further empirical research is needed on the link between pharmaceutical policies and investments in pharmaceutical R\&D. When giving up health today to incentivise pharmaceutical R\&D, we would like to better understand the expected return on that investment. 


\section{CONCLUSIONS}

Price reducing policies will likely lead to fewer new technologies and lower long-term population health, due to reduced incentives for R\&D. Similar reductions in pharmaceutical spending can have different impacts on R\&D incentives, and policy design determines whether patients, payers, or other actors gain from lower prices. This thesis has shown that short- and longterm implications of price-focused policies need to be considered to understand the distributive and intergenerational consequences of price focused policies.

Delayed implementation of cost-effective treatments constitutes a cost to both consumers and producers. Some delays are probably unavoidable and worth their opportunity costs to allow time for reimbursement appraisals aimed at identifying the value of health care interventions. With an estimated 1,000 QALYs lost from delayed implementation of ticagrelor this thesis demonstrates the importance of finding the right trade-off between appraisal rigour and cost.

This thesis shows that reducing regional implementation variation of cost-effective treatments may carry large health benefits. In the case of ticagrelor, reducing regional implementation variation could have increased population health in excess of 1,100 QALYs (with a monetary value of around SEK 275 million). This demonstrates the value of identifying and addressing suboptimal implementation, something that could be done in partnership between health care systems and pharmaceutical companies.

There is no one optimal cost-effectiveness and reimbursement process. This work shows that the process should be flexible to allow agencies to spend time and resources where they are expected to have greatest value. It is important that burden of proof is placed on manufactures and that the process is evaluated and updated continuously to reflect the characteristics of the technologies that are being assessed.

Finally, the thesis shows that the implementation of ticagrelor in Swedish clinical practice has reduced 12-month mortality for patients with myocardial infarction. Instrumental variables provide a way to overcome the non-random treatment assignment when investigating causal inference from observational data and warrant further application within medicine. 


\section{APPENDIX}

Table 7.1 Characteristics of study population (Paper 4).

\begin{tabular}{|c|c|c|c|}
\hline & $\begin{array}{l}\text { Ticagrelor } \\
(\mathbf{N}=\mathbf{3 0 7 7 3})\end{array}$ & $\begin{array}{c}\text { No-ticagrelor } \\
(\mathrm{N}=79820)\end{array}$ & $\begin{array}{c}\text { Overall } \\
(\mathrm{N}=110593)\end{array}$ \\
\hline \multicolumn{4}{|l|}{ Gender } \\
\hline Female & $9032(29.4 \%)$ & $30006(37.6 \%)$ & $39038(35.3 \%)$ \\
\hline Male & $21741(70.6 \%)$ & $49814(62.4 \%)$ & $71555(64.7 \%)$ \\
\hline \multicolumn{4}{|l|}{ Age } \\
\hline Mean (SD) & $67.1(11.5)$ & $72.5(12.4)$ & $71.0(12.4)$ \\
\hline Median [Min, Max] & $68.0[21.0,100]$ & $74.0[16.0,104]$ & $72.0[16.0,104]$ \\
\hline \multicolumn{4}{|l|}{ Age groups } \\
\hline-44 & $843(2.7 \%)$ & $1392(1.7 \%)$ & $2235(2.0 \%)$ \\
\hline $45-49$ & $1406(4.6 \%)$ & $2214(2.8 \%)$ & $3620(3.3 \%)$ \\
\hline $50-54$ & $2303(7.5 \%)$ & $3565(4.5 \%)$ & $5868(5.3 \%)$ \\
\hline $55-59$ & $3388(11.0 \%)$ & $5550(7.0 \%)$ & $8938(8.1 \%)$ \\
\hline $60-64$ & $4170(13.6 \%)$ & $8195(10.3 \%)$ & $12365(11.2 \%)$ \\
\hline $65-69$ & $5416(17.6 \%)$ & $10344(13.0 \%)$ & $15760(14.3 \%)$ \\
\hline $70-74$ & $4791(15.6 \%)$ & $10809(13.5 \%)$ & $15600(14.1 \%)$ \\
\hline $75-79$ & $3793(12.3 \%)$ & $11201(14.0 \%)$ & 14994 (13.6\%) \\
\hline $80-84$ & $2810(9.1 \%)$ & $11743(14.7 \%)$ & $14553(13.2 \%)$ \\
\hline $85-89$ & $1429(4.6 \%)$ & $9653(12.1 \%)$ & $11082(10.0 \%)$ \\
\hline $90-94$ & $385(1.3 \%)$ & $4269(5.3 \%)$ & $4654(4.2 \%)$ \\
\hline $95+$ & $39(0.1 \%)$ & $885(1.1 \%)$ & $924(0.8 \%)$ \\
\hline \multicolumn{4}{|l|}{ Type of MI } \\
\hline NSTEMI & $17239(56.0 \%)$ & $52992(66.4 \%)$ & $70231(63.5 \%)$ \\
\hline STEMI & $13378(43.5 \%)$ & $23259(29.1 \%)$ & $36637(33.1 \%)$ \\
\hline NMI & $154(0.5 \%)$ & $428(0.5 \%)$ & $582(0.5 \%)$ \\
\hline Unknown & $2(0.0 \%)$ & $3141(3.9 \%)$ & $3143(2.8 \%)$ \\
\hline \multicolumn{4}{|l|}{ Previous MI } \\
\hline No & $26410(85.8 \%)$ & $63437(79.5 \%)$ & 89847 (81.2\%) \\
\hline Yes & $4242(13.8 \%)$ & $15682(19.6 \%)$ & $19924(18.0 \%)$ \\
\hline Unknown & $121(0.4 \%)$ & $701(0.9 \%)$ & $822(0.7 \%)$ \\
\hline \multicolumn{4}{|l|}{ History of Stroke } \\
\hline No & $29266(95.1 \%)$ & $70942(88.9 \%)$ & $100208(90.6 \%)$ \\
\hline Yes & $1409(4.6 \%)$ & $7840(9.8 \%)$ & $9249(8.4 \%)$ \\
\hline Unknown & $98(0.3 \%)$ & $1038(1.3 \%)$ & $1136(1.0 \%)$ \\
\hline \multicolumn{4}{|l|}{ History of cardiac surgery } \\
\hline cabg & $1611(5.2 \%)$ & $6323(7.9 \%)$ & $7934(7.2 \%)$ \\
\hline other cardiac surgery & $68(0.2 \%)$ & $459(0.6 \%)$ & $527(0.5 \%)$ \\
\hline no & $29036(94.4 \%)$ & 72619 (91.0\%) & $101655(91.9 \%)$ \\
\hline
\end{tabular}




\begin{tabular}{|c|c|c|c|}
\hline & $\begin{array}{l}\text { Ticagrelor } \\
(\mathrm{N}=\mathbf{3 0 7 7 3})\end{array}$ & $\begin{array}{c}\text { No-ticagrelor } \\
(\mathrm{N}=79820)\end{array}$ & $\begin{array}{c}\text { Overall } \\
(\mathrm{N}=110593)\end{array}$ \\
\hline Unknown & $58(0.2 \%)$ & $419(0.5 \%)$ & $477(0.4 \%)$ \\
\hline \multicolumn{4}{|l|}{ History of PCI } \\
\hline yes & $3206(10.4 \%)$ & $7826(9.8 \%)$ & $11032(10.0 \%)$ \\
\hline no & $27413(89.1 \%)$ & $71104(89.1 \%)$ & $98517(89.1 \%)$ \\
\hline Unknown & $154(0.5 \%)$ & $890(1.1 \%)$ & $1044(0.9 \%)$ \\
\hline \multicolumn{4}{|l|}{ Diabetes } \\
\hline No & $25058(81.4 \%)$ & $62311(78.1 \%)$ & $87369(79.0 \%)$ \\
\hline Yes & $5668(18.4 \%)$ & $17245(21.6 \%)$ & $22913(20.7 \%)$ \\
\hline Unknown & $47(0.2 \%)$ & $264(0.3 \%)$ & $311(0.3 \%)$ \\
\hline \multicolumn{4}{|c|}{ History of CHF } \\
\hline No & $28814(93.6 \%)$ & $70023(87.7 \%)$ & $98837(89.4 \%)$ \\
\hline Yes & $1074(3.5 \%)$ & $6325(7.9 \%)$ & $7399(6.7 \%)$ \\
\hline Unknown & $885(2.9 \%)$ & $3472(4.3 \%)$ & $4357(3.9 \%)$ \\
\hline \multicolumn{4}{|l|}{ Hypertension } \\
\hline No & $16268(52.9 \%)$ & $38359(48.1 \%)$ & $54627(49.4 \%)$ \\
\hline Yes & $14341(46.6 \%)$ & $40680(51.0 \%)$ & $55021(49.8 \%)$ \\
\hline Unknown & $164(0.5 \%)$ & $781(1.0 \%)$ & $945(0.9 \%)$ \\
\hline \multicolumn{4}{|l|}{ Statin at index } \\
\hline No & $23383(76.0 \%)$ & $56623(70.9 \%)$ & $80006(72.3 \%)$ \\
\hline Yes & $7060(22.9 \%)$ & $22416(28.1 \%)$ & $29476(26.7 \%)$ \\
\hline Unknown & $330(1.1 \%)$ & $781(1.0 \%)$ & $1111(1.0 \%)$ \\
\hline \multicolumn{4}{|c|}{ Beta-blocker at index } \\
\hline No & $22340(72.6 \%)$ & $48693(61.0 \%)$ & $71033(64.2 \%)$ \\
\hline Yes & $7997(26.0 \%)$ & $30140(37.8 \%)$ & $38137(34.5 \%)$ \\
\hline Unknown & $436(1.4 \%)$ & $987(1.2 \%)$ & $1423(1.3 \%)$ \\
\hline \multicolumn{4}{|c|}{ ACE-inhibitor at index } \\
\hline No & $25081(81.5 \%)$ & $61534(77.1 \%)$ & $86615(78.3 \%)$ \\
\hline Yes & $5258(17.1 \%)$ & $17308(21.7 \%)$ & $22566(20.4 \%)$ \\
\hline Unknown & $434(1.4 \%)$ & $978(1.2 \%)$ & $1412(1.3 \%)$ \\
\hline \multicolumn{4}{|l|}{ ASA at index } \\
\hline yes & $8048(26.2 \%)$ & $28719(36.0 \%)$ & $36767(33.2 \%)$ \\
\hline no & $22400(72.8 \%)$ & $50332(63.1 \%)$ & $72732(65.8 \%)$ \\
\hline Unknown & $325(1.1 \%)$ & $769(1.0 \%)$ & $1094(1.0 \%)$ \\
\hline \multicolumn{4}{|c|}{ Calcium antagonist at index } \\
\hline yes & $5451(17.7 \%)$ & $15674(19.6 \%)$ & $21125(19.1 \%)$ \\
\hline no & $24906(80.9 \%)$ & $63191(79.2 \%)$ & $88097(79.7 \%)$ \\
\hline Unknown & $416(1.4 \%)$ & $955(1.2 \%)$ & $1371(1.2 \%)$ \\
\hline \multicolumn{4}{|c|}{ Oral anticoagulant at index } \\
\hline yes & $402(1.3 \%)$ & $5964(7.5 \%)$ & $6366(5.8 \%)$ \\
\hline no & $30054(97.7 \%)$ & $73105(91.6 \%)$ & $103159(93.3 \%)$ \\
\hline Unknown & $317(1.0 \%)$ & $751(0.9 \%)$ & $1068(1.0 \%)$ \\
\hline \multicolumn{4}{|c|}{ Digitalis at index } \\
\hline yes & $136(0.4 \%)$ & $2015(2.5 \%)$ & $2151(1.9 \%)$ \\
\hline no & $30323(98.5 \%)$ & $77059(96.5 \%)$ & $107382(97.1 \%)$ \\
\hline
\end{tabular}




\begin{tabular}{|c|c|c|c|}
\hline & $\begin{array}{l}\text { Ticagrelor } \\
(\mathrm{N}=\mathbf{3 0 7 7 3 )}\end{array}$ & $\begin{array}{c}\text { No-ticagrelor } \\
(\mathbf{N}=79820)\end{array}$ & $\begin{array}{c}\text { Overall } \\
(\mathrm{N}=110593)\end{array}$ \\
\hline Unknown & $314(1.0 \%)$ & $746(0.9 \%)$ & $1060(1.0 \%)$ \\
\hline \multicolumn{4}{|l|}{ Diuretics at index } \\
\hline yes & $4445(14.4 \%)$ & $20820(26.1 \%)$ & $25265(22.8 \%)$ \\
\hline no & $25939(84.3 \%)$ & $58106(72.8 \%)$ & $84045(76.0 \%)$ \\
\hline Unknown & $389(1.3 \%)$ & $894(1.1 \%)$ & $1283(1.2 \%)$ \\
\hline \multicolumn{4}{|l|}{ Country of birth } \\
\hline Sweden & $25572(83.1 \%)$ & $68181(85.4 \%)$ & $93753(84.8 \%)$ \\
\hline Nordics & $1591(5.2 \%)$ & $4561(5.7 \%)$ & $6152(5.6 \%)$ \\
\hline Middle East & $935(3.0 \%)$ & $1446(1.8 \%)$ & $2381(2.2 \%)$ \\
\hline Balkans & $747(2.4 \%)$ & $1422(1.8 \%)$ & $2169(2.0 \%)$ \\
\hline East Europe & $430(1.4 \%)$ & $1032(1.3 \%)$ & $1462(1.3 \%)$ \\
\hline West Europe & $381(1.2 \%)$ & $1051(1.3 \%)$ & $1432(1.3 \%)$ \\
\hline South Europe & $143(0.5 \%)$ & $303(0.4 \%)$ & $446(0.4 \%)$ \\
\hline Asia & $522(1.7 \%)$ & $786(1.0 \%)$ & $1308(1.2 \%)$ \\
\hline former Soviet Union & $107(0.3 \%)$ & $388(0.5 \%)$ & $495(0.4 \%)$ \\
\hline Africa & $173(0.6 \%)$ & $266(0.3 \%)$ & $439(0.4 \%)$ \\
\hline Other & $170(0.6 \%)$ & $382(0.5 \%)$ & $552(0.5 \%)$ \\
\hline Unknown & $2(0.0 \%)$ & $2(0.0 \%)$ & $4(0.0 \%)$ \\
\hline \multicolumn{4}{|l|}{ Civil status } \\
\hline Married & $16840(54.7 \%)$ & $39427(49.4 \%)$ & $56267(50.9 \%)$ \\
\hline Unmarried & $4732(15.4 \%)$ & $9682(12.1 \%)$ & $14414(13.0 \%)$ \\
\hline Divorced & $5625(18.3 \%)$ & $13361(16.7 \%)$ & $18986(17.2 \%)$ \\
\hline Widowed & $3517(11.4 \%)$ & $17248(21.6 \%)$ & $20765(18.8 \%)$ \\
\hline Unknown & $59(0.2 \%)$ & $102(0.1 \%)$ & $161(0.1 \%)$ \\
\hline \multicolumn{4}{|l|}{ Educational history } \\
\hline Primary $<9$ years & $7271(23.6 \%)$ & $28376(35.5 \%)$ & $35647(32.2 \%)$ \\
\hline Primary 9 years & $3373(11.0 \%)$ & $7003(8.8 \%)$ & $10376(9.4 \%)$ \\
\hline Secondary $<3$ years & $9524(30.9 \%)$ & $22156(27.8 \%)$ & $31680(28.6 \%)$ \\
\hline Secondary 3 years & $3788(12.3 \%)$ & $8456(10.6 \%)$ & $12244(11.1 \%)$ \\
\hline Tertiary $<3$ years & $2956(9.6 \%)$ & $5807(7.3 \%)$ & $8763(7.9 \%)$ \\
\hline Tertiary $>=3$ years & $3466(11.3 \%)$ & $6587(8.3 \%)$ & $10053(9.1 \%)$ \\
\hline Unknown & $395(1.3 \%)$ & $1435(1.8 \%)$ & $1830(1.7 \%)$ \\
\hline \multicolumn{4}{|l|}{ Disposable income } \\
\hline SEK 0-99,999 & $1541(5.0 \%)$ & $5047(6.3 \%)$ & $6588(6.0 \%)$ \\
\hline SEK $100,000-125,000$ & $2380(7.7 \%)$ & $10669(13.4 \%)$ & $13049(11.8 \%)$ \\
\hline SEK 125,000-149,999 & $4816(15.7 \%)$ & $17279(21.6 \%)$ & $22095(20.0 \%)$ \\
\hline SEK $150,000-174,999$ & $3999(13.0 \%)$ & $11799(14.8 \%)$ & $15798(14.3 \%)$ \\
\hline SEK 175,000-199,999 & $3215(10.4 \%)$ & $8041(10.1 \%)$ & $11256(10.2 \%)$ \\
\hline SEK 200,000-224,999 & $2574(8.4 \%)$ & $5900(7.4 \%)$ & $8474(7.7 \%)$ \\
\hline SEK 225,000-249,999 & $2314(7.5 \%)$ & $4674(5.9 \%)$ & $6988(6.3 \%)$ \\
\hline SEK 250,000-274,999 & $2018(6.6 \%)$ & $3659(4.6 \%)$ & $5677(5.1 \%)$ \\
\hline SEK 275,000-299,999 & $1607(5.2 \%)$ & $2924(3.7 \%)$ & $4531(4.1 \%)$ \\
\hline SEK $300,000-349,999$ & $2385(7.8 \%)$ & $3783(4.7 \%)$ & $6168(5.6 \%)$ \\
\hline SEK 350,000-399,999 & $1456(4.7 \%)$ & $2091(2.6 \%)$ & $3547(3.2 \%)$ \\
\hline
\end{tabular}


The value of evaluating and implementing pharmaceuticals

\begin{tabular}{lccc}
\hline & $\begin{array}{c}\text { Ticagrelor } \\
\mathbf{( N = 3 0 7 7 3 )}\end{array}$ & $\begin{array}{c}\text { No-ticagrelor } \\
\mathbf{( N = 7 9 8 2 0}\end{array}$ & $\begin{array}{c}\text { Overall } \\
(\mathbf{N}=\mathbf{1 1 0 5 9 3})\end{array}$ \\
\hline SEK 400,000-499,999 & $1226(4.0 \%)$ & $1787(2.2 \%)$ & $3013(2.7 \%)$ \\
SEK 500,000+ & $1125(3.7 \%)$ & $2031(2.5 \%)$ & $3156(2.9 \%)$ \\
SEK $<0$ & $58(0.2 \%)$ & $33(0.0 \%)$ & $91(0.1 \%)$ \\
Unknown & $59(0.2 \%)$ & $103(0.1 \%)$ & $162(0.1 \%)$ \\
\hline
\end{tabular}

ACE-inhibitor: Angiotensin-converting enzyme (ACE) inhibitors; ASA: acetylsalicylic acid; CHF:

Congestive heart failure; cabg: coronary artery bypass grafting; MI:myocardial infarction; NSTEMI:

Non-ST-segment elevation myocardial; PCI: Percutaneous coronary intervention; SD: standard devi-

ation; SEK: Swedish krona; STEMI: ST-segment elevation myocardial. 


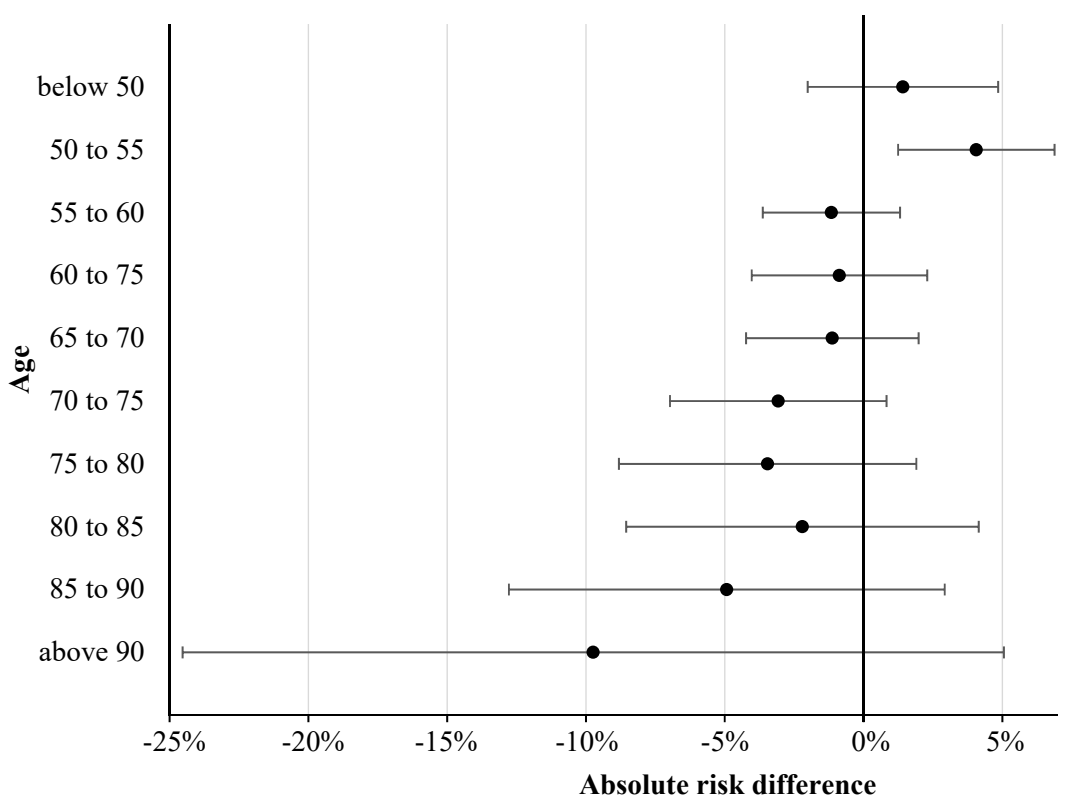

Figure 7.1 Exploratory analysis of the main effect estimates (reduced form) in five-year age groups. 
Table 7.2 Comparison of main (patient level) analysis and analysis on data aggregated on treatment centre. Absolute risk in (1) non-ticagrelor and (2) ticagrelor treated patients, and absolute risk difference on 12-month mortality based on the (3) crude, (4) age adjusted, and (5) fully-adjusted reduced form and 2SLS analyses $(95 \%$ confidence interval).

\begin{tabular}{|c|c|c|c|c|c|}
\hline \multicolumn{2}{|c|}{$\begin{array}{c}\text { Absolute risk } \\
\%\end{array}$} & \multicolumn{4}{|c|}{$\begin{array}{c}\text { Absolute risk difference } \\
\text { percentage point }^{\phi}\end{array}$} \\
\hline $\begin{array}{c}\text { non-tica } \\
\text { (1) }\end{array}$ & $\begin{array}{c}\text { tica } \\
(2)\end{array}$ & & $\begin{array}{c}\text { crude } \\
\text { (3) }\end{array}$ & $\begin{array}{c}\text { age adj } \\
(4)\end{array}$ & $\begin{array}{c}\text { all cov } \\
(5)\end{array}$ \\
\hline $\begin{array}{c}\text { Main (patient } \\
17.10^{* *} \\
(16.84,17.36)\end{array}$ & $\begin{array}{c}\text { evel) analysis } \\
4.82 * * \\
(4.58,5.06)\end{array}$ & $\begin{array}{l}=\text { number of pati } \\
\text { Reduced form } \\
2 S L S\end{array}$ & $\begin{array}{c}\text { nts }=\mathbf{1 1 0 , 5 9 3 )} \\
-2.89^{*} \\
(-5.21,-0.56) \\
-3.82 * \\
(-7.08,-0.56) \\
\end{array}$ & $\begin{array}{c}-2.21^{*} \\
(-4.18,-0.24) \\
-2.95^{*} \\
(-5.71,-0.18) \\
\end{array}$ & $\begin{array}{c}-2.20 * \\
(-4.32,-0.09) \\
-2.94 \\
(-5.93,0.04)\end{array}$ \\
\hline Analysis on $d$ & ta aggregated & $\begin{array}{l}\text { treatment centr } \\
\text { Reduced form } \\
\text { 2SLS }\end{array}$ & $\begin{array}{c}(\mathbf{N}=\mathbf{2 , 1 6 2} \text { obs } \\
2.73^{*} \\
(-5.00,-0.46) \\
-4.31 * \\
(-8.06,-0.55)\end{array}$ & $\begin{array}{c}\text { vations) } \\
2.21^{*} \\
(-4.06,-0.36) \\
-3.50 * \\
(-6.55,-0.45)\end{array}$ & $\begin{array}{c}2.29^{*} \\
(-4.26,-0.32) \\
-3.62^{*} \\
(-6.87,-0.37)\end{array}$ \\
\hline
\end{tabular}

\footnotetext{
${ }^{*} \mathrm{p}<0.05 ;{ }^{*} \mathrm{p}<0.01 ;{ }^{\Delta}$ all regression analysis include fixed effects for quarter and treatment centre; ${ }^{\phi}$ Robust confidence intervals within parentheses, clustered on treatment centre

tica: ticagrelor; crude: analysis without any covariates; age adj: age adjusted analysis; all cov: analysis including all covariation (Table 7.1); 2SLS: two stage least squares; N: number of patients.
} 


\section{ACKNOWLEDMENTS}

I am thankful to many people who have inspired, supported and encouraged me on the journey towards finalising this thesis. With the risk of forgetting someone, I would especially like to express my gratitude to the following:

Martin Henriksson, supervisor and former co-worker, for supporting, encouraging and guiding me from the start to the finish of my PhD studies. Working with and learning from you was a key reason for me coming to Sweden after my studies in York. Discussions with you are always rewarding and energising and I hope that we will continue to work together on unanswered questions, both in an academic setting and over beers.

Lars-Åke Levin, co-supervisor, for helping make this thesis possible in the first place and for guiding me throughout the process. Thank you for sharing your vast knowledge of pharmacoeconomics and for all the educational and engaging discussions we have had over the years.

Magnus Janzon, co-supervisor, for guiding me and sharing part of your extensive knowledge on cardiology with me. I'm grateful for and inspired by your ability and willingness to find time in your busy schedule to support me and the projects we have been collaborating on.

Jonathan Siverskog, $\mathrm{PhD}$ colleague, for an enjoyable and educational collaboration on the comparative effectiveness study of ticagrelor. I have probably learnt more from you than from all the statistical courses I have taken over the years, and I would probably still be trying to implement the data and analyses in $\mathrm{R}$ had it not been for your support. Always a joy to discuss work or non-work related topics.

Erik Grönqvist, professor and "master of metrics", for collaboration and excellent guidance on the instrumental variable analysis. Thank you for sharing your extensive knowledge and for initiating me into applied econometrics.

Mattias Aronsson, $\mathrm{PhD}$ colleague and former co-worker, for great times together both academically as well as over burgers and beers. Always a pleasure and humbling to work with you.

Lars Bernfort, colleague at LiU, for comments on earlier version of the thesis and a couch to sleep on in the hour of need. Always a pleasure to talk and catch-up.

Martin, Lars, Mattias, Jonathan, LÅ and others joining the lunch crew for enjoyable and educational times at Ming Palace; a highlight of all days at LiU. 
Thor-Henrik Brodtkorb, teacher and friend, for introducing me to health economics and getting me started on this journey by encouraging me to get an MSc at the University of York. I greatly enjoy our discussions and spending time together in the outdoors.

Tomas Davidson and other LiU colleagues, for taking the time to read and provide relevant comments on an earlier versions of this thesis.

Lena Hector, for always having the answer and helping to sort out countless of administrative challenges.

All current and former colleagues at the Division of Health Care Analysis, for creating a fun and inspiring environment that has been a pleasure to take part in. I am thankful for the always welcoming attitude during my irregular visits.

Daniel Sperber, friend and former housemate, for your friendship and all you have taught me during and after our time in York. Conversations with you are always (thought) provoking and few people have shaped my view of the world (or beer) as much as you.

Karl Claxton and Mark Sculpher, for providing excellent teaching and a solid foundation for economic analyses within health care, and for great collaboration on Paper 2.

Tomas Jernberg, for collaboration and data for our study on regional variation of ticagrelor treatment based data from the SWEDEHEART registry.

Christoffer Holmberg, my manager, for looking out for my interests and helping to ensure that I had the possibility and time to conduct my PhD studies. Thanks you for sharing you vast knowledge within oncology as well as for keeping me updated on mainstream as well as fringe trends in Swedish politics.

Current and former BMS and AZ colleagues, for making it fun and interesting to go to work every day and for helping me to understand the process of pharmaceutical development, the regulatory process and reimbursement systems. Thank you for your support and understanding while I was working on and finalising this thesis.

Kai \& Arthur, my sons, you certainty did not speed up the process of getting this thesis done, but I would not have it any other way! Thank you for enriching my life and reminding me what truly matters in life. Jeg elsker jer.

Hanna, my wife and life partner, for all the love, support and happiness you bring me. You make me aspire to be a better person and I treasure the privilege of sharing my life and everyday experiences with you. Your support was instrumental to getting this thesis finalised, a debt I will be working off for years. I love you, you are the best. 
Friends and family, for always being there and for keeping in touch despite the countless of times I have moved and numerous different phone numbers I have had. Those of you still here will surely be there in the years to come, something I am forever grateful for. 


\section{REFERENCES}

1. Lichtenberg FR. The impact of biomedical innovation on longevity and health. Nord J Heal Econ 2017; 5: 45-57.

2. Lichtenberg F, Pettersson B. The impact of pharmaceutical innovation on longevity and medical expenditure in Sweden, 1997-2010: evidence from longitudinal, disease- level data. Econ Innov New Technol 2014; 23: 239 273.

3. Lakdawalla DN, Sun EC, Jena AB, et al. An economic evaluation of the war on cancer. J Health Econ 2010; 29: 333-346.

4. Grabowski BDC, Lakdawalla DN, Goldman DP, et al. The Large Social Value Resulting From Use Of Statins Warrants Steps To Improve Adherence And Broaden Treatment. Health Aff 2012; 31: 2276-83.

5. DiMasi JA. Assessing Pharmaceutical Research and Development Costs. JAMA Intern Med 2018; 178: 587.

6. Wouters OJ, McKee M, Luyten J. Estimated Research and Development Investment Needed to Bring a New Medicine to Market, 2009-2018. JAMA 2020; 323: 844-853.

7. European Medicines Agency. From laboratory to patient: the journey of a centrally authorised medicine. 2019.

8. WHO Europe. Medicines reimbursement policies in Europe. Copenhagen, Denmark, 2018.

9. Drummond MF, Sculpher MJ, Torrance GW, et al. Methods for the Economic Evaluation of Health Care Programmes. Third Edit. New York: Oxford University Press, 2005.

10. Lundqvist A, Andersson E, Ahlberg I, et al. Socioeconomic inequalities in breast cancer incidence and mortality in Europe - A systematic review and meta-analysis. Eur J Public Health 2016; 26: 804-813.

11. Wennberg J, Gittelsohn A. Small Area Variations in Heatlh Care Delivery. Science (80-) 1973; 182: 1102-1108.

12. Wennberg JE. Unwarranted variations in healthcare delivery: Implications for academic medical centres. Br Med J 2002; 325: 961-964.

13. Cutler D, Skinner J, Stern AD, et al. Physician Beliefs and Patient Preferences: A New Look at Regional Variation in Health Care Spending. NBER Work Pap Ser; 19320.

14. Johansson N, Jakobsson N, Svensson M. Regional variation in health care utilization in Sweden - the importance of demand-side factors. $B M C$ Health Serv Res 2018; 18: 1-9.

15. Mason J, Freemantle N, Nazareth I, et al. When is it cost-effective to change the behavior of health professionals? JAMA 2001; 286: 2988-92.

16. Horton R. Public health research in the UK: the era of implementation. Lancet 2015; 386: 1.

17. Heinsoo T, Ramsberg J, Linnér L, et al. Tydligare ansvar och regler för 
läkemedel - Slutbetänkande av Läkemedelsutredningen SOU2018:89.

Stockholm, Sweden: Statens Offentliga Utredningar, 2018.

18. Wallström S, Andersson F, Lewin K, et al. Pris, tillgång och service fortsatt utveckling av läkemedels- och apoteksmarknaden SOU2012:75.

Stockholm, Sweden: Statens Offentliga Utredningar, 2012.

19. Leopold C, Vogler S, Mantel-Teeuwisse AK, et al. Differences in external price referencing in Europe - A descriptive overview. Health Policy (New York) 2012; 104: 50-60.

20. European Commission. Directive 2004/27/EC. Off J Eur Union 2004; L 136: 34-57.

21. Danzon PM, Towse A. Theory and Implementation of Differential Pricing for Pharmaceuticals. In: Maskus KE, Reichman JH (eds) International Public Goods and Transfer of Technology Under a Globalized Interllectual Property Regime. Cambridge: Cambridge University Press, 2005, pp. 425456.

22. Kaul I, Mendoza RU. Advancing the concept of Public Goods. In: Kaul I, Conceicai P, Le Goulven K, et al. (eds) Providing Global Public Goods: Managing Globalization. Cary, NC, USA: Oxford University Press, 2003, pp. 78-112.

23. Moon S. Medicines as Global Public Goods: The Governance of Technological Innovation in the New Era of Global Health. Glob Heal Gov; II.

24. Sandler T. Intergenerational Public Goods: Strategies, Efficiency and Institutions. In: Kaul I, Grungberg I, Stern M (eds) Global public goods. New York: Oxford University Press, 1999, pp. 20-50.

25. Pammolli F, Magazzini L, Riccaboni M. The productivity crisis in pharmaceutical R\&D. Nat Rev Drug Discov 2011; 10: 428-38.

26. Wong CH, Siah KW, Lo AW. Estimation of clinical trial success rates and related parameters. Biostatistics 2019; 20: 273-286.

27. M. H, D.W. T, J.L. C, et al. Clinical development success rates for investigational drugs. Nat Biotechnol 2014; 32: 40-51.

28. Mestre-ferrandiz J, Sussex J, Towse A. THE R\&D COST OF A NEW MEDICINE. London, UK: Office of Health Economics, 2012.

29. DiMasi JA, Grabowski HG, Hansen RW. Innovation in the pharmaceutical industry: New estimates of R\&D costs. J Health Econ 2016; 47: 20-33.

30. Avaorn J. The \$2.6 Billion Pill - Methodologic and Policy Considerations. N Engl J Med 2015; 372: 1877-1879.

31. Goozner M. A Much-Needed Corrective on Drug Development Costs. JAMA Intern Med 2017; 177: 1575-1576.

32. Prasad V, Mailankody S. Research and development spending to bring a single cancer drug to market and revenues after approval. JAMA Intern Med 2017; 177: 1569-1575.

33. van der Gronde T, Pieters T. Assessing Pharmaceutical Research and Development Costs. JAMA Intern Med 2018; 178: 587-588.

34. Cutler D. Pricing in the market for anticancer drugs. JAMA 2020; 323: 139162. 
35. Tandvårds- och läkemedelsförmånsverkets (TLV). PPRI Pharma Profile Sweden. Stockholm, Sweden, 2017.

36. Granlund D. Price and welfare effects of a pharmaceutical substitution reform. J Health Econ 2010; 29: 856-865.

37. Lakdawalla D, Sood N. The Welfare Effects of Public Drug Insurance. NBER Work Pap Ser; 13501.

38. Carlton DW, Perloff JM. Patents and Technological Change. In: Modern Industrial Organization. USA: Pearson Addison Wesley, 2005.

39. Persson U, Svensson J, Pettersson B. A New Reimbursement System for Innovative Pharmaceuticals Combining Value-Based and Free Market Pricing. Appl Heal Econ Heal Policy 2012; 10: 217-225.

40. Haynes B. Can it work? Does it work? Is it worth it? Gen Pract 1999; 319: 652-653.

41. Soni PD, Hartman HE, Dess RT, et al. Comparison of population-based observational studies with randomized trials in oncology. J Clin Oncol 2019; 37: 1209-1216.

42. Fanaroff AC, Califf RM, Harrington RA, et al. Randomized Trials Versus Common Sense and Clinical Observation: JACC Review Topic of the Week. J Am Coll Cardiol 2020; 76: 580-589.

43. Mathes T, Rombey T, Kuss O, et al. No inexplicable disagreements between real-world data-based nonrandomized controlled studies and randomized controlled trials were found. J Clin Epidemiol 2021; 133: 1-13.

44. Anglemyer A, Horvath H, Bero L. Healthcare outcomes assessed with observational study designs compared with those assessed in randomized trials (Review). Cochrane Database Syst Rev; 29.

45. OECD, Union E. Health at a Glance: Europa 2020 State of health in the EU cycle. Paris, France: OECD Publishing, 2020.

46. Akehurst RL, Abadie E, Renaudin N, et al. Variation in Health Technology Assessment and Reimbursement Processes in Europe. Value Heal 2017; 20: 67-76.

47. Heintz E, Gerber-Grote A, Ghabri S, et al. Is There a European View on Health Economic Evaluations? Results from a Synopsis of Methodological Guidelines Used in the EUnetHTA Partner Countries. Pharmacoeconomics 2016; 34: 59-76.

48. Maynou L, Cairns J. What is driving HTA decision-making? Evidence from cancer drug reimbursement decisions from 6 European countries. Health Policy (New York) 2019; 123: 130-139.

49. Vogler S, Schneider P, Lepuschütz L. Impact of changes in the methodology of external price referencing on medicine prices: discrete-event simulation. Cost Eff Resour Alloc 2020; 18: 1-9.

50. Drummond MF, Sculpher MJ, Tarrance; George W, et al. Methods for the Economic Evaluation of Health Care Programmes. Fourth edi. Oxford: Oxford University Press, 2015.

51. Claxton KP, Walker S, Palmer SJ, et al. Appropriate Perspectives for Health Care Decisions. CHE Research Paper 54. CHE Research Paper 54, Yrok, UK, 2010. 
52. Stinnett AA, Mullahy J. Net Health Benefits: A New Framework for the Analysis of Cost-Effectiveness Analysis Uncertainty in. Med Decis Mak 1998; 18: S68-80.

53. Tambour M, Zethraeus N, Johannesson M. A note on confidence intervals in cost-effectiveness analysis. Int J Technol Assess Heal Care 1998; 14: 46771.

54. Claxton K. Exploring uncertainty in cost-effectiveness analysis. Pharmacoeconomics 2008; 26: 781-798.

55. Briggs A, Sculpher M, Claxton K. Decision modelling for health economic evaluation. First. Oxford: Oxford unversity press, 2006.

56. Claxton K. The irrelevance of inference: a decision-making approach to the stochastic evaluation of health care technologies. J Health Econ 1999; 18: 341-64.

57. Griffin SC, Claxton KP, Palmer SJ, et al. Dangerous omissions: the consequences of ignoring decision uncertainty. Health Econ 2011; 224: 212-224.

58. Claxton K, Palmer S, Longworth L, et al. Informing a decision framework for when NICE should recommend the use of health technologies only in the context of an appropriately designed programme of evidence development. Health Technol Assess (Rockv) 2012; 16: 1-323.

59. Carone G, Schwierz C, Xavier A. Cost-containment policies in public pharmaceutical spending in the EU. Econ Pap; 461.

60. Statens Legemiddelverk. Maksimalpris på legemidler, https://legemiddelverket.no/offentligfinansiering/maksimalpris\#fastsettelse-av-maksimalpris (2019, accessed 20 April 2021).

61. Claxton K. Value based pricing for NHS drugs: an opportunity not to be missed? BMJ 2008; 336: 251-254.

62. Persson U. Value Based Pricing in Sweden: Lessons for Design? OHE Semin Brief 2012; 12: 1-11.

63. Danzon PM. Price Discrimination for Pharmaceuticals: Welfare Effects in the US and the EU. Int J Econ Bus 1997; 4: 301-322.

64. DANZON P, TOWSE A, MESTRE-FERRANDIZ J. VALUE-BASED DIFFERENTIAL PRICING: EFFICIENT PRICES FOR DRUGS IN A GLOBAL CONTEXT. Health Econ 2015; 24: 294-301.

65. Garau M, Towse A. Pharmaceutical pricing in Europe: is differential pricing a win-win solution? Health Econ.

66. Towse A, Pistollato M, Mestre-Ferrandiz J, et al. European Union Pharmaceutical Markets: A Case for Differential Pricing? Int J Econ Bus 2015; 22: 263-275.

67. Kanavos P, Vandoros S, Irwin R, et al. Differences in costs of and access to pharmaceutical products in the EU. 2011.

68. Kanavos P, Nicod E, Espin J, et al. Short- and Long-Term Effects of ValueBased Pricing vs . External Price Referencing. EMIN€T, 2010.

69. Danzon PM, Epstein AJ. Effects of regulation on drug launch and pricing in interdependent markets. NBER Work Pap Ser 2008; 14041: 1-61. 
70. Tandvårds- och läkemedelsförmånsverkets (TLV). Arsredovisning 2020. Stockholm, Sweden, 2020.

71. Liliemark J, Lööf L, Befrits G, et al. Betalningsviljan för nya läkemedel bygger på etiska principer. Lakartidningen 2016; 113: 1-5.

72. Janusinfo. Så arbetar vi, https://janusinfo.se/nationelltinforandeavlakemedel/saarbetarvi.4.4771ab77 16298ed82ba979d4.html (accessed 20 April 2021).

73. Riksdagen. Prioriteringar inom hälso? och sjukvården Proposition 1996/97:60.

74. Tandvårds- och läkemedelsförmånsverkets (TLV). Underlag för beslut om subvention - Omprövning - Cerezyme (imiglukeras) och Vpriv (velaglukeras alfa) Dnr 1961/2015. 2016.

75. Tandvårds- och läkemedelsförmånsverkets (TLV). Ny tillämpning av etiska plattformen, https:/www.tlv.se/lakemedel/halsoekonomi/ny-tillampningav-etiska-plattformen.html\# (2020, accessed 20 April 2021).

76. Tandvårds- och läkemedelsförmånsverkets (TLV). Tandvårds- och läkemedelsförmånsverkets allmänna råd TLVAR 2017:1. 2017; 1-5.

77. Wennberg J. Time to tackle unwarranted variations in practice. BMJ 2011; 342: 687-690.

78. Jönsson B, steen Carlsson K. The Value of New Medicines. Stockholm, Sweden: SNS Förlag, 2014.

79. Kemetli L, Erik Rutqvist L, Jonsson H, et al. Temporal trends in the use of adjuvant systemic therapy in breast cancer - A population based study in Sweden 1976-2005. Acta Oncol (Madr) 2009; 48: 59-66.

80. Wilking U, Jönsson B, Wilking N, et al. Trastuzumab use in breast cancer patients in the six Health Care Regions in Sweden. Acta Oncol (Madr) 2010; 49: 844-850.

81. Neovius M, Wettermark B, Cars T, et al. Small-area variations in sales of TNF inhibitors in Sweden between 2000 and 2009. Scand J Rheumatol 2010; $1-8$.

82. Jönsson B, Wilking N. New cancer drugs in Sweden: Assessment, implementation and access. J Cancer Policy 2014; 2: 45-62.

83. Calara PS, Althin R, Steen K. Regional Differences in the Prescription of Biologics for Psoriasis in Sweden: A Register-Based Study of 4168 Patients. BioDrugs.

84. Moorkens E, Simoens S, Troein P, et al. Different Policy Measures and Practices between Swedish Counties Influence Market Dynamics: Part 2 Biosimilar and Originator Etanercept in the Outpatient Setting. BioDrugs 2019; 33: 299-306.

85. Beckmann K, Garmo H, Nilsson P, et al. Radical radiotherapy for prostate cancer: patterns of care in Sweden 1998-2016. Acta Oncol (Madr) 2020; 59: 549-557.

86. Varian HR. Intermediate Microeconomics: A Modern Approach. 8th Intern. New York: W. W. Norton \& Co., 2010.

87. Martin Chalkley. Contracts, information and incentives in health care. In: Jones A (ed) The Elgar companion to Health Economics. Edward Elgar 
Publishing, 2006.

88. Mccabe C, Claxton K, Culyer AJ. The NICE Cost-Effectiveness Threshold. Pharmacoeconomics 2008; 26: 733-744.

89. Rawlins MD, Culyer AJ. National Institute for Clinical Excellence and its value judgments. BMJ 2004; 329: 224-227.

90. Rawlins M, Barnett D, Stevens A. Pharmacoeconomics: NICE's approach to decision-making. Br J Clin Pharmacol 2010; 70: 346-9.

91. Culyer a., McCabe C, Briggs A, et al. Searching for a threshold, not setting one: the role of the National Institute for Health and Clinical Excellence. $J$ Heal Serv Res Policy 2007; 12: 56-58.

92. Läkemedelsförmånsnämndens (LFNAR). Läkemedelsförmånsnämndens allmänna råd. Stockholm, Sweden, 2003.

93. Henriksson M, Siverskog J, Johannesen K, et al. Tröskelvärden och kostnadseffektivitet - innebörd och implikationer för ekonomiska utvärderingar och beslutsfattande i hälso- och sjukvården. 2018:3, Sweden: Centrum för utvärdering av medicinsk teknologi Tröskelvärden, 2018.

94. Persson U. Ett QALY är värt mer än två miljoner kronor. Lakartidningen 2018; 115: 2016-2019.

95. Svensson M, Hultkrantz L. A Comparison of Cost-Benefit and CostEffectiveness Analysis in Practice: Divergent Policy Practices in Sweden. Nord J Heal Econ; 5. Epub ahead of print 2017. DOI: 10.5617/NJHE.1592.

96. Siverskog J, Henriksson M. On the role of cost-effectiveness thresholds in healthcare priority setting. Int J Technol Assess Health Care 2021; 1-5.

97. Siverskog J, Henriksson M. Estimating the marginal cost of a life year in Sweden's public healthcare sector. Eur J Heal Econ 2019; 20: 751-762.

98. Tandvårds- och läkemedelsförmånsverkets (TLV). TLVAR 2015:1 Allmäna råd. $2015 ; 1-4$.

99. Camejo RR, McGrath C, Miraldo M, et al. Distribution of health-related social surplus in pharmaceuticals: An estimation of consumer and producer surplus in the management of high blood lipids and COPD. Eur J Heal Econ 2014; 15: 439-445.

100. Grabowski H, Vernon J. The determinants of pharmaceutical research and development expenditures. J Evol Econ 2000; 10: 201-215.

101. Civan A, Maloney MT. The Effect of Price on Pharmaceutical R\&D. $B E J$ Econom Anal Policy 2009; 9: 1-22.

102. Gaessler F, Wagner S. Patents, Data Exclusivity, and the Development of New Drugs. Ration Comperirion 2019; 176: 1-50.

103. Malmberg C. $R \& D$ and financial systems: the determinants of $R \& D$ expenditures in the Swedish pharmaceutical industry. Lund, Sweden: Centre for Innovation, Research and Competence in the Learning Economy (CIRCLE), 2008.

104. Vernon $\mathrm{J}$ a. Examining the link between price regulation and pharmaceutical R\&D investment. Health Econ 2005; 14: 1-16.

105. Budish E, Roin BN, Williams H. Do firms underinvest in long-term research? Evidence from cancer clinical trials. Am Econ Rev 2015; 105 : 
2044-2085.

106. Lakdawalla DN, Goldman DP, Michaud P-C, et al. U.S. Pharmaceutical Policy In A Global Marketplace. Health Aff 2008; 28: 138-151.

107. Sood N, Vries H De, Gutierrez I, et al. The Effect Of Regulation On Pharmaceutical Revenues: Experience In Nineteen Countries. Health Aff 2009; 28: 125-138.

108. Danzon PM. Making Sense of Drug Prices. Regulation 1998; 23: 56-63.

109. Shields L. The prospects for sufficientarianism. Utilitas 2011; 24: 474480.

110. Danzon PM, Towse A, Mulcahy AW. Setting cost-effectiveness thresholds as a means to achieve appropriate drug prices in rich and poor countries. Health Aff (Millwood) 2011; 30: 1529-38.

111. Lichtenberg FR. Pharmaceutical companies' variation of drug prices within and among countries can improve long-term social well-being. Health Aff 2011; 30: 1539-44.

112. Malueg D a., Schwartz M. Parallel imports, demand dispersion, and international price discrimination. J Int Econ 1994; 37: 167-195.

113. Paulden M. Strategic Behaviour and the Cost-Effectiveness Threshold: A New Conceptual Model. In: Pandey H, Paulden M, McCabe C (eds) Theoretical models of the cost-effectiveness threshold, value assessment, and health care system sustainability. Alberta, Canada: INSTITUTE OF HEALTH ECONOMICS, 2018.

114. Lundin D, Ramsberg J. Dynamic Cost-Effectiveness: A More Efficient Reimbursement Criterion. Forum Health Econ Policy; 11.

115. Jena AB, Philipson T. Cost-effectiveness as a price control. Health Aff 2007; 26: 696-703.

116. Refoios Camejo R, McGrath C, Herings R. A dynamic perspective on pharmaceutical competition, drug development and cost effectiveness. Health Policy 2011; 100: 18-24.

117. Claxton K. OFT, VBP: QED? Health Econ 2007; 558: 545-558.

118. Grootendorst P, Hollis A, Edward A. Patents and Other Incentives for Pharmaceutical Innovation. In: Encyclopedia of Health Economics. Elsevier Inc., 2014, pp. 434-442.

119. Bouchard R a, Lemmens T. Privatizing biomedical research-a 'third way'. Nat Biotechnol 2008; 26: 31-6.

120. Cockburn IM, Lanjouw JO, Schankerman M. Patents and the global diffusion of new drugs. Am Econ Rev 2016; 106: 136-164.

121. Lakdawalla D, Sood N. Health insurance as a two-part pricing contract. $J$ Public Econ 2013; 102: 1-12.

122. Danzon PM, Towse A. Differential pricing for pharmaceuticals: reconciling access, R\&D and patents. Int J Health Care Finance Econ 2003; 3: 183-205.

123. Mahlich J, Sindern J, Suppliet M. Cross-national drug price comparisons with economic weights in external reference pricing in Germany. Expert Rev Pharmacoecon Outcomes Res 2019; 19: 37-43.

124. Hubbard T, Love J. A new trade framework for global healthcare R\&D. 
PLoS Biol 2004; 2: E52.

125. Love J, Hubbard T. Prizes for innovation of new medicines and vaccines. Ann Health Law 2009; 18: 155-86.

126. Basheer $\mathrm{S}$. The Invention of an Investment Incentive for Pharmaceutical Innovation. $J$ World Intellect Prop 2012; 15: 305-364.

127. Grabowski H. Increasing R\&D incentives for neglected diseases: Lesson from the Orphan Drugs ACT. In: Maskus KE, Reichman JH (eds) International Public Goods and Transfer of Technology Under a Globalized Interllectual Property Regime. Cambridge: Cambridge University Press, 2005, pp. 457-480.

128. Grootendorst P V, Edwards A. Patents and Other Incentives for Pharmaceutical Innovation. In: Culyer AJ (ed) Encyclopedia of Health Economics. Elsevier Ltd., pp. 434-442.

129. Johannesen KM, Henriksson M. Getting value today and incentivising for the future : Pharmaceutical development and healthcare policies. Nord $J$ Heal Econ 2017; 5: 77-96.

130. Socialdepartementet. Godkannande av en overenskommelse om utveckling av den svenska takprismodellen for lakemedel S2013/6192/FS.

131. Olovsson M, Ekblom A. Betänkandet SOU 2012:75 Pris, tillgång och service - fortsatt utveckling av läkemedels- och apoteksmarknaden. Dnr 2012/7587/FS.

132. Ferrario A, Dedet G, Humbert T, et al. Strategies to achieve fairer prices for generic and biosimilar medicines. BMJ 2020; 368: 1-5.

133. WOUTERS OJ., KANAVOS PG, McKEE M. Comparing Generic Drug Markets in Europe and the United States: Prices, Volumes, and Spending. Milbank Q 2017; 95: 554-601.

134. NICE. Single technology appraisal (STA) timeline, https://www.nice.org.uk/about/what-we-do/our-programmes/niceguidance/technology-appraisal-guidance/process/sta-timeline (2018, accessed 20 April 2021).

135. SMC. Timelines \& submission scheduling, https://www.scottishmedicines.org.uk/making-a-submission/timelinessubmission-scheduling/ (2020, accessed 20 April 2021).

136. Danish Medicines Council. The Danish Medicines Council 's process guide for assessing new pharmaceuticals. 2021.

137. NICE. Guide to the processes of technology appraisal. 2018.

138. Kaltenthaler E, Tappenden P, Booth A, et al. Comparing methods for full versus single technology appraisal: A case study of docetaxel and paclitaxel for early breast cancer. Health Policy (New York) 2008; 87: 389400.

139. Allan Wailoo and Caroline Pickstone. A review of the nice single technology appraisal process. Sheffield, UK, 2008.

140. Walker S, Palmer S, Sculpher M. The role of NICE technology appraisal in NHS rationing. Br Med Bull 2007; 81-82: 51-64.

141. Devlin N, Parkin D. Does NICE have a cost-effectiveness threshold and what other factors influence its decisions? A binary choice analysis. Health 
Econ 2004; 13: 437-52.

142. Dakin H, Devlin N, Feng Y, et al. The influence of cost-effectiveness and other factors on nice decisions. Health Econ 2015; 24: 1256-1271.

143. Svensson M, Nilsson FOL, Arnberg K. Reimbursement Decisions for Pharmaceuticals in Sweden: The Impact of Disease Severity and Cost Effectiveness. Pharmacoeconomics 2015; 33: 1229-36.

144. Johannesen KM, Claxton K, Sculpher MJ, et al. How to design the cost effectiveness appraisal process of new healthcare technologies to maximise population health : A conceptual framework. Health Econ 2018; 27: e41e54.

145. Griffin S, Welton NJ, Claxton K. Exploring the research decision space: the expected value of information for sequential research designs. Med Decis Making 2010; 30: 155-62.

146. Gamba S, Pertile P, Vogler S. The impact of managed entry agreements on pharmaceutical prices. Heal Econ (United Kingdom) 2020; 29: 47-62.

147. Regionernas samverkansmodell för läkemedel. NT-rådets process för förberedande av rekommendationer gällande PD1-och PD-L1-hämmare. 2020.

148. Socialstyrelsen. Läkemedelsförsäljning $i$ Sverige - analys och prognos 2020-2023. 2020.

149. Fenwick E, Claxton K, Sculpher M. The value of implementation and the value of information: combined and uneven development. Med Decis Mak 2008; 28: 21-32.

150. Andronis L, Barton P. Adjusting Estimates of the Expected Value of Information for Implementation: Theoretical Framework and Practical Application. Med Decis Mak 2015; 1-12.

151. Willan AR, Eckermann S. Optimal clinical trial design using value of information methods with imperfect implementation. Health Econ 2010; 561: 549-561.

152. Hoomans T, Ament AJ, Evers SM, et al. Implementing guidelines into clinical practice: What is the value? J Eval Clin Pract 2011; 17: 606-614.

153. Faria R, Walker S, Whyte S, et al. How to invest in getting cost-effective technologies into practice? A framework for value of implementation analysis applied to novel oral anticoagulants. Med Decis Mak 2016; 37: $148-161$.

154. Walker S, Faria R, Whyte S, et al. Getting cost-effective technologies into practice: the value of implementation. Report on framework for valuing implementation initiatives. York, UK, 2014.

155. Johannesen K, Janzon M, Jernberg T, et al. Subcategorizing the Expected Value of Perfect Implementation to Identify When and Where to Invest in Implementation Initiatives. Med Decis Mak 2020; 40: 327-338.

156. Valgimigli M, Bueno H, Byrne RA, et al. 2017 ESC focused update on dual antiplatelet therapy in coronary artery disease developed in collaboration with EACTS. Eur J Cardio-thoracic Surg 2018; 53: 34-78.

157. Collet J-P, Thiele H, Barbato E, et al. 2020 ESC Guidelines for the management of acute coronary syndromes in patients presenting without 
persistent ST-segment elevation. Eur Heart J 2021; 42: 1289-1367.

158. Socialstyrelsen. Nationella riktlinjer för hjärtsjukvård. Socialstyrelsen, 2018.

159. European Medicines Agency (EMA). Brilique - ticagrelor - Authorisation details, http://www.ema.europa.eu/ema/index.jsp?curl=pages/medicines/human/me dicines/001241/human_med_001398.jsp\&mid=WC0b01ac058001d125 (2010, accessed 15 September 2017).

160. Wallentin L, Becker RC, Budaj A, et al. Ticagrelor versus Clopidogrel in Patients with Acute Coronary Syndromes. N Engl J Med 2009; 361: 104557.

161. Tandvårds- och läkemedelsförmånsverkets (TLV). BESLUT 3903/2010. Stockholm, Sweden, 2011.

162. Socialstyrelsen. Komplettering av Nationella Nationella riktlinjer för hjärtsjukvård 2008 och strokesjukvård 2009 - stöd för styrning och ledning slutlig version. Stockholm, Sweden, 2011.

163. Henriksson M, Nikolic E, Ohna A, et al. Ticagrelor treatment in patients with acute coronary syndrome is cost-effective in Sweden and Denmark. Scand Cardiovasc J 2014; 48: 138-147.

164. Jernberg T, Attebring MF, Hambraeus K, et al. The Swedish Web-system for Enhancement and Development of Evidence-based care in Heart disease Evaluated According to Recommended Therapies (SWEDEHEART). Heart 2010; 96: 1617-1621.

165. Harnek J, Nilsson J, Friberg O, et al. The 2011 outcome from the Swedish Health Care Registry on Heart Disease (SWEDEHEART). Scand Cardiovasc J 2013; 47: 1-10.

166. Jernberg T. SWEDEHEART Annual report 2019. Uppsala, Sweden: Tomas Jernberg. Danderyd Hospital, Stockholm, 2020.

167. Roffi M, Patrono C, Collet J-P, et al. 2015 ESC Guidelines for the management of acute coronary syndromes in patients presenting without persistent ST-segment elevation. Eur Heart J 2016; 37: 267-315.

168. Cutler DM, Long G, Berndt ER, et al. The Value Of Antihypertensive Drugs: A Perspective On Medical Innovation. Health Aff 2007; 26: $97-$ 111.

169. Garrison LP, Veenstra DL. The economic value of innovative treatments over the product life cycle: The case of targeted trastuzumab therapy for breast cancer. Value Heal 2009; 12: 1118-1123.

170. Goldman BDP, Lakdawalla DN, Malkin JD, et al. The Benefits From Giving Makers Of Conventional 'Small Molecule' Drugs Longer Exclusivity Over Clinical Trial Data. Health Aff 2011; 30: 84-89.

171. Goldman DP, Jena AB, Lakdawalla DN, et al. The value of specialty oncology drugs. Health Serv Res 2010; 45: 115-132.

172. Grabner M, Johnson W, Abdulhalim AM, et al. The Value of Atorvastatin Over the Product Life Cycle in the United States. Clin Ther 2011; 33: 1433-1443.

173. Lindgren P, Jönsson B. Cost-effectiveness of statins revisited: lessons 
learned about the value of innovation. Eur J Health Econ 2012; 13: 44550.

174. Sahlén A, Varenhorst C, Lagerqvist B, et al. Outcomes in patients treated with ticagrelor or clopidogrel after acute myocardial infarction:

Experiences from SWEDEHEART registry. Eur Heart J 2016; 37: 33353342 .

175. Szummer K, Montez-Rath ME, Alfredsson J, et al. Comparison Between Ticagrelor and Clopidogrel in Elderly Patients with an Acute Coronary Syndrome: Insights from the SWEDEHEART Registry. Circulation 2020; 142: $1700-1708$.

176. Lee Y, Lim YH, Park Y, et al. Real-World Bleeding and Ischemic Events in Asian Patients on P2Y12-Inhibitors After Percutaneous Coronary Intervention: A National Claims Data Analysis. Adv Ther.

177. You SC, Rho Y, Bikdeli B, et al. Association of Ticagrelor vs Clopidogrel With Net Adverse Clinical Events in Patients With Acute Coronary Syndrome Undergoing Percutaneous Coronary Intervention. JAMA 2020; 324: 1640-1650.

178. Zocca P, van der Heijden LC, Kok MM, et al. Clopidogrel or ticagrelor in acute coronary syndrome patients treated with newer-generation drugeluting stents: CHANGE DAPT. Eurointervention 2017; 13: 1-9.

179. Olier I, Sirker A, Hildick-smith DJR, et al. Association of different antiplatelet therapies with mortality after primary percutaneous coronary intervention. Heart 2018; 104: 1683-1690.

180. Lindholm L. Att Beräkna kostnadseffektivitet. In: Carlsson P, Waldau S (eds) Att välja rättvist. Lund, Sweden: Studentlittetatur AB, 2013.

181. Grimaldi-bensouda L, Danchin N, Dallongeville J, et al. Effectiveness of new antiplatelets in the prevention of recurrent myocardial infarction. Heart 2018; 104: 1583-1592.

182. Rezaei SS, Gleiss A, Reichardt B, et al. Use of Clopidogrel, Prasugrel, or Ticagrelor and Patient Outcome after Acute Coronary Syndrome in Austria from 2015 to 2017. J Clin Med 2020; 9: 3398.

183. De Luca L, Zeymer U, Claeys MJ, et al. Comparison of P2Y12 receptor inhibitors in patients with ST-elevation myocardial infarction in clinical practice: a propensity score analysis of five contemporary European registries. Eur Hear J - Cardiovasc Pharmacother 2020; 7: 94-103.

184. Wang CA, Hsieh YC, Huang CY, et al. Comparison between ticagrelor versus clopidogrel in long term outcomes of Taiwanese diabetic subjects with acute coronary syndrome undergoing successful revascularization: From TSOC ACS-DM registry. Medicine (Baltimore) 2020; 99: 1-8.

185. Jernberg T, Held C, Hambraeus K, et al. Årsrapport SWEDEHEART 2012.

186. Grönqvist E. Att studera effekter av medicinska interventioner $i$ klinisk vardag. Uppsala, Sweden, 2020.

187. Laborde-Castérot H, Agrinier N, Thilly N. Performing both propensity score and instrumental variable analyses in observational studies often leads to discrepant results: a systematic review. J Clin Epidemiol 2015; 68: 1232-1240. 
188. Chen Y, Briesacher BA. Use of instrumental variable in prescription drug research with observational data: a systematic review. J Clin Epidemiol 2011; 64: 687-700.

189. Angrist J, Pischke J-S. Mostly Harmless Econometrics: An Empiricist's Companion. Princeton, New Jersey, USA: Princeton University Press, 2009.

190. Cinelli C, Forney A, Pearl J. A Crash Course in Good and Bad Controls. SSRN Electron J 2020; 1-19.

191. Nye Metoder. Metodevurderinger, https://nyemetoder.no/omsystemet/metodevurderinger (2021, accessed 20 April 2021).

192. OECD. Pharmaceutical spending (idicator), https://data.oecd.org/healthres/pharmaceutical-spending.htm (2021, accessed 20 April 2021).

193. Tandvårds- och läkemedelsförmånsverkets (TLV). Apoteksmarknadens bruttoresultat 2012 - en analys av parallellimportens betydelse.

Stockholm, Sweden, 2014.

194. Jervelund C, Brenøe S, Wilke S. The economic impact of parallel imports of pharmaceuticals - An assessment of savings in Denmark. Copenhagen, Denmark, 2019.

195. Centers for Medicare \& medicaid Services. Most Favored Nation Model, https://innovation.cms.gov/innovation-models/most-favored-nation-model (2021, accessed 20 April 2021).

196. Tandvårds- och läkemedelsförmånsverkets (TLV). Underlag för beslut $i$ landstingen - Kymriah (tisagenlekleucel). Stockholm, Sweden, 2019.

197. Tandvårds- och läkemedelsförmånsverkets (TLV). Underlag för beslut $i$ landstingen - Yescarta (axicabtagene ciloleucel). Stockholm, Sweden, 2018.

198. Tandvårds- och läkemedelsförmånsverkets (TLV). Underlag för beslut om subvention - hepatit C. Stockholm, Sweden, 2015.

199. Tandvårds- och läkemedelsförmånsverkets (TLV). Underlag för beslut om subvention - Sovaldi (sofosbuvir). Stockholm, Sweden, 2014.

200. Lundqvist A, Wilking N, Gerdtham U, et al. Målriktad behandling av bröstcancer. Stockholm, Sweden, 2013.

201. Sveriges Kommuner och Landsting. Hälso- och sjukvårdsrapporten 2020 ÖPPNA JÄMFÖRELSER. Stockholm, Sweden, 2020.

202. Kleyn D, Kitney R, Atun R. Partnership and Innovation in the Life Sciences. In: Atun R, Sheridan D (eds) Innovation in the biopharmaceutical industry. Singapore: World Scientific Publishing Co. Pte. Ltd., 2007, pp. 109-133.

203. Taleb NN. Antifragile: Things That Gain from Disorder. New York, US: Random House, 2012.

204. Tandvårds- och läkemedelsförmånsverkets (TLV). TLV accepterar högre kostnad för läkemedel mot sällsynt sjukdom, https://www.tlv.se/omoss/press/nyheter/arkiv/2016-12-20-tlv-accepterar-hogre-kostnad-forlakemedel-mot-sallsynt-sjukdom.html (2016, accessed 20 April 2021).

205. Carlsson P, Hoffmann M, Levin L-Å, et al. Prioritering och finansiering 
av läkemedel för behandling av patienter med sällsynta sjukdomar.

Linköping, Sweden, 2012.

206. Dahabreh IJ, Kent DM. Can the learning health care system be educated with observational data? JAMA 2014; 312: 129-130.

207. Hemkens LG, Contopoulos-Ioannidis DG, Ioannidis JPA. Agreement of treatment effects for mortality from routinely collected data and subsequent randomized trials: Meta-epidemiological survey. BMJ 2016; 352: 1-11.

208. PubMed. PubMed search on propensity score, https://pubmed.ncbi.nlm.nih.gov/?term=propensity+score\&sort=date\&size $=200$ (2021, accessed 20 April 2021).

209. Oster E. Unobservable Selection and Coefficient Stability: Theory and Evidence. J Bus Econ Stat 2019; 37: 187-204.

210. Tandvårds- och läkemedelsförmånsverkets (TLV). Follow-up of cancer pharmaceuticals and other pharmaceuticals via alternative data sources. Stockholm, Sweden, 2019.

211. Claxton K, Martin S, Soares M, et al. Methods for the estimation of the National Institute for Health and Care Excellence cost-effectiveness threshold. Health Technol Assess (Rockv) 2015; 19: 1-504.

212. Edney LC, Haji Ali Afzali H, Cheng TC, et al. Estimating the Reference Incremental Cost-Effectiveness Ratio for the Australian Health System.

Pharmacoeconomics 2018; 36: 239-252.

213. Vallejo-Torres L, García-Lorenzo B, Serrano-Aguilar P. Estimating a costeffectiveness threshold for the Spanish NHS. Health Econ 2018; 27: 746761.

214. Lomas J, Martin S, Claxton K. Estimating the Marginal Productivity of the English National Health Service From 2003 to 2012. Value Heal 2019; 22: 995-1002.

215. Lomas J, Claxton K, Martin S, et al. Resolving the "Cost-Effective but Unaffordable" Paradox: Estimating the Health Opportunity Costs of Nonmarginal Budget Impacts. Value Heal 2018; 21: 266-275.

216. Svensk Författningssamling. Lag (2002:160) om läkemedelsförmåner. 2002.

217. Grabowski HG, Vernon J. The Distribution of Sales Revenues from Pharmaceutical Innovation. 2000; 21-32.

218. Socialstyrelsen. Statistikdatabas för läkemedel, https://sdb.socialstyrelsen.se/if_lak/val.aspx (2021, accessed 20 April 2021).

219. vården i siffror. ADHD-behandling bland barn och unga, https://vardenisiffror.se/indikator/b2c88b08-4a40-49b1-b139c775d920f74d?datefrom=2016-01-01\&dateto=2019-12$31 \&$ periodtype $=$ year\&relatedmeasuresbyentry $=$ kallsystem $\&$ relatedmeasur esbyid=bed1847e-d178-41be-a71f33958 d140b59\&units $=01 \&$ units $=03 \&$ units $=04 \&$ units $=05 \& u(2021$, accessed 20 April 2021). 



\section{Papers}

The papers associated with this thesis have been removed for copyright reasons. For more details about these see:

http://urn.kb.se/resolve?urn=urn:nbn:se:liu:diva-175364 


\section{FACULTY OF MEDICINE AND HEALTH SCIENCES}

Linköping University Medical Dissertations No. 1772, 2021

Department of Medical and Health Sciences

Linköping University

SE-581 83 Linköping, Sweden

www.liu.se 